\title{
Transforming Dalit Identity: Ancient Drum Beat, New Song
}

Fiona Margaret Page Dalton 


\section{Transforming Dalit Identity: Ancient Drum Beat, New Song}

Fiona Margaret Page Dalton Victoria University of Wellington, Wellington, Aotearoa New Zealand

Submitted in partial fulfilment of the Masters of Development Studies degree February 2008 


\begin{abstract}
Folk music is one medium used by the Dalits of India in response to the oppression they face under the country's caste system. This thesis describes research conducted on the effects of music composed by a radical Dalit Christian pastor in South India nicknamed 'Parattai.' The main aims were to investigate how Parattai's religiously affiliated Dalit folk music transformed people, and whether or not its popularity and use had been maintained since Parattai's death in 2005 . The primary data was collated from twenty six semi-structured interviews which took place in Tamil Nadu state between December 2006 and April 2007. The secondary data comprises literature on caste and inequality, and grassroots responses involving religion and music. This research found that Parattai's music was effective because it declared a proud Dalit identity. Parattai embraced and reclaimed the musical and dance styles, vernacular languages, food, and religious ideologies of Dalits so as to transform Dalits from the inside out. Parattai's music continues to empower people with the appreciation of their own strengths. However, further promotion of his folk music style would ensure enduring transformation and activism towards the equality of all Dalits.
\end{abstract}




\section{Acknowledgements}

I thank all the interview participants in Tamil Nadu who readily gave their time and opinions for this research, and the whole TTS community for warmth, welcome and inclusion.

I express my utmost respect and gratitude to my two supervisors at Victoria University of Wellington, Dr Rick Weiss (Religious Studies) and Dr William (Bill) Hipwell (Development Studies). I highly appreciate the commitment you both made to the written words of my thesis and to talking with me. I have learnt so much from all the conversations and discussions with each of you. Thank you very much for your time and your smiles. I am especially grateful to Rick for the gift of Tamil language tuition and to Bill for stretching my mind.

For many encouraging words and support, I honour my friends and my family, particularly Nan, Dad, Lucy, Sam, Jo, Lis and Jeze.

I admire and say thank you to:

Parattai For inspiration

Satya For teaching me the meaning of bravery

David For your love... of your people and of me

Mum For Everything 


\section{Table of Contents}

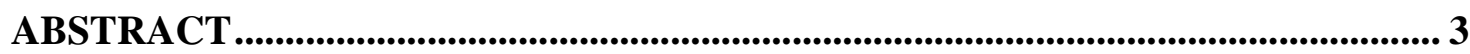

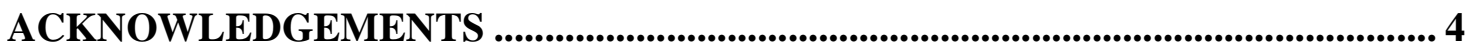

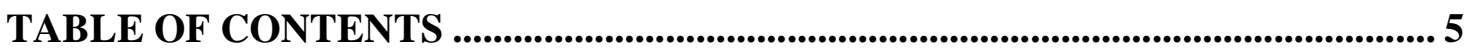

TABLE OF FIGURES................................................................................................................ 8

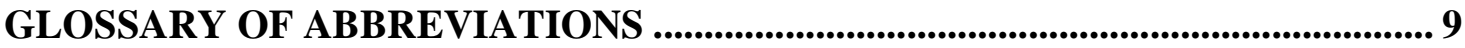

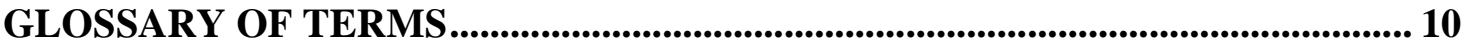

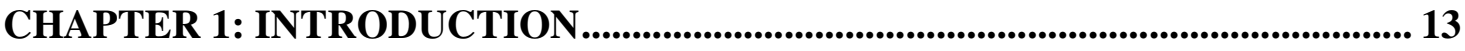

INTRODUCTION

BACKGROUND

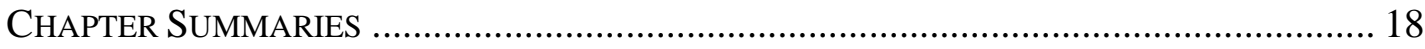

CHAPTER 2: EPISTEMOLOGY, METHODOLOGY AND METHODS................ 23

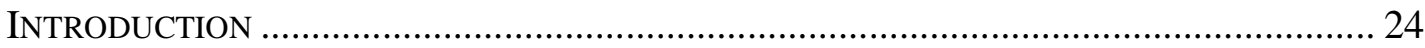

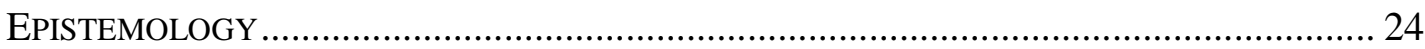

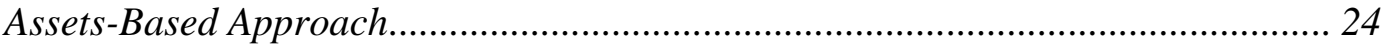

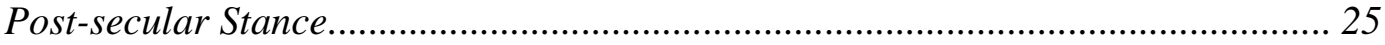

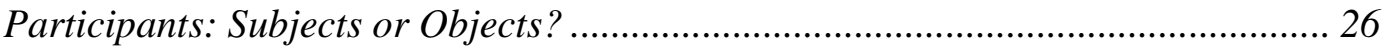

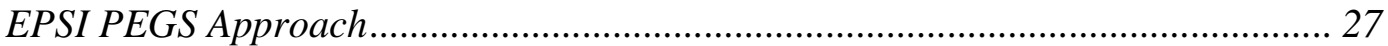

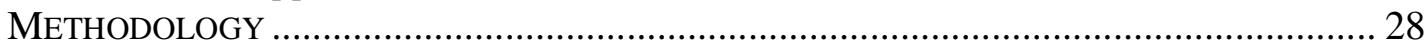

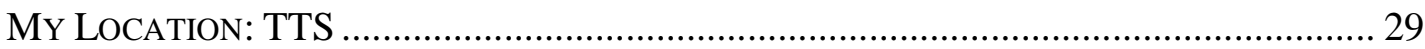

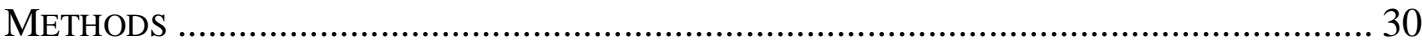

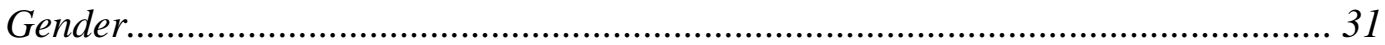

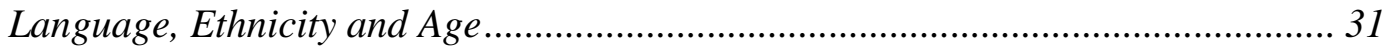

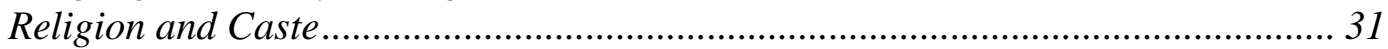

Recruitment Method: 'Snowballing Effect' ........................................................... 32

Interview Structure and the Question Sheet.............................................................. 32

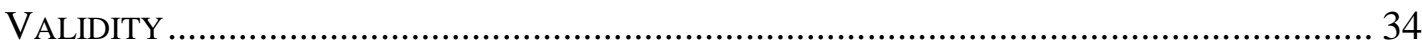

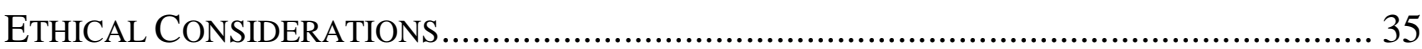

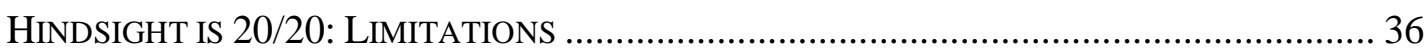

Narrow Range of Participants ................................................................................ 36

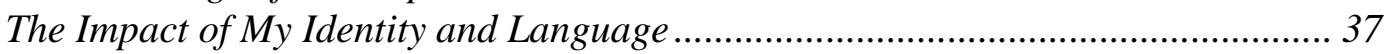

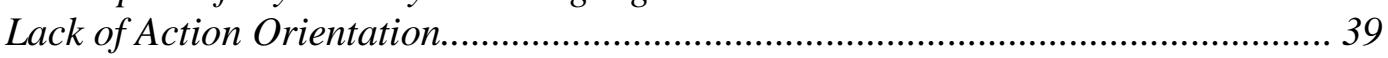

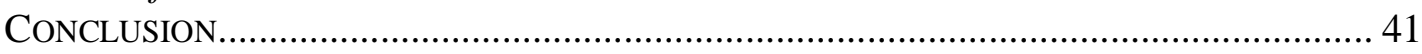

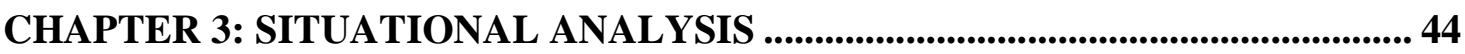

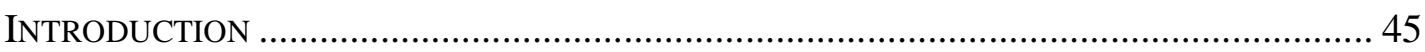

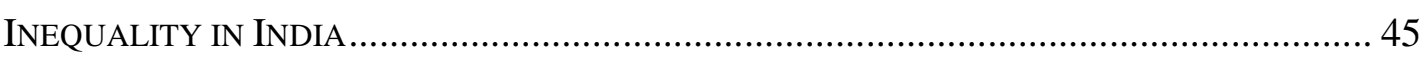

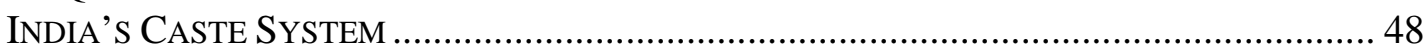

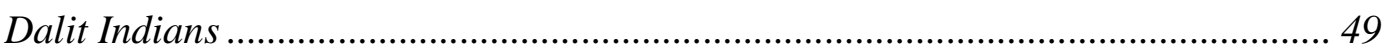

Denial of Personal Safety and Education .......................................................... 53 


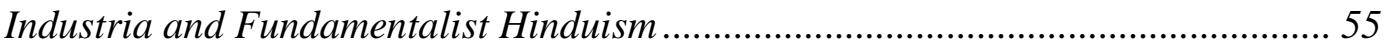

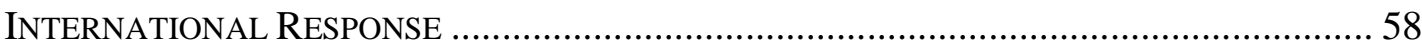

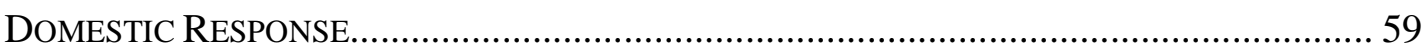

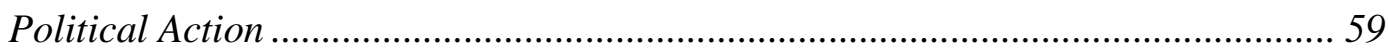

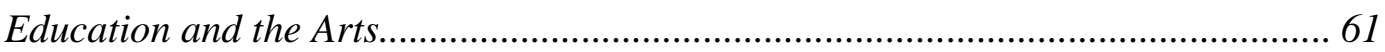

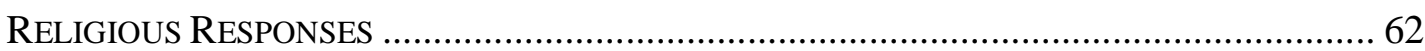

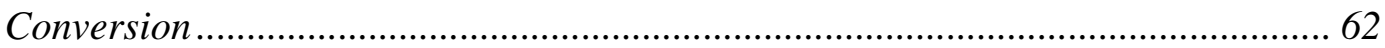

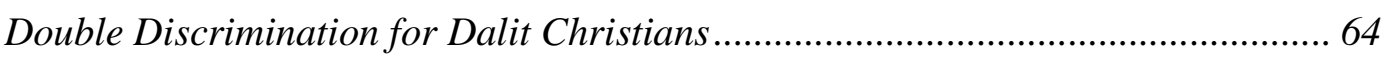

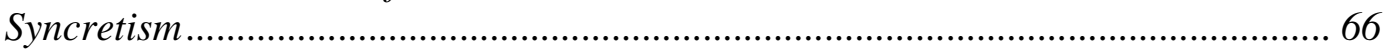

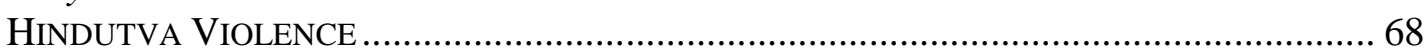

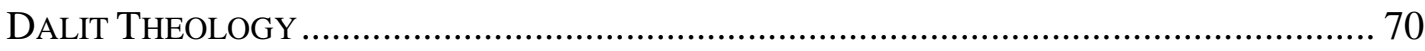

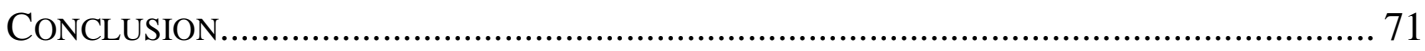

CHAPTER 4: FOLK MUSIC AS A TOOL FOR CHANGE ...................................... 73

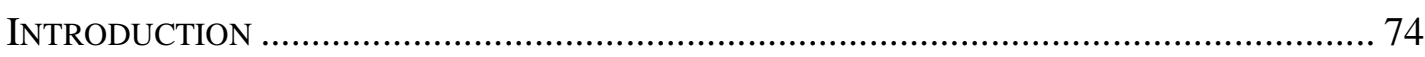

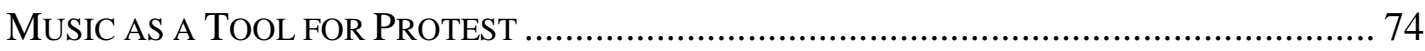

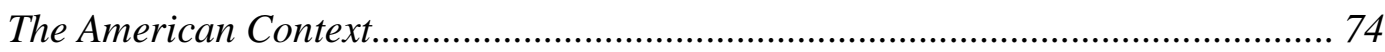

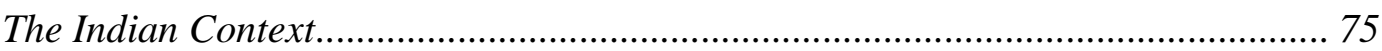

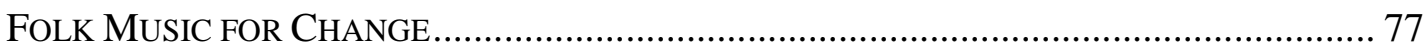

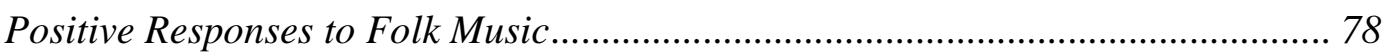

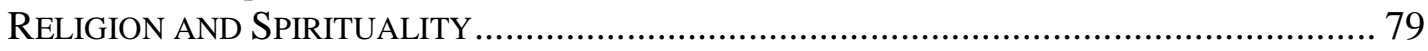

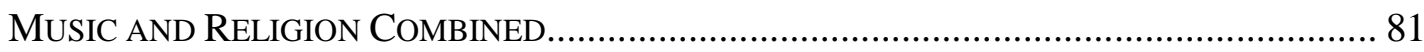

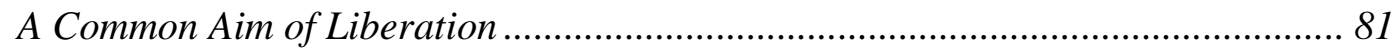

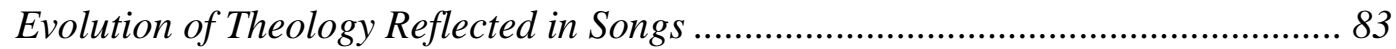

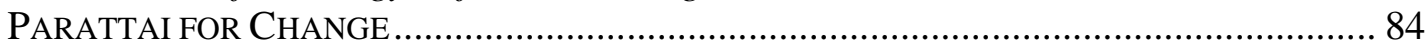

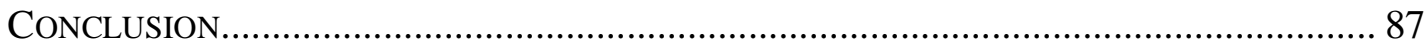

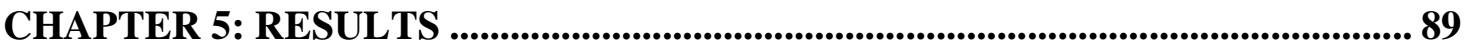

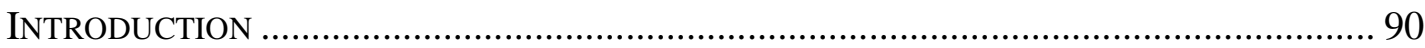

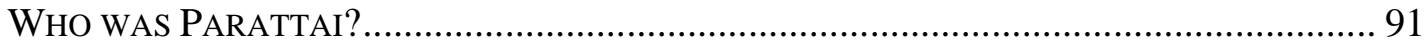

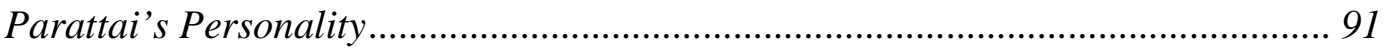

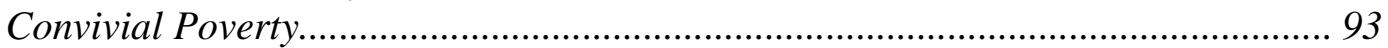

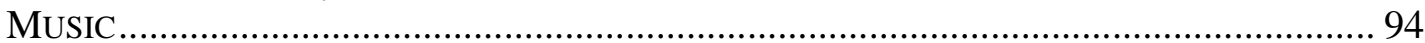

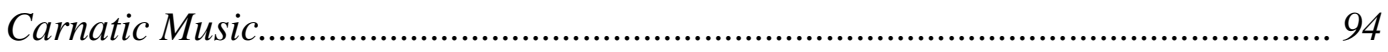

Parattai's Role in the Change to Folk Music .......................................................... 95

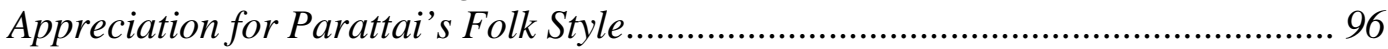

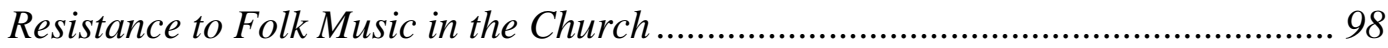

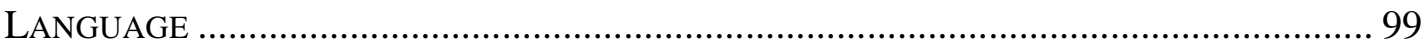

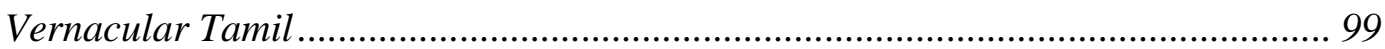

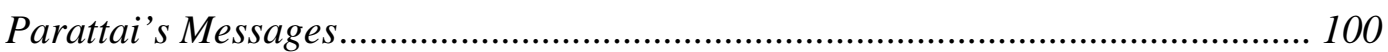

Linguistic Techniques: Humour and Metaphor ................................................. 101

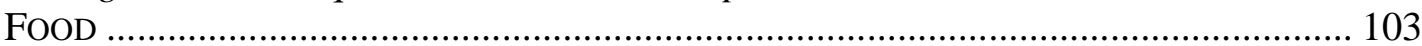

ORU OLAI: MUSIC, DANCING, FOOD AND FEMINISM ……......................................... 105

GENDER JUSTICE: EASIER SAID THAN DONE .......................................................... 107

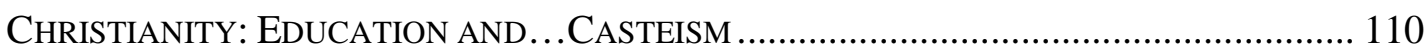

Perceived Advantages of Christianity for Dalits ................................................ 111

Perceived Disadvantages of Christianity for Dalits ............................................. 113 


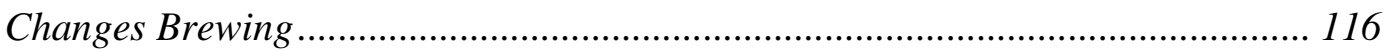

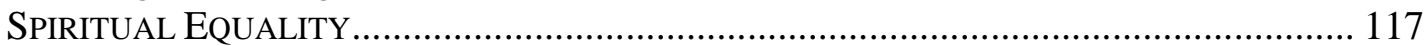

Parattai's Christian Framework ..................................................................... 117

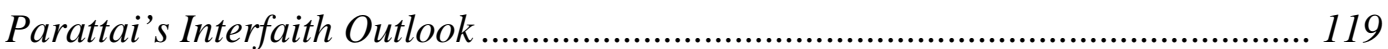

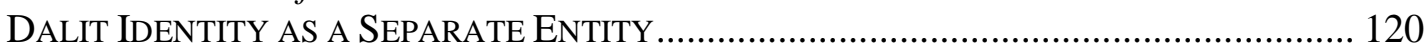

SUSTAINABILITY OF PARATTAI-INSPIRED ACTIONS................................................. 122

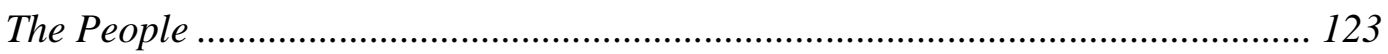

Maintenance of Parattai's Songs: A Mixed Response ........................................... 125

Maintenance of Parattai's Other Works: Liturgies, Plays and Oru Olai............... 127

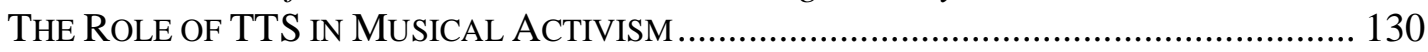

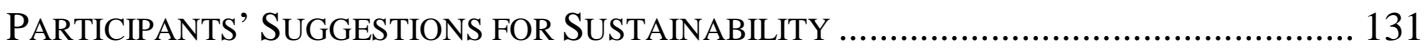

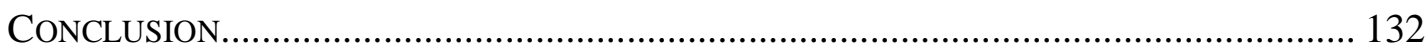

CHAPTER 6: DISCUSSION AND CONCLUSIONS ............................................... 135

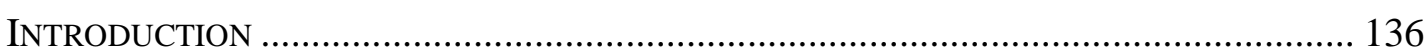

A Multi-FACETED APPROACH FOR EFFECTIVE ChANGE …….................................... 136

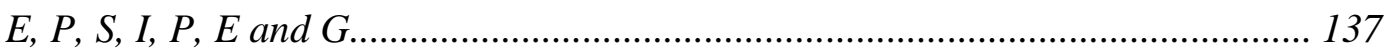

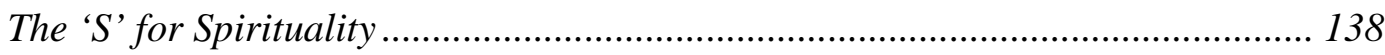

How PARATTAI's DALIT MUSIC TRANSFORMS PEOPLE.............................................. 139

THE IMPORTANCE OF A SEPARATE DALIT IDENTITY .............................................. 140

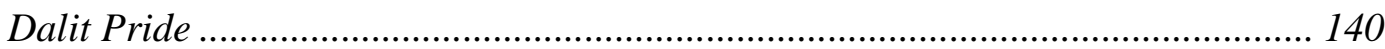

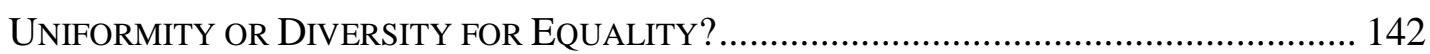

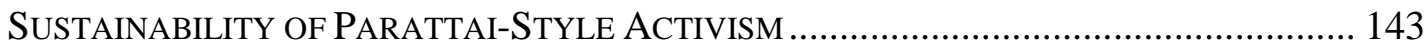

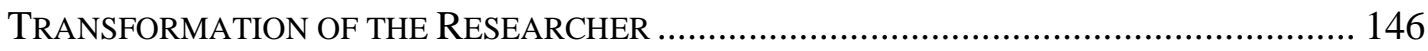

LIMITATIONS AND DIRECTION FOR FUTURE RESEARCH .......................................... 148

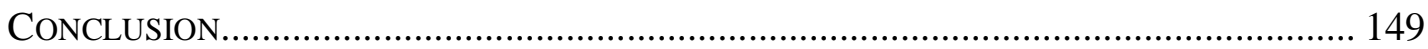

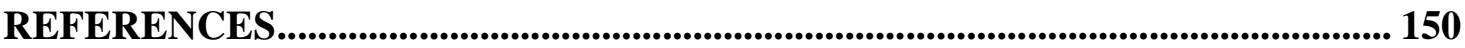

\section{APPENDICES}

APPENDIX I: PARATTAI'S NORMS FOR DALIT LIBERATION MEDIA

APPENDIX II: QUESTION SHEET FOR PARTICIPANTS

APPENDIX III: INFORMATION SHEET FOR PARTICIPANTS

APPENDIX IV: CONSENT FORM FOR PARTICIPANTS

APPENDIX V: CERD RECOMMENDATIONS FOR INDIA

APPENDIX VI: ONWARD CHRISTIAN SOLDIERS

APPENDIX VII: WHO IS MY MOTHER?

APPENDIX VIII: HYMN FOR 1990

APPENDIX IX: THROUGH ALL THE WORLD

APPENDIX X: ORU OLAI AT TTS, FEBRUARY 2007

APPENDIX XI: ELEMENTS FOR HOLY COMMUNION AT TTS

APPENDIX XI: ELEMENTS FOR HOLY COMMUNION AT TTS 


\section{Table of Figures}

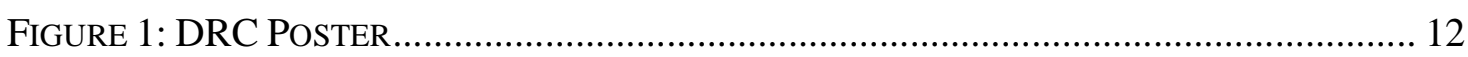

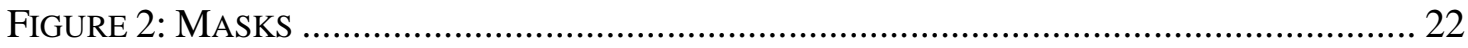

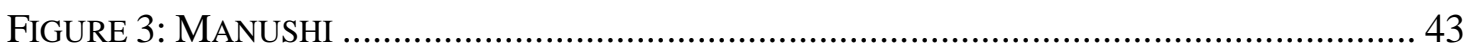

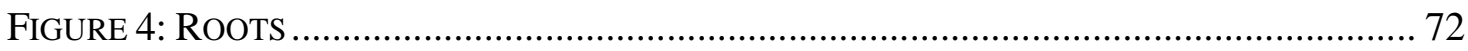

FIGURE 5: INTRODUCTION BOOKLET FOR PARATTAI'S CASSETTE TAPE NIMUNDHU NADA. 88

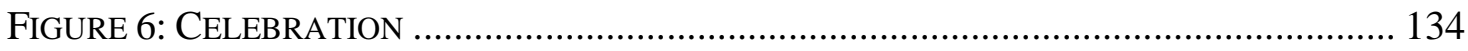




\section{Glossary of Abbreviations}

$\begin{array}{ll}\text { BD } & \text { Bachelor of Divinity } \\ \text { CERD } & \text { Committee on the Elimination of Racial Discrimination } \\ \text { CRM } & \text { Civil Rights Movement } \\ \text { EPSI PEGS } & \text { Economic Political Social Ideological Psychological Ecological } \\ & \text { Gender Spiritual } \\ \text { MDG(s) } & \text { Millennium Development Goal(s) } \\ \text { MTh } & \text { Masters of Theology } \\ \text { NGO } & \text { Non-governmental organisation } \\ \text { TTS } & \text { Tamil Nadu Theological Seminary } \\ \text { UN } & \text { United Nations }\end{array}$




\section{Glossary of Terms}

$\begin{array}{ll}\text { Annan } & \text { Elder brother, or any elder male } \\ \text { Bandh } & \text { Strike, boycott } \\ \text { Carnatic } & \text { Classical (music) } \\ \text { Chappati } & \text { A thin, round bread } \\ \text { Churidaa } & \text { Women's clothing consisting of a long shirt over baggy trousers } \\ \text { Jati } & \text { Caste; subcaste } \\ \text { Kanjee } & \text { A rice porridge } \\ \text { Oru Olai } & \text { The practice of combining ingredients from multiple homes and } \\ \text { then eating the mixed up product together; literally 'one pot.' } \\ \text { Panchayat } & \text { Village council } \\ \text { Parai } & \text { A Dalit drum made from cow hide } \\ \text { Parattai } & \text { Unkempt hair; a nickname given to Rev James Theophilus } \\ & \text { Appavoo } \\ \text { Ragi } & \text { Millet (cereal) } \\ \text { Sari } & \text { Women's clothing comprising one long piece of material wrapped } \\ & \text { around the body over a cropped blouse } \\ \text { Carna } & \text { Caste }\end{array}$




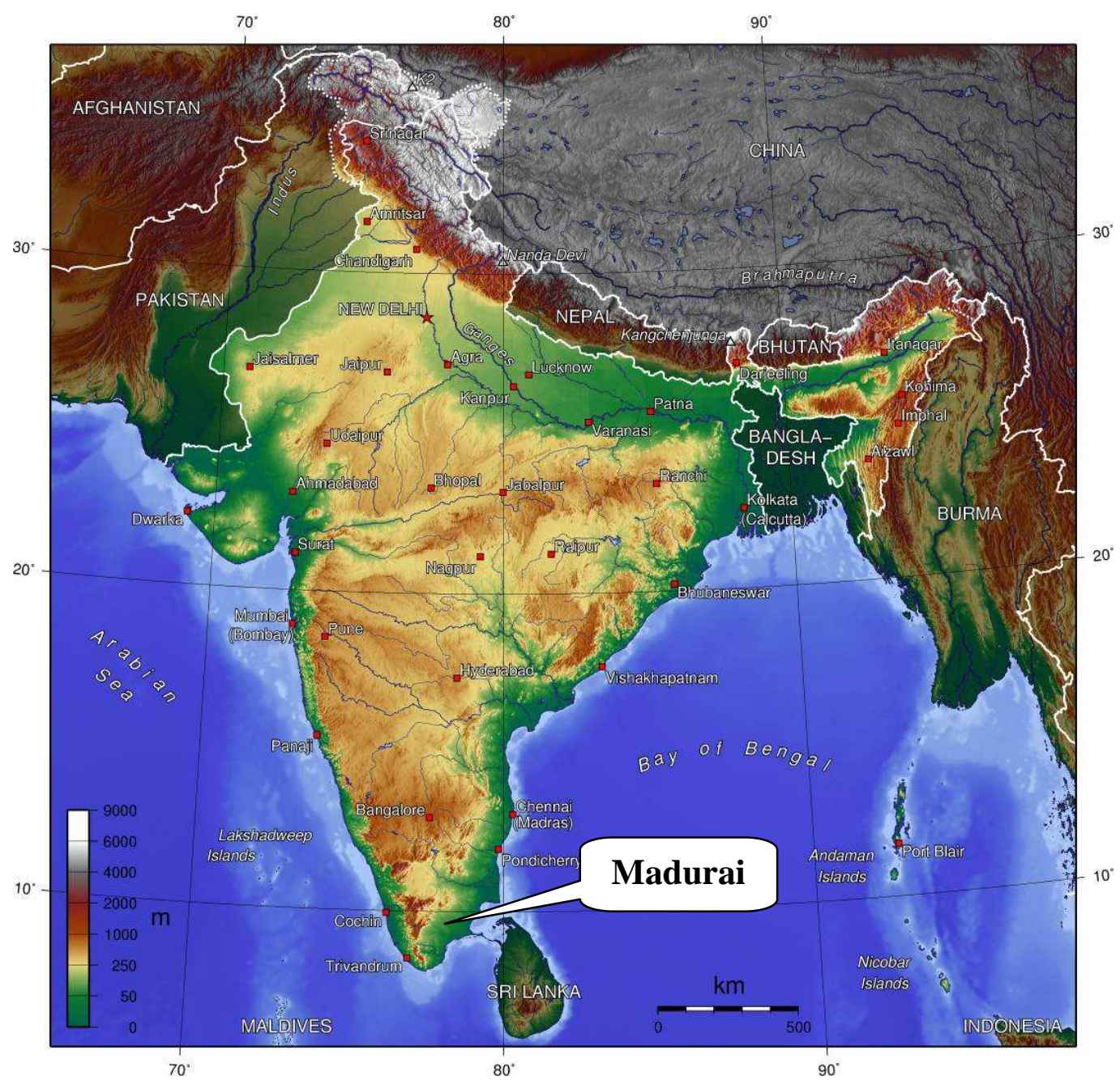

Frontispiece: Map of India Indicating Main Research Site

Source: (Wikipedia, 2007) 


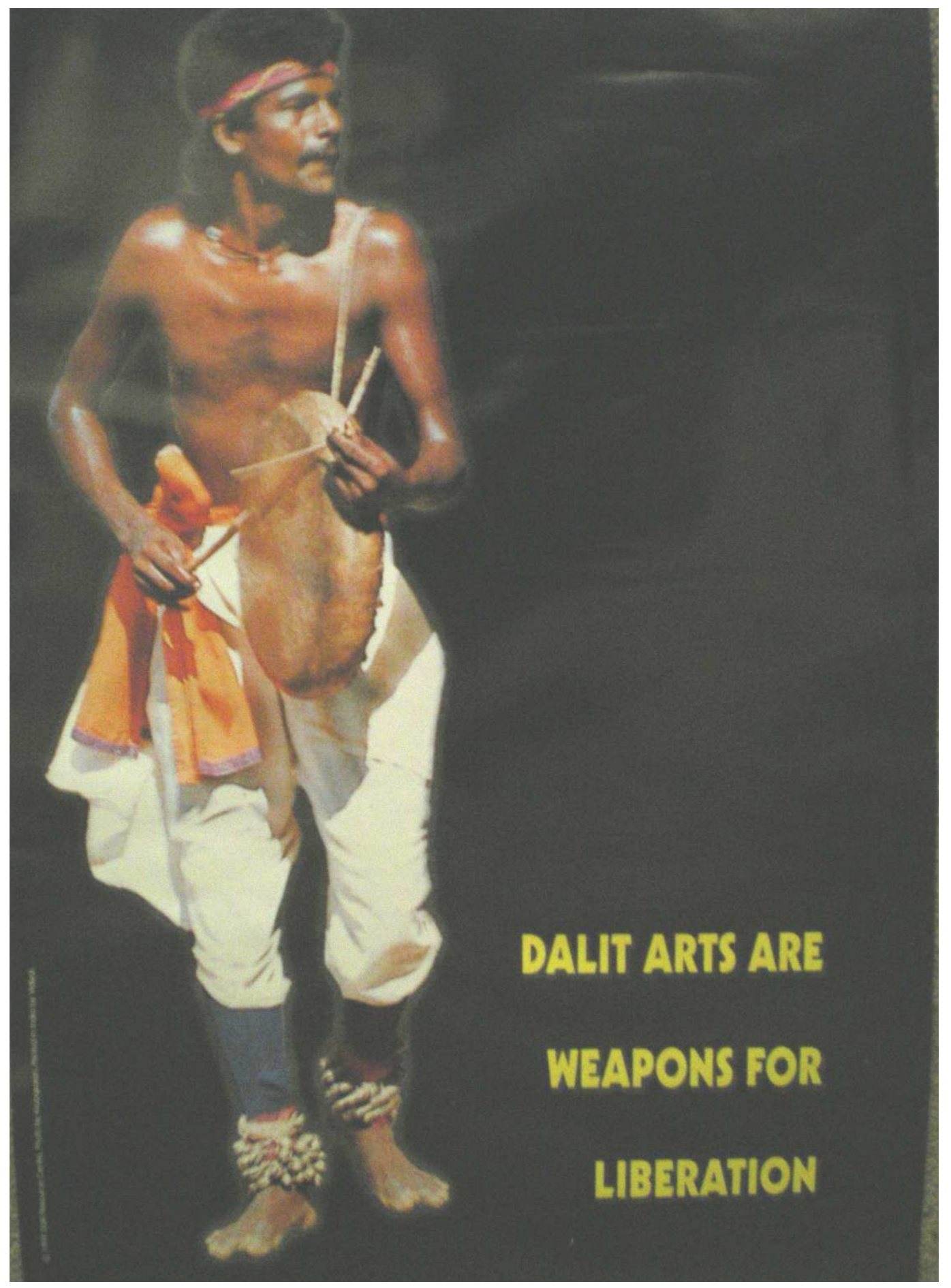

Figure 1: DRC Poster

(Permission to reproduce kindly granted by the Dalit Resource Centre, TTS) 


\title{
Chapter 1: Introduction
}

\author{
Take a step ahead \\ It's enough.
}

Be bold to be liberated.

Raise your voice until it spears the clouds of oppression.

Join your hands, become strong like the mountains.

Women of the nations, be assured of your strength,

Like the waves that roll in the sea.

Fight against the inner voice which tells you that you are a slave.

Shout to God, let him hear the voice of agony.

March forward towards the freedom of Canon.

Stamp on the backsliders 1 and go through,

Because the end is near, the victory is clear.

The Earth is ready to whisper towards

liberty, equality and unity.

(N. M. David Selvakumar, TTS student.

Kindly produced for the purpose of this thesis)

\footnotetext{
${ }^{1}$ Hypocrites
} 


\section{Introduction}

Can music be used to challenge oppression and transform society in India? What kind of music works best for activism? Is there a role for religious music to play? These are the major issues which I explore in this thesis. I spent five months in South India researching aspects of Dalit life. According to India's hierarchical caste system, Dalits are those at the very 'bottom' of society. The term 'Dalit' refers to a diverse range of Indian citizens who live with various forms of oppression inflicted by other Indian citizens. Widespread caste-based prejudice still pervades India today, but the discourse around Dalits is rapidly changing due to various methods of protest. Neither the level of prejudiced abuse nor the effective activism of Dalits is well known or acknowledged outside $^{2}$ India. Therefore I focus upon these issues through both primary and secondary research. The first half of this chapter explains why I chose to research Dalit activism in India, and my reasons for choosing to study music and religion in relation to Dalits. The second half provides chapter outlines for the rest of the thesis.

\section{Background}

[The] Dalit world is a world in itself. Simply the problem is that we do not peep into its windows (Rajawat, 2004b, p. ix).

This thesis looks directly through one of the many windows into the world of South Indian Dalits: their music. The assets-based approach to research suggests that change occurs in communities through the identification of skills or 'assets' rather than needs (Cameron \& Gibson, 2005; Kretzmann \& McKnight, 1993; Mathie \& Cunningham, 2003). Music and religion constitute subgroups of potentially positive assets. In this study, I investigate the power of folk music composed by Dalits of the Church of South India (CSI) in their journey towards equal treatment in society. As the world watches India's economy boom and produce an increasing number of millionaires, a significant change is also occurring amongst those in the lowest earning bracket. Due to urbanisation and the strength of Dalit leaders such as Dr Ambedkar, the ancient ties of India's stratified caste system are slowly loosening. Millions of Dalits across India continue to suffer poverty,

\footnotetext{
${ }^{2}$ And to some extent, inside
} 
caste-based prejudice (casteism) and abuse, but they are also protesting their treatment as the outcasts of society and becoming active in many different ways. I researched the activism of a recent Dalit leader who rose from the Christian community of Tamil Nadu state. This man believed that liberation required a multi-faceted approach which targeted economic, political, social, ideological, psychological, ecological, gender and spiritual factors. His chosen method was Dalit folk music, through which he transformed many lives. I show how he did this, and the power of his music to continue liberating people even since his death in 2005. The man's name was Rev. James Theophilus Appavoo, but he was known affectionately as 'Parattai,' meaning 'guy with messy hair.'

Parattai's compositions involved the use of specific forms of language, so the significance of language became a key finding of my research. This thesis presents the changing discourse around India's caste system steered by Dalits through music, religion, and other forms. It is no longer possible to say exactly what 'caste' means because the definition has been vastly altered due to India's rapid urbanisation in the past half decade. The word 'Dalit' is relatively new, and many authors writing on caste or Dalit issues include a history of the various names which have been used for Dalits, as I do in Chapter 3. Taking language as a form of social practice, analysis of the different names over the years reflects the ways in which the discourse has functioned as resistance to inequality. Pieterse (2000) summarises Escobar's stance on this:

To effect change means to effect a 'change in the order of discourse,' to open up the 'possibility to think reality differently' (p. 180).

The arts in their widest sense are useful in the transformation of discourse. In reference to fine arts, Sivakami (2000) proclaims that "The clear objective of the Dalit art is to put the modern art into question" (p. 16). This study identifies the ways in which Dalit music with a Christian influence questions the style of music used in South Indian churches and the treatment of Dalits, particularly Dalit women. I examine Parattai's musical methods for changing the discourses of oppression and self respect in Tamil Nadu. 
The original inspiration for this research came, as usual, from my mother. She told me of a radio report which stated that the most effective relief work following the 2004 Boxing Day tsunami in the Indian Ocean had been conducted by organisations with religious affiliations. This set me thinking and reading about the role of religion in development organisations such as non-governmental organisations (NGOs), and in active transformation by oppressed groups. In addition to religion, the other major aspect of this thesis is music, particularly Dalit folk music. The reason for this choice is encapsulated in the following Marathi proverb (English translation from Guru, 2001, p. 163):

In the Brahmin house - Writing

In the Kunbi house - Grain

In the Mahar house - Singing

According to the Indian caste system, Brahmins are the 'top' caste and Dalits (of which Mahars constitute one subgroup) are demoted to a position which is beneath the caste system altogether. For thousands of years, Brahmins dominated the field of formal education and Dalits were deprived the basic right of literacy. Thus, much of India's literature has been authored by Brahmins or other 'upper caste' citizens. There is a wealth of Dalit voices, but until recently these were solely found in the form of spoken songs and poems rather than written material. Many people choose to study India's caste system or religions by reading the literature, but this only reflects one small portion of the voices in a country which is famed for its diversity.

In 2007, I attended a lecture series on India's caste system in my hometown of Christchurch, Aotearoa New Zealand. ${ }^{3}$ The series was taken by a Brahmin woman who analysed Brahmin women's literature for her PhD thesis (R. Roy, 2004). During the lectures, this woman criticised the harsh treatment of Dalits in her home country and said that it was terrible to categorise any human beings as 'Untouchables.' However, she kept using the old term 'Untouchables' herself, instead of the name 'Dalit. ${ }^{4}$ She then claimed that the reservation system, which enhances the access by Dalits to higher education and

\footnotetext{
3 'Aotearoa' and 'New Zealand' are the two official names for my country of origin, and may be used together as shown here and throughout this thesis.

${ }^{4}$ See Chapter 3 for a discussion of the difference between these two terms.
} 
employment, has been in place for nearly sixty years and should be abolished as it is now "completely irrelevant" (Lahiri-Roy, 2007). The reservation system is a form of affirmative action ${ }^{5}$ which prescribes quotas of university seats and government sector jobs for Dalits and 'low' caste groups. Even with academic qualifications and experiences equal to those of 'upper' caste people, Dalits still have unequal access to jobs and receive 15 percent lower wages than 'upper' caste Indian citizens for the same jobs in the urban labour market (Madheswaran \& Attewell, 2007). In rural areas where the majority of Indians live, people are much more likely to be employed in their castespecified occupations, so the pay parity and alternative job opportunities are abysmal. Therefore I do not agree with the aforementioned statement made by Lahiri-Roy (2007). However, reservations are largely irrelevant if people expect wholesale change through this policy alone. The caste system pervades many aspects of life in India and is tightly wired into the psyche of all citizens, from Dalits to Brahmins. The words of Sherinian (2002) on Dalits in the state of Tamil Nadu could be applied to all Dalits; "Before Tamil Dalits can organize for structural, economic, and socio-political change, it is necessary to break the psychological barriers that prevent them from believing change is possible" ( $p$. 248). This is where Dalit folk music has enormous strength: as a tool which addresses multiple facets of caste-based oppression, including those which are subjective and internal.

Rather than maintaining a rigid structure for the sake of tradition or preservation of the status quo, folk music and other folk art forms act in pursuit of change by keeping useful matter and discarding the irrelevant, as situations evolve. However, due to their political nature and lower status in the general public, such strong media for influencing public opinion have largely been ignored in academia. Gilbert (2007) claims that the main motivation for her article was to rectify this situation in South Africa. Despite their huge impact on the anti-apartheid struggle, there was an extreme lack of detailed research on the predominantly informal and un-professionalised South African freedom songs. Sherinian (2005) similarly found a gap in the literature on Tamil Dalit folk music. She claims that while folk music is the least valued, it is the most often employed musical

\footnotetext{
${ }^{5}$ Reverse discrimination
} 
style in protest situations (Sherinian, 2005). There has been insufficient research into the implications of mainstreaming Dalit folk music into the Dalit theology of Indian Christianity or any other religion. My research therefore investigates the use and efficacy of Dalit folk music for Dalit theology, and also its ability to cross the religious divides so as to unite all Dalits. I was inspired by Sherinian's work to stay at the Protestant Tamil Nadu Theological Seminary (TTS) and follow in her footsteps by studying Parattai. Parattai chose folklore such as folk music because it is a non-elitist, non-commercial form of communication which comprises an alternative communication system for those people left out of mainstream society (Appavoo, 1986). Dalit folk music may therefore function as counter-hegemonic discourse which shapes the reality of Dalits. Sherinian (2002) reports that reception to Parattai's folk music liturgy since its composition in 1994 was positive but slow in the first eight years. This was at least partly due to the great challenge of interesting the middle class and urban Christians in Dalit drumming and folk song, a style of music which represents "everything the lower-caste Christians in these communities have attempted to leave-poverty, caste identity, and an oppressive village context" (Sherinian, 2002, p. 248). Due to Parattai's death in 2005, I was not able to directly learn from him as Sherinian had done. However, this thesis investigates the extent to which and the ways in which Parattai's folk music was sustained between 2005 and 2007. Was Parattai really just "a voice crying in the wilderness" (Dayanandan, 2005, p. 10)?

\section{Chapter Summaries}

\section{Chapter 2}

Chapter 2 outlines my epistemology, methodology and methods. I explain my assets-based, post-secular approach, and the EPSI PEGS approach developed by Parattai. I discuss the position of project participants as subjects versus objects, and the issue of project initiators' subjectivity. The chapter then describes the beautiful campus of TTS in South India at which I stayed for five months, and introduces the twenty six individuals whom I interviewed. I report the changes that I made to the interview procedure and question sheet as a result of staying at TTS for four months before starting my main interview period. This amount of time in the field allowed my own identity to emerge, 
and I discuss the validity of such non-neutrality and familiarity as the interviewer. I then outline the ethical considerations of my research procedure. A total of five months in South India enabled me to learn a great deal and adjust my research methods. However, I was unable to conduct interviews with the widest possible spectrum of participants or to integrate an action component into my research. The chapter discusses these limitations and then concludes by indicating the direction for further research.

\section{Chapter 3}

In Chapter 3, I provide details from secondary sources on the lack of social development in India, the caste system, and life for Dalits. For approximately three millennia, Dalits have faced prejudice and abuse due to their position below caste people in India's caste system. Despite progress in legislation against caste-based prejudice, in 2007 the de facto situation in India differs remarkably from that de jure. I outline some of the casteist practices of verbal, psychological, sexual and physical abuse which continue daily. I then investigate the ways in which globalisation puts further pressure on those in the lowest socioeconomic bracket. Unsurprisingly for a country of approximately 1.1 billion people, the millennia-old practice of casteism manifests itself in a myriad of ways. What is surprising, however, is that casteism only came onto the radar screens of major international organisations in the last one to two decades. I address both international and local interventions to casteism, and the added complications which such interventions sometimes cause. The chapter illustrates the role of Dr Ambedkar and the effects of education for Dalits. I then consider the wide range of religions and sects to which Dalits have sometimes converted in order to reduce the influence of the caste system upon their lives. I review both the double discrimination faced by Dalits who convert to Christianity, and the new Dalit theology which affirms Dalit identity.

\section{Chapter 4}

Chapter 4 investigates music as a form of activism. A brief history of music as a form of protest employed by African Americans is followed by a comparison of the various styles and uses of music in India. I discuss the mixed reactions to the relatively recent introduction of Dalit folk music into Indian Christianity. This divide sets the 
precedent for discussion later in the thesis on the relative merits of reclaiming or burying Dalit identity in the pursuit of equality. Through examples from around the world, I show that folk music has proven popular in situations of oppression due to its familiarity, ability to cleverly convey empowering messages, and potential for organising and uniting people. I relate these examples from different countries to Parattai's own stipulations for folklore. The next section of the chapter considers the role of spirituality and religion, especially the similarities between African Americans and Indians in these facets of life. I illustrate the overlap between liberation music and liberation theology next, providing examples from Latin America and Africa before turning to the Indian context. I look at the ever-changing face of Christian theology in my home country of Aotearoa New Zealand, as reflected in the hymns sung in churches. Finally, I explore Parattai's place at the cutting edge of Dalit theology in India, through his folk music style. The end of the chapter provides the lyrics and discussion of Parattai's Tāyi Tagappanārēe (Oh Mother and Father) as an example of his radical messages and powerful imagery.

\section{Chapter 5}

In Chapter 5, I report the results from my interviews in Tamil Nadu. Parattai had lived in accordance to the theology and ideology which he espoused in his songs to such an extent that participants could not discuss the songs and the man separately. The first section of the chapter therefore details Parattai's personality and lifestyle. The next section features the aspects which were attributed to the popularity of Parattai's compositions: folk music style, vernacular language, celebration of local food and religions. My experiences of Parattai's dancing, singing, food-sharing extravaganzas, known as Oru Olai, are then described. This is followed by the issues which arose through Oru Olai regarding gender equality and Parattai's feminism. A large section then deals with the significance of the Christian context in which Parattai's songs and liturgies were created. I discuss the advantages and disadvantages of Christianity as perceived by the predominantly Christian participants themselves, and the current changes pertaining to this dynamic. I then address Parattai's emphasis on spiritual equality and interfaith cooperation. After I report on the debated benefits of the distinct Dalit identity promoted by Parattai, I turn to the sustainability of his compositions. I show the extent to which 
Parattai's messages and artistic forms of expression have continued as a motivating force for transformation both inside and outside TTS since Parattai's death in 2005. The chapter concludes with identification of the many ways in which TTS incorporates music into campus life, and participants' recommendations for the maintenance of Parattai style musical activism.

\section{Chapter 6}

The final chapter combines my findings from primary and secondary sources. I review the ways in which single factor approaches to change for Dalits have been unsuccessfully attempted, with particular attention to the factor of spirituality. I then summarise the reasons why Parattai's music was popular, concluding that it was the affirmation of a positive identity for Dalits which was the key. I discuss the sensitive issue of asserting a separate Dalit identity both in general within India and within the Church of South India. This debate centres around the opinion divide between uniformity for equality and diversity for equality. The next section indicates the ways in which Parattai's messages and methods may be sustained. I summarise the transformation which I underwent through the process of my living and learning in South India for five months. This leads to an assessment of the limitations of my project and suggestions for the way forward, followed by the conclusion of the thesis. 


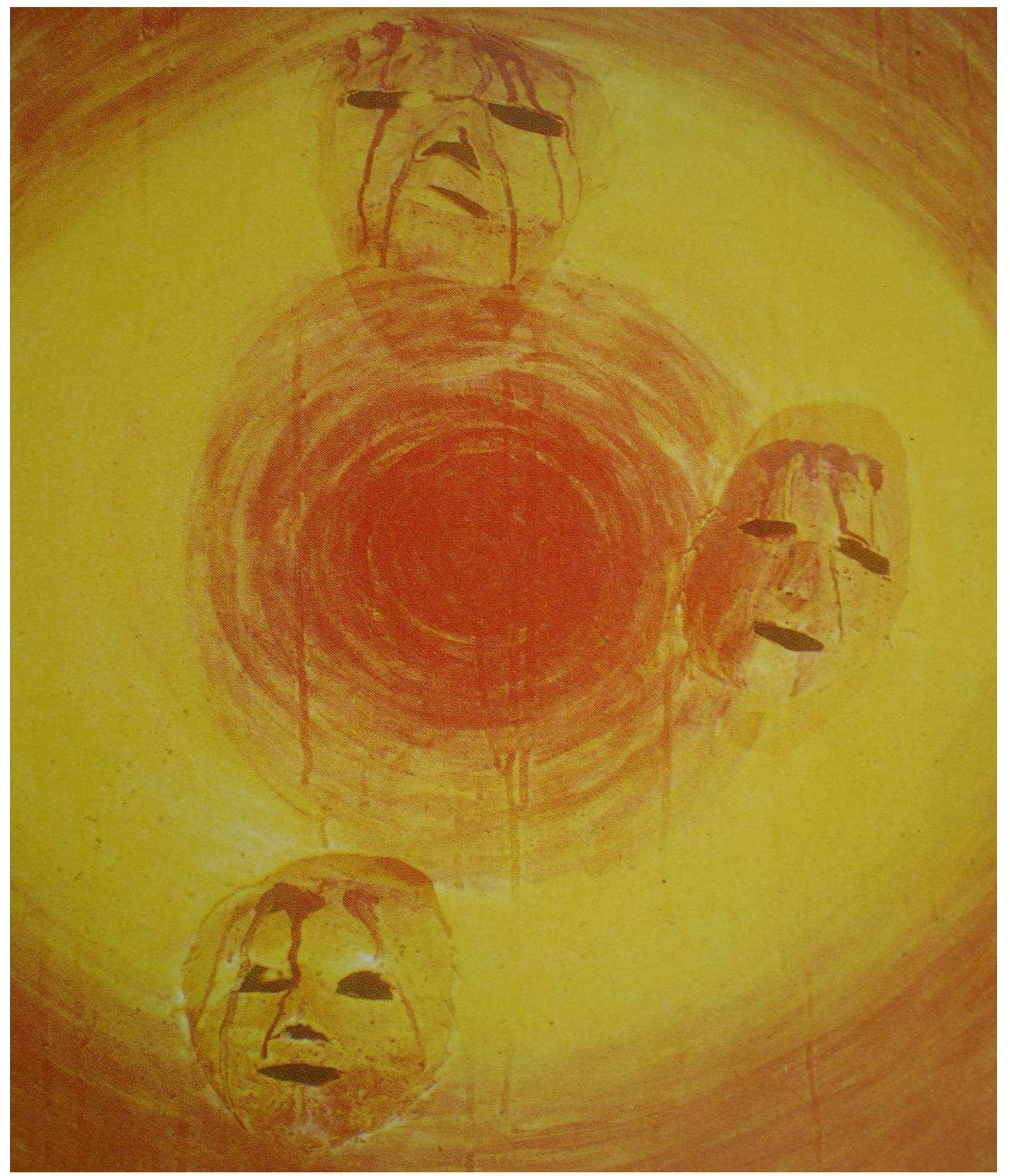

\section{Figure 2: Masks}

(Original work by C. Porkodi, appearing in Larbeer, P. M. and Alexandar, V. (2000). Permission to reproduce kindly granted by P. M. Larbeer). 


\title{
Chapter 2: Epistemology, Methodology and Methods
}

\author{
Ammādi Kutti Ponnē (Oh Little Girl)
}

Oh little girl you are always crying.

Get up! Rise up! You are the freedom-giving sindhu song.

Tell who beat you up. Kill that arrogance.

You have to become like Mother Mary (bold enough to be a virgin)

That male dominance devil, that demon

Scare and drive it away oh mother.

The words which Gabrielle spoke, there is no one here to repeat.

The people who are teaching the bible are shamelessly getting dowry these days.

The Elizabeths of our city are burning like witches in kerosene oil.

When they come forward to welcome liberty the stoves will explode.

As salvation came from Mary's belly

You have the inspiration of Virgin mother Mary.

Don't worry, salvation will come from your lap.

The powerful people's position will be destroyed.

Trembling they will go under (fall).

The powers that will spoil you in your youth

Will become powerless, my girl.

(Parattai, Eng. trans. from Sherinian, 1998, p. 845) 


\section{Introduction}

This chapter begins with explanations of my epistemology, methodology and methods. I describe my post-secular, assets-based approach. I then outline Parattai's application of the EPSI PEGS approach in his search for a suitable Dalit liberation medium. In accordance with my epistemology, the methodology of my primary research is qualitative. I explain my location for this research at TTS in South India. The chapter describes the twenty six individual, semi-structured interviews which I conducted. I outline the gender, language, ethnicity, age, religion and caste of the participants, who provided me with their opinions and knowledge of Parattai's compositions and actions. This is followed by a section explaining my recruitment method, and then an outline of the interview structure and my question sheet. As I lived at TTS for four months before starting the interview process, I was better able to understand the context than before arrival in India, and thus the interview questions were revised. After sections on the validity and ethical considerations of my research, the chapter concludes with acknowledgement of certain limitations, suggesting ways in which a longer period of time in the country of field research would have enhanced the project.

\section{Epistemology}

My research took place within the Development Studies programme in the School of Geography, Environment and Earth Sciences at Victoria University of Wellington. Musical and religious activism is not classical development, so some people may try to classify it under either 'alternative development' or 'alternatives to development' (see Pieterse, 2000). I do not feel the need to classify my research or the work of Parattai in such a way. I simply aimed to learn from Dalits how Parattai's activism had transformed Dalits. I took an assets-based approach which allows for a post-secular stance in this research, in coordination with Parattai's multi-factor EPSI PEGS approach.

\section{Assets-Based Approach}

In reference to India, Dayanandan (2006) claims that it is the oppressors who have a problem (or are a problem), rather than the oppressed. In his words, "The oppressors need help as they struggle to free themselves from the demonic forces of caste, race and 
patriarchy which keep them bonded to the various forms of oppression that they perpetrate" (Dayanandan, 2006, p. 101). However, the oppressed become burdened with the problems of their oppressors. In the Indian context, Dalits form the largest sector of society which is oppressed by the caste system, and many attempts at change have originated from or led to minority religions and sects. Massey claimed in 1995 that a Dalit theology based on the needs of Dalits was non-existent and therefore should be established in order for Dalits to regain their lost identity and basic human rights (Massey, 1995). However, since 1995, a move has been made in the field of development research from the problem-centred, needs-based approaches towards assets-based approaches. 'Assets' in this context means strengths, and refers largely to skills and activities rather than financial investments. As a formal research methodology, the asset-based community development (ABCD) approach was developed by Kretzmann and McKnight in several North American contexts (Cameron \& Gibson, 2005). Cameron and Gibson (2005) demonstrate in Australia that focusing on the assets or strengths possessed by people in economically and socially disadvantaged situations is more likely to lead to positive action towards alternative economic and social identities. In encouraging participants to assess the skills which they possess rather than those which they lack, more enthusiasm and belief in the efficacy of action is evoked (Cameron \& Gibson, 2005). Needs-based development tends to focus on identifying problems of oppressed peoples, thus promoting a negative identity as problem-ridden people. This negative selfimage is in itself harmful, and maintains oppression by feeding a sense of helplessness and hopelessness. In the Dalit context, this phenomenon has been termed the 'wounded psyche.' I chose to explore Dalit initiatives which address the wounded psyche by focussing on assets rather than needs.

\section{Post-secular Stance}

The assets-based approach allows for certain forms of religion to be seen as a positive feature of people living today. Social scientists often regard all religion as something which had its place for social transformation or modernisation in the past, but is of little or no help to such issues in the present (Ganguly, 2004). Ganguly (2004) 
speaks of the uneasiness caused to secular-modernist researchers by the ambivalently religious Buddhist writings of Dalit leader Dr Ambedkar. Secular social scientists' analyses often disregard religion, especially that which involves syncretic practices such as the continued participation in Hindu rituals and festivals by Dalit Buddhists (Ganguly, 2004). A post-secular stance provides room for religion to function as an asset, or positive feature, of those people alive right now. This respects the "heterotemporal modalities of living" (Ganguly, 2004, p. 49), or multiple and diverse ways of dwelling in the present exhibited by Dalits and all other people with respect to caste, religion and other aspects of life. In its acceptance of diversity, the post-secular vision should fit with the general postmodernist stream of current social science. However, religious differences are less often accepted than cultural differences by the average postmodern social scientist. For example, a Muslim women's rights activist in Tamil Nadu failed to achieve sufficient funding for the building of a women's mosque for empowerment of women and improved gender equality (Nomani, 2007). Her project was based around Muslim women's familiar territory and assets of prayer and daily ritual. However, she was denied funding from the New York-based Global Fund for Women on the grounds that the mosque did not fit the group's human rights agenda (Nomani, 2007). This thesis considers how one Dalit Christian man in India recognised both the religions and music of his people as assets, and acted in an assets-based way to unite and transform Dalits.

\section{Participants: Subjects or Objects?}

Participatory action is the key to development and research aiming for positive social change in the lives of oppressed peoples. Blah (2005) stresses the necessity for positive participatory development, emphasising an example of a participatory rural development project carried out in India which gained local acceptance. This contrasted sharply with negative forms of development which have caused trauma, followed by militancy or other violent acts of protest in response to the trauma (Blah, 2005). For effective change, the people living in situations of oppression must become the subjects of the project rather than the objects. Whether the project is that of a researcher, a government, an NGO or any other development agency, the facilitator must establish a partnership with the local people and allow them to own the project by becoming the 
subjects creating the change rather than the objects being changed by another party.

Objects can not act by themselves towards their own liberation and thus the sustainability of an objectifying project is doomed from the outset. Cameron and Gibson (2005) state that the identity of any given individual is not fixed, so anyone can become the subject, but only if the project is designed well and participatorily. Many aid projects treat local people as objects instead of subjects, making the people dependent and their situations static, claim Boff and Boff (1987). When the poor are seen as merely people who have nothing at all, then assets such as the strength to resist, and the abilities to understand their own rights, organise themselves and transform their own lives tend to be completely ignored (Boff \& Boff, 1987). Worgs (2006) explains violent action by oppressed people in this way. One result of violent action as a response to oppression is that it provides a humanising power, moving the person's position from object to subject because they are taking action themselves, thus providing internal liberation in the absence of external freedom (Worgs, 2006). The assets-based approach to Liberative transformation depends upon a platform of participation by subjects. One example of such a methodology is the EPSI PEGS approach.

\section{EPSI PEGS Approach}

Although Parattai did not use the term 'assets-based,' EPSI PEGS is a model of such an approach. It demands the participation of Dalits in their own transformation and the use of their own positive skills and talents for this process. EPSI PEGS is an alternative, non-violent approach which places great importance on internal liberation. It is a holistic approach adapted from Marx's EPSI by the Rev. James Theophilus Appavoo, otherwise known as 'Parattai' (Sherinian, 1998). Economic, Political, Social, Ideological, Psychological, Environmental, Gender and Spiritual (EPSI PEGS) factors are all considered in the analysis of a tool or medium for liberation. Parattai analyses both mass media and folklore using these eight factors, concluding that for the liberation of poor and oppressed peoples, mass media is of no use whilst folklore has some degree of potential (Appavoo, 1993). Poverty is usually an economical issue, but it is much more than simply a lack of money. Poverty is a humanitarian problem and is now defined by international and domestic institutions in holistic terms which include the deprivation of 
dignity, human rights, opportunities and equality (Desai \& Potter, 2002). Furthermore, poverty is rarely due to a single factor but is the combination of many factors, and thus a multi-faceted approach must be taken for poverty reduction and eradication. Parattai dedicated his life to searching for an approach which would address the most significant of these factors, and thus he designed and applied his eight-part EPSI PEGS approach. On an international scale, the eight Millennium Development Goals (MDGs) of the United Nations (UN) (United Nations, 2005) relate to the various EPSI PEGS factors and also illustrate the many intertwining aspects of oppression in the world. Parattai extends the broad categories of EPSI PEGS to fourteen "norms" required for a medium suited to Dalit liberation (see Appendix I). The EPSI PEGS norms demand an inside knowledge of multiple aspects of the situation of Dalits, which can only be obtained through participation by Dalits themselves. Therefore, the norms promote a 'bottom-up' participatory approach to action. Certain aspects, especially those relating to the psychological and spiritual effects of oppression, can not be understood by those who have not personally undergone such hardship or experiences. Furthermore, the second norm states that whatever liberation media is chosen should not be one which is controlled by the oppressors. Thus, any project which is not fully participatory does not fulfil this criterion. EPSI PEGS is an assets-based approach to development, as any attempts to change a situation and strive for liberation should involve only hardware or equipment which is accessible and should not depend upon skills which take time to acquire (Appavoo, 1993).

\section{Methodology}

The real objectivity starts with the declaration of the subjectivity. If one's subjectivity is in tune with the subjectivities of majority [sic], then only it becomes objective one [sic] (Appavoo, 1993, p. 4).

The analysis of my primary data is entirely qualitative, which reflects my epistemology. Dietrich (2006b) claims that Parattai's EPSI PEGS is relevant because "experiential data are more important than quantitative generalizations" (p. 60) for the analysis of many aspects of human beings. My research supports Dietrich's claim that Parattai's 
methodology was most centred on two facets of EPSI PEGS: the psychological and spiritual. Qualitative research is essential for such aspects of human experience which are largely subjective. I was interested in the experiences and actions of Dalits, so I chose to interview Dalits. This decision means that my research may be classified as bottom-up research in development lingo. Many other foreign researchers and officials choose the 'top-down' approach. Dietrich and Parattai criticise Dumont, who "would not be bothered to see caste through the eyes of Dalits" (Dietrich, 2006b, p. 59), and based his studies of caste around his fascination with the 'upper' castes' power hierarchies. I report the opinions of a small number of those on whom caste power hierarchies have the most negative effect. I do not claim to 'know' the feelings of a Dalit living in India, but I listened to the words of a select group of people in one state of India and now present some of their stories in this thesis. I spent five months living amongst a group of highly politicised Christians. Approximately half of the people on campus were of a Dalit background and the other half were of non-Dalit backgrounds which are at the bottom of the caste system but therefore slightly 'higher' in society than the Dalits, who are 'under' the system altogether. Through their religious affiliation the members of TTS were united, but through their caste differences they were sometimes divided. Their stories which I report revolve around this major issue.

\section{My Location: TTS}

All interviews took place in Tamil Nadu, the southeastern-most state of India. The majority of the participants were members of TTS in Madurai, South Tamil Nadu, where I was situated for my five months in India (see Frontispiece, page 11). Madurai is the former capital of the Pandyan kings and is famous all over India for music, dancing, and the enormous Sri Meenakshi Amman temple. The city is arranged with Sri Meenakshi Amman at the centre, and has the great Vaigai River running through it. TTS is on a main road near the city centre. The lush green TTS campus is home to students, teaching staff, administration, cooks, gardeners, physical labourers, watchmen, and staff of the library, onsite bookshop, Dalit Resource Centre (DRC), and Centre for Social Analysis (CSA). The tall coconut palms and red earth below are also home to rabbits, pigs, cows, birds, butterflies, snakes, cockroaches, scorpions, an abundance of mosquitoes, and a handsome 
gaggle of geese. The employees of TTS live in houses on campus with their families, as do students in their first and fourth years of study. Most students come to the Bachelor of Divinity (BD) course in their mid to late twenties, so many are married and some have children. Students who are unmarried or unaccompanied by their spouses live in separate men's and women's hostels, and students accompanied by their families are allotted houses on campus. Parattai used to call the campus a village, according to one of his daughters. This 'village' was recommended to me by several Christian Indian contacts from whom I sought advice when I was researching Christianity in South India, before I first read about Parattai. After learning of Parattai's crucial influence on South Indian Christians and finding that he had lived for almost three decades at TTS, it was the obvious choice of location.

\section{Methods}

This thesis reports findings from both primary and secondary sources. The secondary data presented in Chapters 3 and 4 is from the literature available in English regarding Dalits, caste, gender, religion, music, poverty and inequality. The earlier part of this research was conducted with databases in Aotearoa New Zealand, but it was added to dramatically once I gained access to new sources in Madurai. The TTS bookshop and library supplied me with key literature such as the $\mathrm{PhD}$ thesis of $\mathrm{Dr}$ Zoe Sherinian on Parattai and folk music, Parattai's Masters of Theology (MTh) thesis, book and cassette tapes, TTS's own Arasaradi Journal of Theological Reflection, and copious other useful books. The current chapter describes the primary data which I collected during twenty six individual, semi-structured interviews. Twenty interviewees were residing at TTS, four had previously resided there or had close contact with the seminary, and two were familiar with Parattai but less familiar with TTS. The participants at TTS included teaching staff, teachers' spouses, librarians, gardeners, cooks, on-site students, and a small number of off-campus students. Whilst most participants were living together on the TTS campus in Madurai at the time of the interviews, they had grown up in a variety of villages, towns and cities across the state of Tamil Nadu, or even in neighbouring states. 


\section{Gender}

I conducted interviews with sixteen men and ten women. I made a conscious effort to find female participants but it was difficult to maintain a gender balance as the majority of TTS students and faculty is male. TTS is endeavouring to encourage females to study theology, and only requires female students to pay a tiny percentage of the annual school fees. I found negative attitudes towards this amongst some of the nonsponsored male students who were struggling to pay for themselves. The uneven gender ratio at TTS is partly due to a nationwide cultural practice of families spending less on education for daughters than sons because they must save for the daughters' wedding dowries. The dowry system is officially illegal but is still practised by many people in India, including Christians and even parents of some students at TTS.

\section{Language, Ethnicity and Age}

The village interview, the slum interviews and three on-campus interviews were conducted in Tamil with a translator, and the other twenty were conducted in English. All participants were residing in Tamil Nadu. Twenty three were of Tamil ethnicity, one Malayali, and two long-time Madurai residents who originally hail from Germany. I did not ask for ages, but all participants were adults between approximately 25 and 75 years old.

\section{Religion and Caste}

Twenty one of the participants identified as Christian, two were Muslim, one was a Buddhist, and one man stated that he had been born into a Hindu family and was thinking of converting to Buddhism but was currently of no particular faith. Of the Christians, there was one Catholic, two Lutherans and the rest belonged to the Church of South India (CSI). I did not ask participants to identify their caste group, but it would be safe to assume that the majority were of a Dalit background. Some Dalits volunteered this information, in certain cases identifying themselves also by their jati. ${ }^{6}$

\footnotetext{
${ }^{6}$ Caste or subcaste (see Chapter 3 for further information)
} 


\section{Recruitment Method: 'Snowballing Effect'}

I never had to ask anyone who I should interview, as I either met people in the course of my involvement in campus life or was advised to talk to certain individuals by interviewees or other members of the campus. The latter is known as the 'snowballing effect,' whereby each person's new suggestions add to the momentum and steer the snowball (or researcher) down an increasingly specific path (Murray \& Overton, 2003). Some names were recommended more than once, so I made sure to interview those key people and also tried to interview as many of the others as possible. Some participants kindly offered to call people or help me contact certain others whom they thought would be useful as interviewees. A list of suggestions given to me by the principal on my first day was also very helpful. I had to reschedule a few interviews when people did not turn up, but overall it was very easy to find and interview many people who could teach me a lot about Parattai. It was an advantage to be staying on the TTS campus and have so many willing interviewees readily available. I found a marked difference in sense of time between myself and people in Tamil Nadu, which was helpful for my interviews.

Thinking as a New Zealander, I assumed that busy people such as lecturers would want to schedule an interview time some time in the following few weeks. However, when I asked most participants for an interview, they invited me in to their home to do it straight away or said that they could do it that evening. One person wanted to do her interview on the same day so that she would not have to make an appointment and remember it. I could never understand how people suddenly fit me in to their day, but happily it resulted in many interviews taking place more quickly than I had expected. This was one indication of the way that Tamil people live in the present, whereas I with my penchant for planning was dubbed a 'futuristic thinker.'

\section{Interview Structure and the Question Sheet}

Most interviews lasted from one to one and a half hours, and all but three took place in the participants' own homes or rooms. Two participants accepted the offer to do their interviews in my room on the TTS campus, and the village interview was conducted in the doorway of an empty makeshift classroom approximately twenty metres from the participant's house. The main pre-interview questions asked were why I had chosen the 
topic and how I had come to know about Parattai all the way over in New Zealand. Almost all participants ticked the option on the consent form to request a summary of the research, which was an encouraging sign of their interest in the topic. One professor on the TTS campus started his interview by telling me how happy he was that I was focussing on Parattai's music, as it was rare for music other than Western style, organ based hymns to be studied. The questions on my question sheet (Appendix II) were followed reasonably closely in all interviews, but some participants answered in the order that the questions were listed, others answered in an 'easiest to hardest' order and others spoke generally in a way which combined answers from several questions into one story, anecdote or opinion. The question sheet was invaluable in conveying what I wanted to discuss and keeping people on track. I did not need to talk much at all and was able to simply listen and take notes. Apart from the women in the slum who were slightly shy and did not know me beforehand, all participants were strongly opinionated and willing to talk, so were easy to interview. I heard some of the same comments about Parattai many times, but each person contributed different information and gave me new things to think about, which was highly rewarding and very useful. This may have been due to the fact that many participants were employed at a liberal theological college which places a strong emphasis on social analysis, so they were well used to discussing ideas such as the ones which I raised.

In the early stages of my interviewing I simply gave the question sheet to participants at the start of the interview, but many said that they wanted some time to think and formulate answers so I changed my system and started giving out the sheet a few days beforehand. I did, however, request that those participants not show the sheet to anyone else or discuss it with others, as I was interested in fresh, individual opinions. The question sheet which I gave to participants in India differed a little from that which I had originally designed in Aotearoa New Zealand. The advantage of living at TTS for four months before conducting the majority of my interviews was that I was able to change the focus of my research. Having absorbed the culture, comments and practices around me, and especially after having participated in Oru Olai myself, I realised the need for a much stronger emphasis on gender analysis. Before going to India, I had read Sherinian's 
(2005) article in which she describes the way she challenged Parattai over tonal ranges in his songs that she considered sexist and male-biased. However, I had not initially intended to focus on the gender-related aspects of Parattai's works myself. This was due to my ignorance of the extent to which gender-based discrimination restricts even educated urban women in South India, and relates to both caste and class. I underestimated the need for the "G" in EPSI PEGS.

The theme of the question sheet also changed from being rather Oru Olai-specific to asking more broadly about Parattai's music and other works. That change, too, was due to my ignorance of the situation, namely the many varied skills which Parattai had possessed and used, and the widespread nature of his songs as opposed to the predominantly TTS-restricted Oru Olai. One item on the revised question sheet which was queried by a number of participants was the last one (see Appendix II). Some interviewees pointed out to me that Dalits who do not belong to a minority religion such as Christianity or Islam also do not belong under the umbrella of Hinduism. These participants said that 'upper' caste right wing Hindu politicians incorrectly claim Dalits as Hindus in order to gain votes and create a stronger, united force against minority religions. Therefore they did not feel that it was correct to create a comparison between 'Hindu Dalits' and 'Christian Dalits,' as I had on the question sheet. However, some Dalits and other people referred to 'Hindu Dalits' during interviews and in general conversation. It was difficult to find an appropriate alternative wording. Simply using the term 'Dalit' does not suffice, because that word is used across religions as a unifying identifier. As the comparison was usually with Christian Dalits, the word 'non-Christian Dalit' usually became the replacement for 'Hindu Dalit.'

\section{Validity}

The validity of data may be brought into question when the majority of participants live on the same seminary campus. However, the teachers, other workers and students of TTS were one of the main groups with whom Parattai was involved and whom he influenced. Furthermore, the proximity of these politically minded participants did not seem to produce a uniformity of opinion. On the contrary, I often received 
conflicting answers even to reasonably clear cut questions, such as whether or not females danced during Oru Olai when Parattai was facilitating the event. My research did not initiate action in itself but rather describes the assets-based, grassroots level actions of one particular Dalit called Parattai and his followers. Rahnema (1992) claims that grassroots movements focus on the micro level rather than the macro level, and most importantly on what brings about change in their own contexts. Thus it matters little to such people whether their methods are replicable in other places or conform to idealistic models of action invented elsewhere. People act according to their human instinct and the present conditions rather than trying to fit their actions to a blueprint of predefined ideas about the best course of action (Rahnema, 1992). This describes Parattai's style well. Assets-based development is essentially micro level action, as opposed to needs-based assessment which is justified through its scientific basis but often irrelevant (Rahnema, 1992). Ladkin (2004) sums the issue up nicely by maintaining that the final arbiter of validity is simply usefulness. If a useful change occurs in the lives of disadvantaged people and those near or far from them, then validity is self-evident.

\section{Ethical Considerations}

In line with the regulations of Victoria University of Wellington through which I conducted this research, I received consent from the university's ethics committee for my project. I started the interview process by giving the participant an information sheet about the research and a consent form to sign, both in either English or Tamil. Twenty three participants chose the English versions, and these are available in Appendices III and IV respectively. After allowing the participant time to read and ask any questions, I went through the consent form with him or her before starting the recording. Many participants started talking enthusiastically about Parattai before signing the form so I had to stop them, explain the reason for the consent form and ask them to sign it. In contrast to my concern about protecting the privacy of my participants, several people told me that consent forms were unnecessary and that I was welcome to use their names in my thesis. I have not however done so, as that would violate the ethical contracts to which I agreed with my university and with my participants on their consent forms, and might also create conflict between members of TTS. I have used pseudonyms for this thesis, but 
the pseudonym is omitted in certain places in order to prevent the tracking of multiple comments made by the same participant, which could potentially reveal his or her identity. Many Christian Tamil Indians have Biblical names such as Mary, David, or Moses, but some have Tamil names or Hindi names. The pseudonyms I have chosen reflect this variety. The date of the interview appears with each name. I recorded all the interviews on a dictaphone and took extensive notes. I wrote down most interviews almost verbatim and found this very useful when I came to analyse the data. All the recorded dictaphone cassette tapes will be destroyed within two years of the interview dates, as outlined on the consent form.

\section{Hindsight is 20/20: Limitations}

\section{Narrow Range of Participants}

In hindsight, I might have spent more time interviewing in villages and slums. This would have produced a wider array of responses due to the differences in geographical area, situations, experiences, religions and levels of literacy. The majority of my participants were university-educated Dalit, Church of South India (CSI) Christians at TTS. Whilst a tertiary education does not necessarily free Dalit Christians from oppression, they suffer discrimination in different ways. Parattai was concerned about liberation for all Dalits, but particularly for the very poor Dalits who were denied even the right to a basic education. He found more people willing to embrace his folksongs in the villages where there existed neither the urban snobbery towards such styles of music, nor people highly trained in other styles such as carnatic (classical) music (Sherinian, 2002). Thus I was keen to interview villagers and slum dwellers who were familiar with Parattai's works, and they would have answered my questions in a different way. A significant number of my participants were lecturers at tertiary institutions (predominantly TTS), and so the way in which they responded to my questions was the analytical, critical thinking style of academia. This was a wonderful source of information, but the research would be better balanced if I had undertaken interviews with a more varied range of people. I only managed to talk at length with one man in a village, and two women from the same family in a slum. In both of these situations, I was dependent on people who had offered to take me and translate for me, 
and felt unable to control the time as I would have liked. Unfortunately the man in the village was drunk but perhaps due to the language and cultural differences, I was not aware of that during the interview. He was a great friend and fan of Parattai's, so he sat and talked animatedly about the positive changes which Parattai had made in his life and the long-lasting effects of Parattai's influence on him. I found him rather repetitive but did not know that he was inebriated until I was informed by my interpreter at the end of the interview.

Trying to organise interviews in villages created a dilemma for me. I felt that it would be rude to simply go into villages with a translator who was unknown to the people and start asking questions about Parattai. I was also unlikely to get answers that way because the villagers may have been shy, afraid, or simply fearful that I was some kind of government spy. I was advised by several urban people not to take and pens or paper into villages because if I was seen to be recording what the villagers said, they would assume I was a government official. Furthermore, due to the increasing levels of violence and fear inflicted upon Christians and those of other minority religions (Lobo, 2002), I had to protect my participants and ensure their safety. Going with Parattai's eldest daughter (as I did) to the village was wonderful in terms of instant rapport with the villagers due to their familiarity and obvious fondness of her, but is likely to have affected the way in which the one participant there answered the questions.

\section{The Impact of My Identity and Language}

Another obvious discrepancy between interviews with rural poor and with educated TTS members was the language in which the interviews were conducted. Considering my insufficient Tamil language ability and the Tamil medium orientation of TTS, I was very fortunate that most teaching staff and many students at TTS spoke English. On the other hand, there are undoubtedly nuances that I missed because the medium of the interviews there was predominantly English. According to Gabriele Dietrich who set up the TTS Centre for Social Analysis, certain things that can be expressed in Tamil can not be translated or verbalised in English (Dietrich, 2006a). Because the mother tongue of most participants was Tamil, there may be concepts which 
were not voiced because they were not able to be expressed in English, or because speaking in English creates a different frame of mind for expression. Furthermore, talking to me rather than to a Tamil or Tamil-fluent person will have influenced the participants to some extent. Not only my language but my cultural and ethnic background differentiated me from my participants both visually and behaviourally. Walsh's (1996) study exemplifies the effects upon interviewees in situations when the interviewer's ethnicity differs from that of themselves.

Most of the people I met at TTS, especially younger adults, had not travelled outside India and viewed Westerners as a homogenised mass of people. The stereotypes were polarised; either Westerners were all colonising ogres intent on globalising the world to India's detriment, or they were all people to be grateful to (for education and other opportunities à la foreign missionaries of times past) and lived lifestyles to be emulated. Interview participants and other people around TTS appeared to view me as an activist or a feminist because of sexism and other issues around me that I noticed and questioned. Coming from 'post-feminist' (but certainly not sexism-free) Aotearoa New Zealand, it felt strange to be labelled a feminist, although in many instances I did feel extremely irked at the blatant gender inequality. Initially I was hesitant to broach such topics because I thought it disrespectful to my host culture. However, I soon bounced off the encouragement of students who told me that while patriarchy exists, it is neither Indian nor Tamil culture, and is especially contradictory to Dalit culture. The idea of a culture which defines all Indians, Tamils or Dalits is misleading, but their point was that "patriarchy is the culture of patriarchy" and not a defining feature of their culture. TTS is a safe place to question society's various status quos, and I appreciated this environment.

My identity at TTS therefore affected my study in uncontrollable ways. Rapley (2004) claims that an interview is inherently an interactional experience, and may explain more about the interaction between the interviewer and interviewee than about the reality of the interviewee him/herself. Some researchers argue that maximum neutrality by the interviewer is essential, while others insist that neutrality removes the human nature of the activity and creates an asymmetrical, hierarchical relationship whereby the 
interviewee becomes an object (Rapley, 2004). It was impossible to make my interviews neutral, as the majority of participants knew me to some extent beforehand. Despite the effect that this lack of neutrality undoubtedly had on the responses, it was good to conduct most of the interviews after having absorbed the context for four months. I was better able then to know what to ask and how to understand participants' answers than if I had conducted the interviews at the beginning of my stay at TTS, when I was unknown. During the interviews themselves I was quite neutral because I did not speak much except sometimes to guide participants to remaining questions on the question sheet.

\section{Lack of Action Orientation}

I identify with the kind of epistemology espoused by Borda (2006), which promotes unity through valuing diversity. Participatory Action Research (PAR) fits this epistemology when used in a genuine manner with the humanitarian intentions from which it evolved. PAR is a political process, with the promotion of social change for vulnerable peoples at its core. Although this project does not constitute PAR, the process of going to India and conducting interviews fits some of the early general precepts established at the first PAR world congress in 1977, which Borda (2006) considers to have advanced in the last thirty years. These include:

- Generation of a body of knowledge centred on the realities, contexts and issues of a particular setting.

- Combining the knowledge from formal academia, informal wisdom and popular experience.

- Transformation of the researcher's own personality and culture in order to enhance the experiential involvement and moral and ideological commitment to the struggle for radical change in the society in question.

Because this project comprised only interviews and did not facilitate any specific action (participatory or otherwise), it obeys only these three precepts. However, Parattai's life of action and writing obeyed all the precepts listed by Borda (2006), including those three and the following two others: 
- Developing a body of knowledge which is useful and intended to free them from exploitation, oppression and submission.

- Critical recovery of the history and culture of deep-rooted or indigenous communities or other group and the return of this knowledge in a way which is easily understood by ordinary people.

PAR involves cycles of action and reflection, which take a lot of time and collaborative planning. Action focussed religion, research and lifestyles were important to Parattai. Sherinian (1998) explains that Parattai needed to see her social activism in order to respect her as a researcher. According to both Sherinian (1998) and Dietrich (2006b), Parattai developed the concept of 'purpose analysis' through his own experiences and research in villages. A longer period of exposure to the situation, experiences, and transformation of the researcher's personality and culture as mentioned above would allow for such an extension of this research in the future.

A larger amount of planning before embarking on my trip to India may have enabled me to conduct interviews in villages and ensure an action component in my research. However, this is somewhat a 'Catch 22' situation, as my epistemology predicts that I will go with a minimum of preconceived ideas and learn from the people about what they do and how they do it. Initially I had booked to leave India after three months, but I found that I was learning so much every day just by living there, that I extended my time. This was also to fit in a 140 hour NGO internship course requirement which I had chosen to take up in India. My idea that doing the internship in my country of research would aid my understanding of the context and provide a different perspective for the thesis certainly turned out to be accurate. However, in hindsight, I was trying to fit too many things into my short timeframe. I am indebted to the people of TTS for the steep learning curve upon which I found myself in Tamil Nadu. I was included in campus life and chose to eat most of my meals with the students in the mess hall. Due to the friendliness and welcome nature of faculty, staff, and students, I spent many hours in conversation and travelling around Tamil Nadu. I am grateful not only to my interview participants, but to all the people who spent time talking to me at TTS and further afield. In particular, I 
appreciate the students who offered to take me to their homes and showed me around their churches and the villages and cities across Tamil Nadu in which they lived. Through this I learnt an enormous amount which I could never have imagined by staying in Aotearoa New Zealand and reading. In this respect, I was fortunate to have a scholarship which helped me pay for the flights to India. The value of hands-on experience for learning and transformation of a researcher should not be undervalued.

\section{Conclusion}

The assets-based, bottom-up, participatory approach which is currently gaining popularity in the development world suggests that a positive view of oppressed peoples be taken in order to create change. Firstly, any action towards transformation of society must constitute employment of skills which the people possess, rather than pessimistic documentation of the 'have-nots.' Secondly, the oppressed must be the actors or the subjects in the situation rather than mere objects. My methodology and methods reflect this epistemology. So did Parattai's, as evident in his multi-factored EPSIPEGS approach. In this chapter I have detailed the twenty six individual interviews which I conducted mostly on the campus of TTS, at which I stayed for five months. Interviewees were willing to participate and provided a large amount of information about Parattai and his compositions. The 'snowballing effect' guided me to key interviewees, and people were generally happy and intrigued that I had come all the way from Aotearoa New Zealand to ask about Parattai. Many participants were residing in the TTS campus where Parattai spent nearly thirty years of his life, and most were highly educated Dalit Christians. Despite the homogeneity of this group of people, the information provided was diverse. After finishing all twenty six interviews, I wrote:

As a whole, all very strongly opinionated people, so they were easy to interview!

Each so distinctive in their point of view, I couldn't mistake one for the other!

(Diary: April 19, 2007).

I changed some items on my question sheet as a result of spending time in the field before beginning interviews, and the whole process was carried out in accordance with the ethical consent which I had gained from my university in Wellington. The 
respondents knew Parattai well and many were openly great fans of his, so their responses to my questions were very subjective. Nonetheless, because of this familiarity, they knew a great deal about him. Due to the participants' close relationships with and interest in Parattai, the man and his influence on a large range of people were illustrated clearly to me. It is certain that my identity at TTS impacted to some extent upon the responses of participants and the interactive interview process. The TTS community was one of the main groups upon which Parattai had a strong influence, but the other group was the rural poor. Five months based at TTS allowed time to familiarise myself with the former of these groups and learn a great deal through reading, direct conversations, travelling to students' hometowns, and osmosis. However, formal dialogue with the latter group is lacking. A longer stay in Tamil Nadu would enable me to learn more Tamil language and establish better links with village-dwellers. This would provide the skills to discuss the skills or assets and join in the activism of the people about whom Parattai undoubtedly cared the most. My research did not involve any action component due to my restricted length of time in the field. However, the first step of PAR is to start an understanding of the context, and this was achieved. Further work would facilitate some sustained activism. 


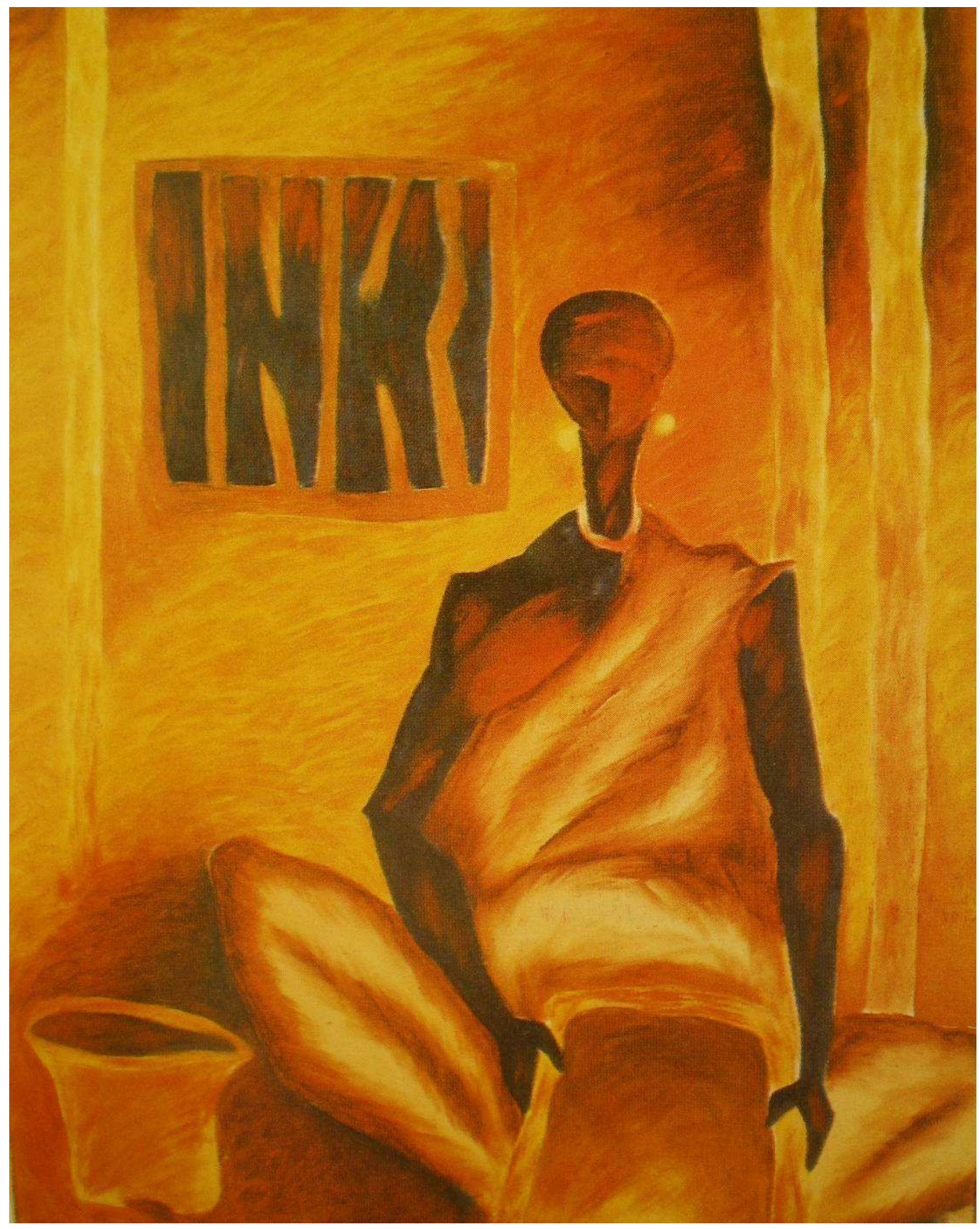

\section{Figure 3: Manushi $^{7}$}

(Original work by N. Vaijayanthi, appearing in Larbeer, P. M. and Alexandar, V. (2000). Permission to reproduce kindly granted by P. M. Larbeer).

\footnotetext{
${ }^{7}$ Woman
} 


\section{Chapter 3: Situational Analysis}

Pandit, ${ }^{8}$ look in your heart for knowledge.

Tell me where untouchability

came from, since you believe in it.

Mix red juice, white juice and air-

a body bakes in a body.

As soon as the eight lotuses are ready, it comes

into the world. Then what's

untouchable?

Eighty-four hundred thousand ${ }^{9}$ vessels

decay into dust, while the potter

keeps slapping clay

on the wheel, and with a touch

cuts each one off.

We eat by touching, we wash

by touching, from a touch

the world was born.

So who's untouched? asks Kabir.

Only he

who has no taint of Maya ${ }^{10}$

(Bhakti poet-saint Kabir, Eng. trans. from

Zelliot \& Mokashi-Punekar, 2005, pp. 260-261)

\footnotetext{
${ }^{8}$ A master or expert, originally an exclusive term for a Brahmin ('uppermost' caste) teacher or scholar.

${ }^{9}$ The traditional number of lives one must live before attaining salvation (Zelliot \& Mokashi-Punekar, 2005)

${ }^{10}$ In this context, Maya means 'illusion' (Zelliot \& Mokashi-Punekar, 2005)
} 


\section{Introduction}

One step worse than apartheid is hidden apartheid: a state of gross discrimination towards a group of people which is denied by the oppressors. Apartheid is not a word usually associated with India, and yet the country has practised a strict system of segregation for the past three thousand years. Following an assessment of life in India through the eyes of the United Nations' Millennium Development Goals, I discuss the Brahminical Hindu caste system and the associated practice of Untouchability. I explore life as a Dalit at the 'bottom' of the societal ladder, with consideration of the effects caused by increasing globalisation. I compare the slow international response to India's religiously sanctioned prejudice with grassroots action such as the Dalit Movement and conversion by Dalits to minority sects and religions. In this discussion, I highlight the vital role played by education in the turning point of Dalit action towards liberation. The last section of this chapter analyses life as a Dalit Christian. I identify both the ways in which caste allows inter-religious activity, and the increasing danger of violent attacks on Christians posed by fundamentalist Hindu forces. Finally, I review the newly evolved area of Dalit theology and its role in the transformation of society.

\section{Inequality in India}

India's Information Technology (IT) industry is booming, the economy is developing rapidly, the country is becoming 'richer' and is on its way to sharing the limelight with China as a new world superpower. However, what are the effects of this economic progress on those earning the least? Does an increase in the salary of an educated IT worker result in better wages or quality of life for the street cobblers or the brick carriers? In order to answer this question, World Bank calculations of the number of Indians living on less than a dollar per day ${ }^{11}$ are rather unhelpful (UNDP, 2005). The World Bank is the largest producer of this data so we tend to rely on it, but the Bank's methodologies for calculating economic poverty are unreliable (Islam, 2005; Kakwani, 2004; Monbiot, 2003; Wade, 2003). Moreover, poverty can not be measured by economic status alone; rather, poverty encompasses a number of factors such as lack of access to food, clean water, education, health, clean air and other basic resources (Desai \& Potter,

${ }^{11}$ (or the new international yardstick of US $\$ 1.08$ (Ravallion, 2004)) 
2002). The best way to measure poverty or progress of a country is to consider the degree to which such life-sustaining resources are equally distributed. The MDGs provide some clues as to the quality of life and progress made for the multitudes in India on low or no wages. Although Indian officials agreed in 2000 to the MDG pact, which requires the country to rectify major issues pertaining to the wellbeing and survival of its poorest citizens by 2015, UN data show that many of the promises are not on target to being fulfilled.

This year, 2007, marks the halfway point for the MDG instatement period (20002015). The MDG 2007 Progress Report (United Nations, 2007) states that in Southern Asia, ${ }^{12}$ either no progress has been made or a deterioration of the situation has occurred in the following targets:

- $\quad$ Reduction of maternal mortality by three quarters

- $\quad$ Reversal of the loss of forests

- Halving of the proportion of the population without sanitation

Furthermore, the target is not expected to be met by 2015 for the:

- $\quad$ Reduction of hunger by half

- Improvement in paid employment opportunities for women

- Equal representation of women in national parliaments

- $\quad$ Reduction in the mortality rate of under-five year olds by two thirds

- Improvement in the rate of measles immunisation

- Halt and reversal of the spread of HIV/AIDS

- Halt and reversal of the spread of malaria

- Halt and reversal of the spread of tuberculosis

- $\quad$ Reduction in youth unemployment

- $\quad$ Increase in the number of internet users

Alongside India's exponential economic growth, there is a failure by the government to meet the basic human rights of access to food, healthcare and safety for millions of the country's citizens. These forms of poverty derive from other facets of poverty as defined

\footnotetext{
${ }^{12}$ India, Afghanistan, Bangladesh, Bhutan, Maldives, Nepal, Pakistan and Sri Lanka
} 
by Desai and Potter (2002); the deprivation of social life, spiritual freedom and political freedom.

Were India to show the same level of dynamism and innovation in tackling basic health inequalities as it has displayed in global technology markets, it could rapidly get on track for achieving the MDG targets (UNDP, 2005, p. 30). Whilst there is a general world trend towards the rich becoming richer and the poor becoming poorer (Islam, 2005; Monbiot, 2003), there are various country-specific reasons for this polarisation. One large factor related to inequality-based poverty in India and a handful of other countries, is caste. Caste, or the caste system, is the hidden apartheid (Bob, 2007) or invisible apartheid (Ghose, 2003) which has existed for approximately three thousand years and continues to operate in contemporary India. Although the Indian government no longer officially condones this strict, hierarchical system of segregation, the ever-present prejudice and abuse of those relegated to the bottom is often likened to apartheid. Caste in India is religiously sanctioned by many people, including Hindus and those of other faiths (Ghose, 2003; Jesus: a Dalit, 2006). Instances of apartheid in other countries have involved religious justification, but India's situation differs due to the great length of time over which it has been maintained.

The most obvious and specific activism by unified groups of caste-oppressed people identifying as 'Dalits' only started in the $20^{\text {th }}$ century, and the first ever World Dalit Convention was held as recently as 1998. The Convention sought acknowledgement from the UN that caste-based discrimination was a problem currently affecting at least 300 million people around the world, and a situation much worse than that of race relations ever in South Africa or the USA (Bob, 2007). Former bishop of Madras, Bishop Azariah, also describes the situation in his country as worse than apartheid in South Africa (Azariah, 2000), and Prime Minister of India Manmohan Singh said publicly in December 2006 that the practice of Untouchability has only been paralleled by apartheid in South Africa (CERD, 2007; Rajagopal, 2007). My point here is not to incite a debate over which country in the world has the worst situation of discrimination, but rather to draw a comparison between the global reaction, general opinion and awareness regarding 
South Africa versus that of India. This stark difference is largely due to the Indian government's minimisation of casteism and claims that the issue is strictly an internal matter (Chakma, 2007; Smith, 2005).

\section{India's Caste System}

Identity in India is largely determined by caste, along with class, religion, gender and region (Sivanarayanan, 2004). Class interacts with caste in various ways, especially depending upon religion (Sherinian, 1998). This aspect appears later, but the current section focuses on caste. The English word 'caste' encompasses two levels of an integrated system: varna, the four main categories, and jati, the multitudinous subdivisions within each varna. Varna is broadly organised as a four-tiered socio-econopolitical system determined by familial line, although not all four varnas are present in every region of India. For example, the middle varnas are uncommon in South India (Bayly, 1989). The caste system is outlined in an ancient sacred Hindu scripture, the Manu Dharma, and prescribes social status along with occupation. The highest varna is the Brahmins who traditionally worked as Hindu temple priests, followed by Kshatriya ${ }^{13}$ (the warrior caste), Vaishya (the merchant/trader caste) and Sudra (the servant caste). Whilst there is still some relationship between occupation and caste, an ever-increasing fluidity now allows some social mobility. The Purusha-sukta hymn in the Manu Dharma states that Brahmins are born from the mouth of Purusha (primordial man), and those of the other three varnas are born from the arms, thighs and feet respectively (Larbeer, 2003; Rajawat, 2004b).

In addition to people of varna, there are many citizens who remain outside the varna system altogether, including Dalits and tribal peoples. At least $16.2 \%$ of the population or 166,635,700 people (Office of the Registrar General and Census Commissioner, 2007b) are born as Dalits (officially called 'Scheduled Castes' or 'SCs'). This places them socially beneath the varna system itself and therefore amongst the very lowest ranks in society. The figure of $16.2 \%$ was reported in India's 2001 Census, but the

\footnotetext{
${ }^{13}$ An earlier term 'Rajanya' was later replaced by the name 'Kshatriya.' For a discussion of the significance of this name change, see Rajawat (2004b).
} 
data collection and wording of the Census have been hotly debated, and this is likely to be a very conservative estimate (Shahin, 2001). Dalits do not come from any place on Purusha's body according to the Manu Dharma, so they are considered to be not born at all ('unborn'), and are often treated with less dignity or respect than animals (Rajawat, 2004c). Division in India is not only limited to these five or six groups. Under the umbrellas of the four varna groups and the Dalits, there are many hierarchical distinctions or jati, so everyone knows their exact relative worth in comparison to everyone else. These are however sometimes subjective distinctions, as there are thousands of jati in India, but no official register or list is known to exist. Nonetheless, some claim that jati is more rigid and more prevalent than varna these days (Appavoo, 1993). Tribal peoples (officially called 'Scheduled Tribes' or 'STs') comprise 8.2 percent of India's population, or 84,326,240 people (Office of the Registrar General and Census Commissioner, 2007b). They are generally considered to be completely separate from all other groups and systems, but suffer from severe poverty rates and discrimination on a similar level to Dalits (CERD, 2007).

\section{Dalit Indians}

'Help,' 'Exclusion,' 'Wounded,' 'Despair under Death,' 'The Ruins,' 'Untouchability,' 'Identity,' 'Terracotta,' 'Mingling Tears of Agony,' 'Anger,'

'Equation,' 'Time to Gain,' 'Bull to be Tamed,' 'Heritage,' 'Roots,' 'The

Humiliated beside the Haughty,' 'Celebration,' 'Street Hawkers,' 'Yearning,'

'Journey,' 'The Quiver,' 'Drummer,' 'Masks,' 'Entry,' 'Black and White,'

'Labour Sans Triumph'...

These are the titles chosen by a range of Dalit artists for their paintings. The pictures all appear alongside photographs of their creators in a beautiful book called The Colours of Liberation which was compiled by the Dalit Resource Centre at TTS (Larbeer \& Alexandar, 2000). I have interspersed four of the pictures in this thesis. However, one does not even need to see the works of art to understand the theme, for the titles themselves paint a picture of Dalit life. The words chosen to represent these works indicate the importance of identity for Dalits, and the life experiences alluded to through these titles represent their identity struggles. Some Dalits climb the social mountain, live 
an urban middle class lifestyle and hide their caste identity as well as possible. Others strive to replace a feeling of unworthiness with a proud Dalit identity and embrace all the associated cultural practices. Still others wish to change their identity but are unable, or do not wish to change at all.

Whilst some Dalits in urban areas maintain a middle class lifestyle relatively free from prejudice, the majority of Indians live in rural villages where Dalits are considered 'untouchable.' According to Brahminical Hindu logic, that which is pure must be separated from that which is impure (Ghose, 2003). Thus, the so-called impure and untouchable Dalits are forced by 'upper' caste people to live in segregated areas of villages and avoid touching (and therefore 'defiling') such resources as water wells and power supplies. It is common practice to have separate cups for Dalits to drink from at tea stalls (IDSN, 2007; Jayaharan, 2007, January; Sherinian, 2002). The Dalit area of a village is invariably the most impoverished part, situated so as to be furthest from any bus stops for buses going in both directions, to allow non-Dalit villagers to get on and off first ${ }^{14}$ (Jayaharan, 2007). Even after reading about such conditions, I was shocked when visiting various villages in Tamil Nadu to find that every time we reached the Dalit area, the power lines (if present at all) and the concrete roads literally stopped. If nothing else, the roads were a clear indicator that those who step out of their houses on to a concrete road were segregated both physically and socially from those who had to walk along a dirt path to get home.

One Dalit man I spoke to in a city had grown up in his village suffering daily the humiliation and desperation of having to beg 'upper' caste women to fill his family's water container for him, as he was forbidden from touching the well himself. In the past and to some extent still today, Dalits are denied entry by Brahmin priests into Hindu temples for non-Dalits, so they must pray outside. There are also separate, 'lesser' gods with inferior weapons for Dalits to worship. Most rural Dalits are landless, bonded labourers who toil daily to produce food (Rajawat, 2004c). In addition to hard physical

\footnotetext{
${ }^{14}$ This is geographically possible because the bus stops on either side of the road are not directly opposite each other.
} 
labour, they must serve caste villagers in various ways, including the provision of music (drumming and singing) for caste people's funerals, and handling the 'impure' dead bodies of humans and other animals. Occupations allotted to Dalits in urban areas are the cleaning out of human waste by hand from hole-in-the-ground toilets (known as 'scavenging') and street cleaning (Sherinian, 2002), washing and cobbling. The leather with which cobblers work is considered impure, as it comes from the bodies of dead animals. Dalits have typically been considered by 'upper' caste people to be so spiritually unclean and untouchable, that even falling in the shadow of a Dalit causes fear of being polluted or dirtied (Rajawat, 2004c).

Such forms of discrimination are known as 'Untouchability,' hence the old name for Dalits which is still used by some people now; 'Untouchables.' These and many other casteist practices continue despite the constitutional ban on Untouchability which has existed since 1950. Dalits have been classified under many names by dominant Hindu society over the years, including 'A-varna' (casteless), 'Dasas' (slaves), 'Chandalas' (cursed ones), 'Panchamas' (the fifth ones), Gandhi's word 'Harijans' (people of God), 'Untouchables' and the current legalese 'Scheduled Castes' (SCs) (Azariah, 2000). Some people, including Dalits themselves, currently continue to use the multitudinous jati subgroupings instead of a collective name. However, many politicised Dalits or those who have gained a formal education tend to prefer the name 'Dalit.' This is used by Dalit networks such as the National Campaign on Dalit Human Rights (NCDHR) and the International Dalit Solidarity Network (ISDN), and in academic literature. The term 'Dalit' is preferred by such people because the Sanskrit root word 'dal' means crushed or trodden on, which represents the reality of most Dalits in society (Azariah, 2000). Amongst all Indians of Dalit background, the Christians have had more access to education, and the majority of Christians come from a Dalit background. Therefore, Christian theological seminaries and colleges such as TTS use the word 'Dalit.' In accordance, I have chosen to use the name 'Dalit' for the large, heterogeneous group to which I refer in this thesis. 
According to its legal meaning, the term 'Dalit' refers only to those of the fifth group which comes below the Hindu caste system, and generally does not include the tribal peoples or those of other faiths such as Christianity and Islam. Within the category of 'Dalit,' there are many jati, of which the Paraiyah (parai drum player) is most numerous in Tamil Nadu. The English word 'pariah' is a derivative of this Tamil word Paraiyah and the Malayalam ${ }^{15}$ word Parayan (Simpson, 1989). In contrast to the stricter legal definition of the word, many liberal Christians of Dalit background with whom I spoke used the name 'Dalit' in an inclusive way to describe any person who is oppressed. I was told emphatically by TTS students that anyone is welcome to identify as 'Dalit,' and that this solidarity would strengthen ties across religions and class differences. Thus, while these people wish to eradicate caste from the Church and India in general, they often proudly describe themselves as 'Dalit Christians,' in order to fight the hierarchy which oppresses them. In line with the terminology used by staff and students at TTS, I refer to 'Dalit Christians' throughout this thesis. Choosing the more inclusive meaning of 'Dalit' means adjusting the number of Indians negatively affected by casteism to one much larger than the aforementioned 16.2\% calculated in India's 2001 Census. Azariah (2000) claims that there are more than 250 million Dalits in India today.

Caste was declared illegal in the 1950 Constitution of newly independent India (Jaffrelot, 2005), and the country was decreed secular (Puniyani, 2005). However, caste has been well maintained since then, to the extent that the caste of a stranger can often be determined immediately by their name, or at first glance by their clothing, hairstyle, forehead markings from temple visits, body language and other visual clues. Such a system, which has survived for approximately three millennia, can not be expected to disappear overnight. However, a promising reduction in discrimination evident in metropolitan areas is compromised by the active maintenance of caste through marriage. Parents generally arrange marriages for their children in India. Even the majority of those who claim to be liberal and non-discriminatory towards those of 'lower' caste in daily life will still not choose suitors for their children from castes other than their own (Ghose, 2003). Two families in the segregated Dalit area on the outskirts of a village near

\footnotetext{
15 The language of Tamil Nadu's neighbouring state, Kerala
} 
Chennai ${ }^{16}$ told me that no one from the main part of the village would "give or take girls," meaning that caste villagers do not allow their children to inter-marry with Dalit children. Young urbanites who now study and work in more mixed-caste groups sometimes fall in love with a person from another caste. However the parents of both parties usually oppose marriage between the pair and the couple risks disownment by their respective families if they insist upon doing so (Wingate, 1999). Caste is often associated with Hinduism but it is certainly not exclusive to Hinduism. Caste matters even more than religion (Rajawat, 2004d), so parents of similar or same-caste Hindu and Muslim children or same-caste Hindu and Christian children are generally more appeaseable than parents of two young people belonging to the same religion but different castes. In some villages, Dalits are not allowed to own cows, goats or dogs for fear of Dalits' animals mating with non-Dalits' animals (Jayaharan, 2007).

\section{Denial of Personal Safety and Education}

Despite the beliefs and fears of 'pollution,' Untouchability is not practised when it comes to rape (IDSN, 2007). The rape of Dalit girls and women by 'upper' caste men is common in rural areas, and often unavoidable because even the fathers and husbands are unable to protect them. Authorities regularly fail to deal with such cases (Dietrich, 2005; History, 2006). According to Justice Bhagwati, "rape is increasingly becoming a form of caste war" (cited in Dietrich, 2005, p. 64). A Dalit life is literally considered of less value than that of an 'upper' caste person, so Dalits are often beaten or murdered at whim. Reports of some atrocities have started filtering through to newspapers, but many thousands of Dalits are killed every year in caste-related crimes (Bob, 2007; Ghose, 2003). No just resolution of these crimes can be found through the legal system, where police often side with the 'upper' caste perpetrators of the crimes and physically beat victims or their family members (Third World Institute, 2005). Many cases do not even get as far as the police station, as Dalits who are financially dependent on abusive employers risk the consequences of losing their employment and being socially ostracised if they report such incidents (Appavoo, 1993). Dietrich illustrates instances in Tamil Nadu in which Dalit men have been accused of inciting communal (caste-based)

\footnotetext{
${ }^{16}$ Formerly known as Madras
} 
violence and sent to jail upon protesting police inaction regarding the rape and murders of Dalit women. The punishment for the verbal protesters is often more severe than that for the perpetrator of the rape or murder (Dietrich, 2005).

Poisoned Bread (Dangle, 1992) is the title of an anthology of Dalit poems translated from Marathi to English. The introduction to this book from 1992 indicates that it was the first ever published anthology of Dalit poetry. The extreme recency of such an event indicates the millennia-old oppression of Dalit culture and arts, and their lack of access to education and printing technology. On the positive side, the achievement of this anthology signifies the change in Indian society since the 1980s and the extent to which Dalits and others have fought for such changes. It also provides an encouraging outlook for continued efforts towards lifting the oppressive and discriminatory forces still at work in everyday life. A small number of Dalits have benefited from placements in higher educational institutions and government jobs officially reserved for Dalits, and maintain a comfortable standard of living. This affirmative action was started in Tamil Nadu, as a movement against the Brahmin domination of the educational arena (Panandiker, 1997). However, Parattai ${ }^{17}$ claims that reservation policy and other social services benefiting a tiny proportion of Dalits only create false hope and prevent Dalits from fighting for real change. In Parattai's words, "They know even a worm would retaliate if it were driven into a corner" (Appavoo, 1993, p. 29).

Reservations have certainly stirred a fighting spirit in some 'upper' caste students, who passionately demonstrate against such access to education by Dalits (Panandiker, 1997). Some 'upper' caste students feel so strongly about the issue that they immolate themselves in protest (Ghose, 2003). Such reports have regularly appeared in Indian newspapers, especially in the past two decades. Writing a decade ago, Panandiker (1997) claims that non-Dalits are becoming progressively angrier about reservations and feeling less guilt about the situation of inequality in India. According to Panandiker (1997), the reservation issue is "the most explosive threat" (p. v) to peace in society and has the potential to ignite a civil war. These days, reservations are becoming increasingly useless

\footnotetext{
${ }^{17}$ Also known as Appavoo
} 
for Dalits. There is no policy in place to provide reservations in the private sector, despite the fact that India is rapidly privatising and the number of public service positions is decreasing (Bob, 2007; Ghose, 2003). The UN Committee on the Elimination of Racial Discrimination (CERD) put pressure on India's government to enhance access by Dalits to the labour market and suggested extending the reservation policy to the private sector (CERD, 2007). Some large private firms such as computer services company Infosys have started their own schemes of training and hiring Dalits in the face of "threats" by the government to impose even stricter caste-based hiring quotas (Business and caste, 2007). According to Business and caste (2007), there is less opposition to reservation policy in Tamil Nadu, which may be due to the higher efficacy of the policy there. On the other hand, the higher literacy and prosperity of 'lower' caste people in Tamil Nadu may be due to the overall efficiency in the running of the state, rather than the state's relatively high reservation rates for government jobs. Business and caste (2007) claims that "lowcaste Tamils" may have simply benefited from the above average economic growth of the state due to this relative efficiency. However, some credit must be given to the reservation policy, because as the UNDP (2005) states, income poverty reduction relies not on overall economic growth alone, but also on the portion of that growth available to the poor. N. Vasudevan, Chief official of the Backward Classes, Most Backward Classes and Minorities Welfare Department in Chennai, believes that reservation policy should end "when everyone becomes equal" (cited in Business and caste, 2007, para. 34).

\section{Industria and Fundamentalist Hinduism}

The problems for oppressed, poor Dalits are exacerbated by a certain type of globalisation, referred to by Shiva (2005) as "corporate globalization" (p. 143), and by Hipwell (2007) as "Industria." Hipwell's definition provides a more detailed identity for the globalisation which is stifling much of human and non-human life: Industria is a parasitic web of geographical power which is encircling and feeding off the Earth. It is maintained in the constantly increasing interactions of urban consumers with global state and corporate elites, polluting and homogenising the world (Hipwell, 2007). As the intrusion of foreign-owned multinational companies makes the rich sector of India even richer, the pollution, environmental degradation and loss of fertile land due to these 
companies' factories spell disaster for the low-wage agricultural workers (Shiva, 2005). With no land to be worked, the only options for these illiterate agricultural workers are to move from their villages to the cities and find low paid employment which lacks job security and basic rights, live in overpopulated slums, or join the begging masses on the streets. India's business world claims praise for the country's rapidly rising economic success and is readying itself to be one of the new world superpowers along with China. However, the reality is that little money trickles down from this success at the top to the masses who are suffering in poverty at the bottom (Ramesh, 2006). The relationship between income and social progress is not automatic, and the little trickle which does flow appears to be slowing down in some major areas of public health (UNDP, 2005). India's ability to redistribute the benefits of economic growth through the fiscal system is restricted by the longstanding tax to revenue ratio of only 10 percent (UNDP, 2005).

The Bharatiya Janata Party (BJP) and other Hindutva (Nationalist Hindu) practitioners seek to create a country united by one religion; a Hindu-only India (Sebastian, 2005). Hipwell's image of Industria as a homogenising parasite on life supports the contention by Shiva (2005) that fundamentalist ideologies such as that of Hindutva practitioners function as the "handmaiden of globalisation, helping to keep it in place" (p. 144). Shiva (2005) claims that fascism is the only choice for politicians wanting to gain popularity when the economic control of their own country has been taken out of their hands and they can not win votes by old-fashioned means such as guaranteeing food security. When the International Monetary Fund (IMF) and the World Bank control all decisions relating to basic necessities (ownership of land, seeds, waterways, etc) through the institution of Structural Adjustment Policies ${ }^{18}$ and the World Trade Organisation makes those changes legally binding, national democracy means almost nothing (Shiva, 2005). Thus, politicians fall back on nationalistic tactics which feed fear amongst citizens, drawing them towards the party which offers protection from the outside world. In this way, minority groups are sacrificed for the sake of the majority. In India's case, this spells danger for all people of minority religions, especially those religions which originated outside the country. In 2002, Christianity and Islam were

\footnotetext{
${ }^{18}$ Now part of the Comprehensive Development Framework (CDF) policy.
} 
declared as alien religions which were against the Indian ethos (Third World Institute, 2005). In the words of Hipwell (2007), "We must recognise that political, theological or philosophical enemies of diversity are enemies of Life" (p. 312). Christian missionaries certainly contributed to the destruction of diversity during the era of British control (Eaton, 1997). However, it is Hindutva, started in the 1920s but lying dormant until recent decades (Puniyani, 2005), which has now taken over as the leading homogenising religious threat to life in India.

There are suggestions that affirmation of conversion to other religions (especially Christianity) pre-1950 and the establishment of India as a secular state in 1947 were due to a solidarity between Hindus and Christians which was necessitated by the shared desire to overthrow the British (Sebastian, 2003a, 2003b). However, between the time of Independence and the present day, a situation has evolved so that:

When militant sections of the majority-dominant community are persuaded that the secular paradigm has only functioned to offer space to minority communities, then there is a backlash in terms of the "othering" of such communities (Sebastian, 2003a, p. 208).

This feeling was present even well before Independence, when Dalit leader Dr Ambedkar first started encouraging then-called 'Untouchables' to convert to other religions, and Buddhists, Sikhs and Muslims alike were vying for his attention (Jaffrelot, 2005). The Hindu Mahasabha (a Hindu nationalist organisation) was aware that if a sufficient number of 'Untouchables' converted out of Hinduism, then unity may develop between 'Untouchables' and those of minority religions, and the majority-dominant community would be demographically and thus also electorally affected for the worse (Jaffrelot, 2005).

The BJP purports to be anti-globalisation, but when in power they passed legislation which enabled free trade in agriculture and the privatisation of water, in addition to other harmful policies (Shiva, 2005). It was no coincidence that the trade liberalisation policies of the 1990s came about at the same time as the BJP was rising to power (Shiva, 2005) and numerous acts of violence were being carried out by 
fundamentalist Hindus on Muslims in Bombay ${ }^{19}$ and Ayodhya (Third World Institute, 2005). India's social development regressed while the country was in the grips of the Hindutva-promoting BJP (Puniyani, 2005). The UN Human Development Report for 2005 states that annual progress in reducing the child death rate in India has slowed since 1990, the time when globalisation and economic growth started to increase dramatically (UNDP, 2005). Furthermore, the gap between child mortality rates for the richest and poorest sectors of India increased during the 1990s. If the current average child mortality rate were to fall to that of the richest 20 percent of Indians, the overall total would reduce by more than half, or approximately 1.4 million deaths (UNDP, 2005). In addition, the 2005 UNDP data show that the mortality rate of girls between the ages of 1 and 5 is 50 percent higher than that of boys, so the rates could be dramatically reduced if gender inequality were addressed effectively.

\section{International Response}

Forms of casteism exist in some African countries, Japan and most of South Asia. However, the largest number of people negatively affected by caste is the approximately 166 million Dalits living in India. Compared with neighbours such as Pakistan and Bangladesh, India has been much more progressive in legislating against caste-based discrimination. However, widespread casteist oppression has continued. Despite centuries of protest and attempts to change the invisibility of Dalits, breakthrough at the international level only occurred belatedly in the last few years of the $20^{\text {th }}$ century. Firstly, CERD finally stated in 1996 that caste-based discrimination should be included in the definition of racial discrimination. This led to a decision the following year by NGO Human Rights Watch to report on caste-based discrimination (Bob, 2007). This in turn led to the establishment of united organisations both at the domestic level in 1998 (the NCDHR) and at the international level in 2000 (the ISDN) (Bob, 2007). The way in which India has allowed such a large issue of human rights abuse to continually be swept under the carpet is to equate the situation de facto with the situation de jure (Appavoo, 1993; Bob, 2007). Because the law has not allowed for any discrimination based on caste, race or sex since 1950 (Jaffrelot, 2005), the Indian government has claimed that such

\footnotetext{
${ }^{19}$ Now known as Mumbai
} 
prejudice does not exist (Chakma, 2007). Thus, what is required and lobbied for is not a change in law, but rather enforcement of the law and changes in practice (Bob, 2007).

At the most recent UN International Convention on the Elimination of All Forms of Racial Discrimination (ICERD) in early 2007, CERD produced one of their longest lists of recommendations ever made, based on India's state report. According to Chakma (2007), Indian government representatives failed to convince CERD this time that the issue of discrimination against Dalits and tribal peoples was irrelevant to the CERD agenda. The CERD document re-emphasised that caste is included in their definition of discrimination on the basis of descent. It included recommendations to punish those responsible in at least sixteen major areas of caste-based discrimination, or rectify the situations (see Appendix V). These situations include the widespread, remaining de facto practices of Untouchability which prevent Dalits from accessing basic resources, health, safety, education and jobs due to the lack of implementation or reinforcement of relevant laws. India was also criticised for neither making their State reports for CERD readily available to the public at the time of submission, nor available in any language other than English. The country was requested by the UN to rectify this situation, and provide proof of both this rectification and those regarding the situations listed in the recommendations document (CERD, 2007).

\section{Domestic Response}

\section{Political Action}

Far preceding and eventually prompting the international spotlight on India's caste discrimination have been various forms of grassroots protest and activism by Dalits. Gorringe (2005) claims that in Tamil Nadu, the biggest changes and transformations of power relationships occur at the local level. As general politics, and therefore the politics of casteism, differ between states and also change over time (Kaviraj, 1997), caste and religious affiliations should not be considered static (Bayly, 1989). Despite the continued silencing of their voices, many Dalits do not simply accept passively their own destiny or that of their children. There are now over seventy different Dalit organisations in the state of Tamil Nadu alone (Gorringe, 2005), and many forms of social movement and action 
exist. Whilst slower to change than those in some other states, Dalits in Tamil Nadu since the 1970s have become increasingly organised, politically minded, and demanded their own constitution (Gorringe, 2005). Reasons for the slow progress of early activists include the decentralised, uncoordinated nature of Dalit civil society organisations around India and their limited international contacts (Bob, 2007). Furthermore, international development agencies have focussed on the effects of casteism such as poverty, child labour and violence against women, without considering their root cause (Bob, 2007). Dalits are not a unified group yet within India, and were even less so in the past. There was not one leader of this heterogeneous group who was actually a Dalit him/herself in all of history until Dr Bhimrao Ramji (Babasaheb) Ambedkar rose to the position in the first half of the $20^{\text {th }}$ century, and no one has filled his shoes since (Azariah, 2000).

It is pertinent to note here that Dr Ambedkar was one of the first Dalits ever to receive higher education (Jaffrelot, 2005). He trained as a lawyer not in his own country, but in the UK and the USA. He was then appointed in 1947 by Jawaharlal Nehru as the head of the drafting committee for India's new Constitution which prohibited caste, race and sex-based discrimination (Jaffrelot, 2005). With Dr Ambedkar as their role model, many Dalits have since worked towards transformation of their society. He is very clearly the hero for many Dalits in India as evidenced by the posters, stickers and effigies of him which abound in Dalit areas of villages and cities alike. Mohandas (Mahatma) Gandhi is much better known on the world scale, and honoured by a large portion of Indian society as the 'Father of the Nation,' with his image appearing on all the country's banknotes. However, most Dalits I met at TTS expressed the view that Gandhi was a false hero. They felt that he sympathised with the poor and this gained him some support from the Dalit sector of society, but he did not follow through his words with action towards abolition of the caste system. Further disenchantment in this vein is evident in such articles as 'Unmasking Gandhi,' published in the Dalit magazine Unbroken People (M. C. Raj, 2006c).

Zelliot (2001) explains that the highly political terminology used by Gandhi and Ambedkar respectively indicate their differences. Gandhi's 'Harijans' (people of God) is 
compassionate but places the people as objects of pity, whereas Ambedkar's 'Dalits' (broken or cracked) is a strong word which proudly and boldly states the truth of the matter (Zelliot, 2001). Gandhi viewed the caste-based prejudice of Untouchability as an aberration of Hinduism which could be dissolved, whereas Dr Ambedkar considered Untouchability to be an inextricable component of Hinduism (Smith, 2005). Jaffrelot (2005) outlines the rivalry which existed between Gandhi and Ambedkar, mentioning that Ambedkar was the only Indian politician whom Gandhi ever contested by fasting. The work of charismatic social justice leaders such as Dr Ambedkar and Gandhi has now been well documented, but literature regarding grassroots Dalit action and Dalit empowerment organisations is still thin on the ground (Rajawat, 2004c).

\section{Education and the Arts}

For some Dalits, particularly those with no formal education, arts such as music, poetry, drama and drawing have been utilised as ways of expressing feelings of injustice and hope for a different future. Perhaps the most influential action ever taken regarding Dalits was by foreign Christian missionaries who developed "the radical idea of extending education to the Dalits" (Ghose, 2003, p. 87). One missionary report from 1896 states that "caste Hindus regard the opening of a school in the Pariah [Dalit] quarter of their villages [as] a sign of revolution" (Clarke, 2003, p. 343). Amongst other basic skills such as numeracy and literacy, education encourages critical thought and enquiry. Frequently, this results in the questioning of one's position in society (Gorringe, 2005). According to Ghose (2003), it was from the schools set up for 'Untouchables' by missionaries and the British administration in the 1840s that the first Dalit activists, writers and politicians emerged. Whilst the Dalit Panthers ${ }^{20}$ disbanded a few years after their establishment in 1972, it is notable that most members were poets and writers who composed a large amount of radical literature (Ghose, 2003). The greatest problem for Dalit movements has been elitism within the Dalit community itself. The upwardly mobile, educated Dalits have discriminated against other Dalits, compromising unity for all (Gorringe, 2005). Nonetheless, continued signs of arts used for awareness of Dalit issues include the annual 'One Billion Eyes' Indian documentary film festival in Chennai.

${ }^{20}$ Name inspired by the Black Panthers of the USA (Ghose, 2003) 
The theme of the film festival for 2007 was 'Caste,' with all films focussing on untouchability and the unacceptable conditions faced by Dalits in everyday life. The winning film, India Untouched, is "Perhaps the most comprehensive look at untouchability ever portrayed on film" (Caste, 2007). It was shot over four years in eight states, and considers the continued casteism and untouchability practised by Dalits and non-Dalits of Hindu, Sikh, Christian and Muslim faiths (Caste, 2007).

\section{Religious Responses}

\section{Conversion}

If such degrading treatment derives from one's position within a 'Hindu' system, then why not change religion? Brahminical Hinduism creates a hierarchical society with inequality in the religious, social, spiritual and political aspects of life (Azariah, 2000; Clarke, 2003). On the other hand, Christianity, Islam, Jainism, Sikhism, Buddhism and certain other sects of Hinduism are all opposed, at least ideologically, to the Brahminical Hindu notion that the family into which one is born determines one's human rights. In certain times and places in India, conversions to other religions and sects have occurred as attempts to eradicate or escape casteism. However, the rates of success have been varied. Inter-religious and intra-religious struggles intertwine with inter-caste and intracaste issues, creating both strife and also alternative lifestyle options. Dale (2003) claims that as with Christianity, 'lower' caste converts to Islam have often chosen the religion as a social alternative to their degraded status. As Muslims, 'lower' caste Indians were better able to challenge the social presumptions of the 'upper' castes (Dale, 2003). “Awakening" to Jainism implied the strong rejection of Brahmin authority (Dundas, 2003, p. 121). Hindus were also attracted to Sikhism through different periods in history as a way of escaping the discriminatory caste system (Fenech, 2003). However, change in social status and social structure has been overestimated as the motivation for conversion, according to Bayly (1989). Conversion has not always occurred as a wholesale transformation of beliefs and practices. Furthermore, the pursuit of other desired qualities such as power and sacred energy were at least as important as egalitarianism for many early converts to Islam in South India (Bayly, 1989). On the other hand, some scholars claim that early conversions to Christianity were predominantly attempts at liberation 
from casteism because it was Dalits who first sought out the missionaries, and there was sharp retaliation from 'upper' caste people (Appavoo, 1993). Eaton (1997) states that Indians were often the subjects rather than the objects of conversion. They made reasoned decisions to convert, integrating elements of outside religions into their pre-existing worldviews, instead of accepting foreign ideas wholly or blindly (Eaton, 1997). The main problem in ascertaining the true motivations for conversions to Christianity is that they have very often been recorded and reviewed historically only from the viewpoint of foreign missionaries commissioned to convert (Bayly, 1989; Doniger, 2002).

Puniyani (2005) states that there are two important faces of religion in every country. One enjoys life as it is, reaps the benefits of the established system and resists societal change. This face is usually the state religion, or in the case of officially secular countries such as India, the de facto state religion. The other face is the folk or popular religion, pushed by those who want change towards egalitarianism and an end to their oppression (Puniyani, 2005). The Bhakti movement started in Tamil Nadu as one such protest against the caste system and Brahminism. Bhaktis have been variously classified as Hindus or Muslims, but many refuse to be confined to one category. Thus, they function as a bridge between the two major religions, promoting interfaith dialogue, social equality, anti-elitism, the position of women in society, and anti-caste egalitarianism (Puniyani, 2005). Many famous Bhakti leaders or saints used the arts in order to protest social order; for example, the poet Kabir, who denounced caste and Untouchability, and Nanak, who composed and sang songs to the accompaniment of a string instrument called the rabab (Puniyani, 2005). ${ }^{21}$ The Bhakti movement gave hope, and "People oppressed by the spiritual tyranny of the Brahmins got a feeling of their worth in society" (Puniyani, 2005, p. 39).

Some academics suggest that all other religions originating in India came into existence as signs of protest against Brahminical Hinduism, and most converts made conscious choices to leave the majority-dominant religion. Mehta (cited in Puniyani,

\footnotetext{
${ }^{21}$ Examples of Bhakti poetry which derides caste and Untouchability appear at the start of chapters 3 and 6 of this thesis. For more examples, see Rajawat (2004b) or Zelliot and Mokashi-Punekar (2005).
} 
2005) lists Lokayat, Ajivikas, Nath and Siddha cults, the various Tantric sects, Sufi movements and the Jotirao Phule following as alternative faiths devised and utilised by oppressed sections of Indian society over a long period of history. However, according to Appavoo (1993), Lokayat attacks on casteism were relatively small. Appavoo (1993) also claims that the larger protests involving the masses, namely Buddhism and Jainism, were contained by Brahminical Hindus and had lost their revolutionary character by the time they reached South India. Nonetheless, Ghose (2003) places Buddhism, Jainism and the Bhakti groups as successive reform movements against the caste-doctrinal Brahminical Hinduism. Buddha, Mahavira and the Bhakti saints all espoused egalitarian faiths based on compassion, which influenced later leaders such as Gandhi and Ambedkar (Ghose, 2003).

Some contemporary leaders such as Bishop Azariah have written about Buddhism as a revolt against oppressive Brahminical Hinduism which was brought into India by the Aryans. Azariah (2000) asserts that Gautama Buddha was the first and biggest leader of the indigenous non-Brahminical people who are now known as Dalits. Dr Ambedkar created a new sect of Buddhism called Navayana Buddhism after his high profile conversion out of Hinduism as a move to weaken caste barriers (Tartakov, 2003). His desire to change was fuelled more by his wish to convert from Hinduism than his wish to convert to any other particular religion, so Dr Ambedkar carefully considered a number of other major religions. His eventual establishment of Navayana Buddhism focussed primarily on the idea that distinctions between human beings should be made based on an individual's actions rather than familial lineage (Tartakov, 2003).

\section{Double Discrimination for Dalit Christians}

A major reason why oppressed peoples choose popular religion as a tool for change may be the unity that religion (or a subgroup within the religion) provides. Unity enables a powerful, dominating force to be confronted through collective, cooperative efforts. Nonetheless, intra-religious splits often occur because a small subgroup inevitably controls the masses, be it within Hinduism, Christianity or any other religion. Christianity began in Europe with the poor and the slaves, but developed a hierarchy with 
the establishment of clergy (Puniyani, 2005). This pattern was repeated down the generations as Protestants split off from Catholics, and then numerous divisions occurred within Protestantism, each subgroup tweaking the religion as desired. Similarly, in India, it was the poor and oppressed who initially converted in large numbers to Christianity. The more egalitarian views of Christians enabled early Chuhra Punjabi converts to Christianity to attain a new "emancipatory identity" (Webster, 2003, p. 373). According to Clarke (2003), Christian conversion by the poor and oppressed in Tamil Nadu has in certain periods of time provided hope, liberation, dignity and increased social status. India was very progressive in uniting many of the Protestant denominations through the early establishment of the Church of North India (CNI) and the Church of South India (CSI), but much of the Anglican-style hierarchy is still evident. Furthermore, casteism is found extensively in all Churches, from the CSI and CNI to the Roman Catholic, Lutheran and Evangelical Churches. This is a legacy created especially by Syrian Christians during Ambedkar's time. The Syrian Christians considered themselves to be above other Christians and were not at all keen on Ambedkar's mass conversion projects. He was already disenchanted with Christianity for the very reason that Christians persisted with caste (Jaffrelot, 2005). Sherinian (1998) claims that:

Christians have recontextualized caste relations within the churches. They ascribe their own meaning to this difference, often not applying it consistently (p. 27).

Indeed the segregation goes to the grave, with even separate burial grounds for Dalits (Jesus: a Dalit, 2006). It is the backlash against this hierarchy and continued domination which has led to the emergence of Dalit theology within the CSI. Several Dalit Christians have now undertaken the position of bishop in CSI dioceses of Tamil Nadu, but the number of Dalit bishops is not proportional to the number of Dalit Christians.

Dalit Christians are twice discriminated against, as they struggle with caste-based, elitist prejudice both within their own religion and as a 'foreign' minority religion in an increasingly fundamentalist Hindu dominated country. However, such Brahminical Hinduism is not an appealing alternative. Neither is following saints who from humble beginnings are now also becoming increasingly elitist and Brahminical, such as Sai Baba 
and Lord Jagannath (Puniyani, 2005). Another option which may seem viable to those less familiar with Indian society is for Dalits to become agnostic or atheist. However, it appears to me that if Indians do not belong to any other religion then they are Hindu by default, and it would be difficult in the Indian context to establish an identity as someone who shuns all gods. Indeed, in India's most recent census held in 2001, 80.5 percent of the population identified as Hindu and 99.9 percent classified themselves as either Hindu, Muslim, Christian, Sikh, Buddhist, Jain or Other Religion and Persuasion, leaving the 'Religion Not Stated' column reading 0.1 percent (Office of the Registrar General and Census Commissioner, 2007a). By comparison, 29.6 percent of New Zealanders identified themselves as being of no religion in Aotearoa New Zealand's 2001 Census and that figure had risen to 34.7 percent in the 2006 Census (Statistics New Zealand, 2007). Attempts at secularisation of Indian society as a whole were strong in the time immediately after Independence, under the new Constitution. However, since the end of the 1980s there has been a reversal of this process of secularisation which had begun to reduce the dominance of clergy and improve caste and gender relations (Puniyani, 2005). Further reason for the lack of interest in atheism or agnosticism as potential paths for castelessness is due to the opinion that the problem of caste oppression is religious, so the solution must therefore be found through religion. Azariah (2000) holds such a view, and names new Dalit ideology created by Dalit theology as the path to choose.

\section{Syncretism}

Caste and politics are related at every level, and whilst certain issues sometimes divide opinion, there is a very high level of unity within castes (Kaviraj, 1997). The strength of caste over religion is evident when Hindus and Christians celebrate festivals together. S. J. Raj (2002) finds that people from these two religions converge for pilgrimages to the shrine of St John de Britto and rituals at the shrine such as cattle processions. However, pilgrims tend to form tight cliques which enhance intra-group harmony rather than inter-group harmony, particularly pertaining to caste. S. J. Raj (2002) claims that no difference in terms of religious identity can be found at all between Hindus and Christians during certain pilgrimages, and that religion is less important when caste is carefully maintained. This signifies the strength of the caste system, but it is also 
a positive indication of the ability of Dalits and 'lower' caste people to achieve unity across such wide barriers as religion. Syncretism most commonly occurs between Catholic Christians and Hindus, as Catholic traditions and rituals are more similar to Hindu rituals and lend themselves to shared celebrations. At the famous Velankanni Shrine in Tamil Nadu, Catholics and Hindus celebrate the biggest event of the Church year together, Mother Mary's birthday, on September $8^{\text {th }}$ (Meibohm, 2002). However, the degree of shared living and celebration varies according to location and time in the vast country of India. Missionaries in Goa used to insist upon orthodox Catholicism more than those in South India, and closer ties to the Vatican in addition to the rise of Hindu nationalism do not bode well for syncretic practices in current times (Meibohm, 2002). Protestants are the least syncretic Christians in India, which stems from suspicion of Hindu practices considered to be superstitious by early Western Protestant missionaries (Kent, 2002).

Doniger (2002) claims that calling Indians 'syncretic' implies a Western hegemony on the construction of faith: the assumption that religions are in fact discrete but Indians try to blur the lines. Surely one could expect that less exclusion between religions would enhance mutual understanding and peaceful interactions between peoples of different faiths. However, this syncretism may be the reason why low caste and Dalit Hindus are never able to escape completely the oppressive caste system. If Christianity is not so distinctly different from Hinduism, then what does it mean to convert and 'become' a Christian? Can any social or economic gain be made through conversion out of Hinduism, and is there any hope of ridding the Church of caste-based prejudice? On the other hand, perhaps Indian religions remain more syncretic because the caste system ties them together. If caste unity across religious groups was taken away, little commonality may remain at any level, and combined Hindu-Christian celebrations may become a thing of the past. Whilst caste is often called a Hindu system, some now consider it instead a part of Indian or South Asian culture. Support for this theory is found when we consider the lower levels of casteism amongst expatriate Indians living abroad, and the high levels in neighbouring countries such as Nepal and Sri Lanka (Bob, 2007), and the predominantly Muslim Bangladesh (Narayanan, 2002) and Pakistan (M. C. 
Raj, 2006a). Fundamentalist Hindus encourage such an idea and use it to render nationalistic support for an India united by Hinduism, claiming that those of 'foreign' religions are unpatriotic and have sold out to Western powers (Sebastian, 2005).

\section{Hindutva Violence}

It is commonly acknowledged that 'Hinduism' was a term coined by the British, encompassing a wide variety of religious practices and rituals in India (Bayly, 1989; S. J. Raj \& Dempsey, 2002; Sebastian, 2003a). Until the beginning of the colonial era, caste was ill-defined, especially between urban and rural dwellers. 'Traditional Hinduism' and a 'traditional caste system' were concepts invented by $18^{\text {th }}$ and $19^{\text {th }}$ century European colonisers (Bayly, 1989). Some scholars claim that both Hinduism and Christianity are diverse and pluralistic, so the correct terminology is 'Hinduisms' and 'Christianities' (S. J. Raj \& Dempsey, 2002). Whether or not such divisions are helpful for unity within and between religions, it is especially important to distinguish between fundamentalist, Brahminical Hinduism (Hindutva) and other Hinduisms. Hindutva differs from traditional Hinduisms because it is inherently an ideology of violence and thus requires a hate-object to sustain itself (Melanchthon, 2002). Formerly the enemy was usually Muslims, but in recent decades Christians have become the main target. Although Christianity has existed in India for approximately 2000 years, it has always been a minority group and thus is still accused of being a 'foreign' religion. Numerous attacks on Christians have been documented, from the ransacking of schools to sexual violence and murder. Nuns have been raped, priests have been stripped naked, frogmarched down the street and killed, and Australian missionary Graham Staines was burned alive with his two young children in their car (Melanchthon, 2002). In addition to these high profile cases, many lay Christians have been subjected to hate literature, graffiti, and xenophobic anti-minority speeches (Lobo, 2002; Melanchthon, 2002).

Both Lobo (2002) and Melanchthon (2002) stress the rise in attacks on Christians in the four years leading up to 2002, and discuss the involvement of the exclusively male Rashtriya Swayamsevak Sangh (RSS). The RSS is an umbrella of Hindutva organisations in India, described by activist and author Arundhati Roy (2003) as a group which "has 
not been shy of admiring Hitler and his methods." By close association with the RSS, the aforementioned BJP, the Vishwa Hindu Parishad (VHP) and the Vanwasi Kalyan Ashram (VKA) are also implicated in this discrimination and violence towards people of faiths other than Hinduism. The RSS, the BJP, the VHP (Universal Hindu Assembly, largely comprised of merchants and traders), the VKA (a group which carries Hindutva agenda to tribal peoples in remote places) and the Bajrang Dal (storm-trooper style militants) can be collectively described as the 'Sangh Parivar.' These Hindu Nationalist groups are described by Lobo (2002) as those which "intertwine each other like the strands of a rope and put a noose around the necks of the minorities" (p. 118). A report by the Coalition Against Genocide is one of many papers which detail the Sangh Parivar's fascist and Nazi influences and its evolution as a response to British colonisation (Chatterji, McKean, $\&$ Sur, 2005). The group continues to promote a free India for 'upper' caste Hindu people while wielding "social and cultural power" (Chatterji et al., 2005, p. 8) over Muslims, Christians, 'lower' caste and tribal peoples. Functioning as the social infrastructure of Hindutva are the modern day saints such as Asaram Bapu and Pandurang Shashtri Athwale, upholders of the Brahminical status quo (Puniyani, 2005). The Third World Institute (2005) dates the escalation of violence against Christians to 1998, when Keshubhai Patel became the BJP chief minister. In 1999, the telephone numbers, vehicle information, links with foreign countries and police records were required of all Christians and Muslims in Gujarat's census (Third World Institute, 2005).

Sikand (2000) claims that Hindu militancy or Hindutva is currently being heavily promoted in South India. Due to the proud, anti-Brahminical and anti-Aryan (anti-North) nature of the Dravidian South Indians, especially those in Tamil Nadu, Hindutva has hitherto been less influential. However, Hindu militants are now using the same trick of creating divisions between Hindus and Muslims (most successfully in Tamil Nadu's neighbouring state Karnataka). This reduces unity and syncretism, allowing Hindutva forces to gain more power over everyone (Sikand, 2000). With this resurgence of Hindutva power, many people or whole villages who formerly converted to Christianity are now converting back to Hinduism (Wingate, 1999). Being a Christian is no longer so appealing in this climate of violence against non-Hindus, where one must suffer the 
double discrimination of being both a Christian and a Dalit. Dalits who would otherwise have qualified for the reserved seats in universities and government have been unable to take these opportunities if their official religion was Christianity. They were reminded that their religion claims to be caste-less, and denied such placements. Now, however, the Tamil Nadu government lists selected categories of Dalit Christians ${ }^{22}$ amongst the 142 Dalit subgroups included as 'Backward Classes' to which certain reservations apply. Another issue is the perceived danger in converting now. Some states have instituted laws which require people to seek permission before converting to another faith, and to report any conversions they perform to the authorities. However, Hindutva impacts negatively upon all Dalits, not only those of Christian faith. Chief Minister Narendra Modi and the BJP state government of Gujarat have displaced hundreds of thousands of non-Christian Dalits with the Narmada Dam, in addition to creating problems for Christians (Third World Institute, 2005).

\section{Dalit Theology}

Despite their decreasing numbers in some areas, the double discrimination faced by Dalit Christians makes them some of the most steadfast activists in the drive for equality in India. Melanchthon (2002) suggests that it is the suffering of Jesus Christ with which many Dalits identify, and thus Christ is an attractive choice among the wide variety of deities in India to whom one might pray. Dalits are not the first or only people to identify with the Israelites and other oppressed peoples mentioned in the Bible. The oppressed Minjung people of Korea started developing Minjung Theology within Korean Christianity in the 1970s, a decade before the emergence of Dalit Theology (Massey, 2006). From the beginning of this new way of thinking, the Minjung asserted that they should be the subject of their own history and destiny. As they insisted upon this change in identity, respect slowly followed (Kim, 2006). Biannual Dalit-Minjung theological conferences have been held alternately in Korea and India since the early 1990s. The

\footnotetext{
22 "Converts to Christianity from any Hindu Backward Classes Community or Most Backward Classes Community or Denotified Communities except the Converts to Christianity from Meenavar, Parvatharajakulam, Pattanavar, Sembadavar, Mukkuvar or Mukayar and Paravar" and "Converts to Christianity from Scheduled Castes irrespective of the generation of conversion for the purpose of reservation of seats in Educational Institutions and for seats in Public Services," (Government of Tamil Nadu, 2007).
} 
most significant conference was held in 2005 and attended by scholars from Serampore University, the most reputed Protestant theological institution in India (Prabhakar \& Kwon, 2006). Similar to Minjung theology, Dalit theology is essential for the transformation of objectified, generalised views of oppressed and poor people into appreciation of their diverse experiences, histories and ambitions (Massey, 2006). Azariah often uses the term 'wounded psyche' in reference to the low self-esteem, hopelessness and lack of motivation in Dalits to fight for freedom from oppression. However he remains optimistic, saying that "The healing of this wound is the process of the liberation of the Dalits" (Azariah, 2000, p. 158). The caste system started approximately 3000 years ago and the Dalit movement is only considered to have started in the 1980s, so the transformation has just begun.

\section{Conclusion}

The caste system and Untouchability as prescribed by Brahminical Hinduism are a dominant cause of inequality and therefore poverty in India. Many Dalits continue to live in extremely substandard conditions. International pressure on India's elite is only a recent phenomenon. However, those most negatively affected by the caste system have tried many ways to break out of this system of oppressive and inhumane subordination. Increased access to education and the leadership of Dr Ambedkar were major breakthroughs in the formation of Dalit movements and progress towards emancipation. Conversions to many other faiths over the centuries have in some circumstances occurred as reaction to the caste system. In this chapter I have focussed on conversions to Christianity. Despite the overflow of casteism into Christianity and the increasing threat of violent abuse by fundamentalist Hindus, Dalit Christians appear to have found yet another way to fight for their basic rights. In the tradition of protestant religion, Dalit theology is a breakaway group from the other, more caste-retentive branches of Christianity in India. This liberation-focussed thought and action is one path providing hope for change in the treatment of all Dalits. 


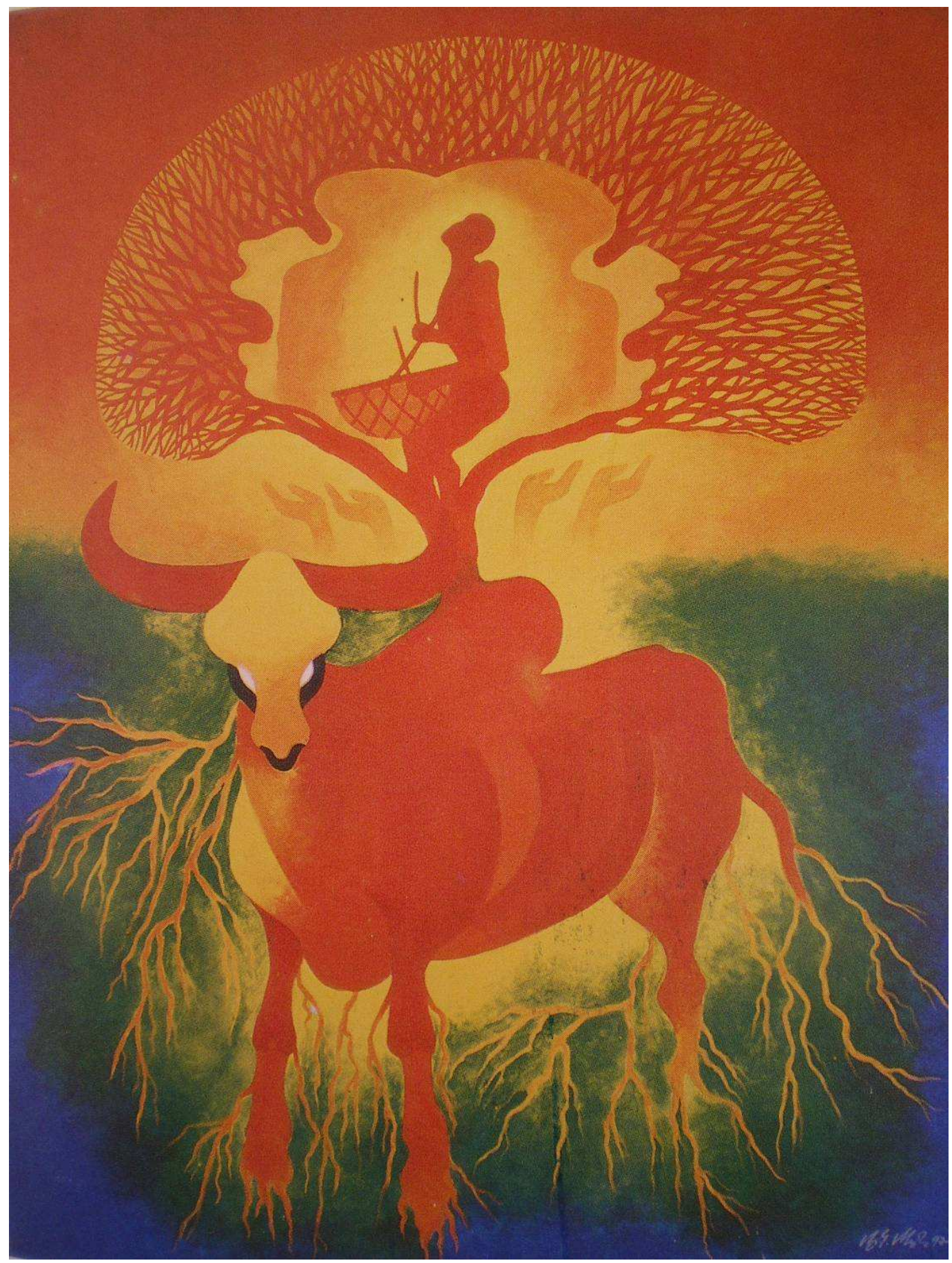

\section{Figure 4: Roots}

(Original work by B. G. Magendran, appearing in Larbeer, P. M. and Alexandar, V. (2000). Permission to reproduce kindly granted by P. M. Larbeer). 


\section{Chapter 4: Folk Music as a Tool for Change}

Which Language should I Speak?

Chewing trotters in the badlands

my grandpa,

the permanent resident of my body,

the household tradition heaped on his back,

hollers at me,

"You whore-son, talk like we do.

Talk, I tell you!"

Picking through the Vedas ${ }^{23}$

his top-knot well-oiled with ghee,

my Brahmin teacher tells me,

"You idiot, use the language correctly!"

Now I ask you,

Which language should I speak?

(Kamble, Eng. trans. from Dangle, 1992, p. 54)

${ }^{23}$ Ancient Indian texts 
If I can't dance, I don't want to be part of your revolution. (Popularised summary of words by Emma Goldman, cited in Shulman, 1991, para. 2)

\section{Introduction}

Music is one of the many tools which may be employed for protest. Various kinds of music have been used around the world to unite people and push for change. Folk music is the most effective type as it comes from and belongs to the people, and specifically addresses the issues at hand. After consideration of the disadvantages for Dalit Christians in using Dalit folk music, I explore the use of folk music for change around the world. The chapter then analyses the place of religion and spirituality, illustrating the issue with a comparison between the African American and Indian situations. An international look at combinations of religion and music finds that the two often come together in situations of protest against oppression. The music illustrates the theology of the times, and thus a look at hymns from over the years provides an insight into the developments and changes which have occurred in various versions of religious thought. Finally, I examine Parattai's folklore in the context of assets-based theory and the changing face of Christianity, with translated lyrics of one of his songs and an emphasis on his clever imagery.

\section{Music as a Tool for Protest}

\section{The American Context}

Where music is used for more than mere entertainment, an important message or emotion may be expressed to the audience. Music becomes a form of communication rather than simply a pleasant means of passing time. These musical styles, such as national anthems and protest songs, are strong and self- disseminating. Much of the music used around the world in protest for liberation and human rights is indigenous folk music. Examples include the musical accompaniment to the martial art/dance form Capoeira which was created by Brazilian slaves, and the music used by black slaves in the U.S.A. Alridge (2005) elaborates on the strong relationship between the hip hop music of today and the Civil Rights Movement (CRM) and Black Freedom Struggle of 
the past. Although the young and the old may both struggle to see their commonality, Alridge (2005) claims that hip hop, especially socially and politically conscious (SPC) hip hop, is a modern form of protest (albeit mass media) against the discrimination which still plagues African Americans. Hip hop began in the mid to late 1970s, as expressions of responses to poverty, drugs, police brutality and other race and class based prejudices (Alridge, 2005). Since then, many technical strategies have been employed by modern rappers such as Public Enemy and dead prez to evoke images or words of famous CRM leaders such as Martin Luther King and Malcolm X (Alridge, 2005). Worgs (2006) finds a transformative effect in the violent literature, music and films by African Americans, interpreting the fantasies of violence as reactions to oppression and injustice. The power of music to transform is also espoused by Frame and Williams (1996), who suggest that the liberating nature of African music renders it a helpful and healthy tool in counselling African American youths. Rap music may be angry and aggressive, but it directly addresses the hypocrisies prevalent in society and the oppression suffered by African Americans (Frame \& Williams, 1996).

\section{The Indian Context}

In India, classical music was used as a great uniting tool to resist the British in the struggle for independence. Indian nationalism was born concurrent with the beginning of involvement and patronage by the middle class in classical music, at the end of the $19^{\text {th }}$ century (Moro, 2004). Hinduised nationalism created much anti-Muslim aggression as well as anti-British sentiment, and its link with the classicisation of music led to a takeover of music by middle class Hindus from Muslim musicians (Moro, 2004). On the other hand, Dalits were more concentrated on their own freedom struggle within Indian society than on freedom from British rule. In Ghose's words, "For Dalits, patriotism for India itself came to be seen as an upper-caste activity" (Ghose, 2003, p. 88). Moro's article detailing the change in classical music from an elitist 'upper' class activity to the realm of the 'middle' class makes no mention of 'lower' caste or Dalit citizens. Dalits in Tamil Nadu were traditionally excluded from religious discourses and therefore from the formulaic structures of classical Tamil poetry (Sivanarayanan, 2004). Modern Dalit poems are poetry of protest in both their words and in form. By employing the folk style 
of poetic form which is indigenous to Dalits and which rejects the classical, Hindu nationalistic style considered superior by elitists, such poetry produces a specifically Dalit identity (Sivanarayanan, 2004).

A subgroup of Dalits who suffered less exclusion from education and religious discourse is those who converted to Christianity. The Tamil Christian population today is approximately three million people (Sherinian, 2002). However, in an attempt to create an independent and indigenised Indian Christianity, Tamil carnatic (classical) music rather than Tamil Dalit folk music was used by both Tamil Christians themselves and the missionaries in the late $19^{\text {th }}$ and early $20^{\text {th }}$ centuries (Sherinian, 1998). Some Dalits were keen to embrace classical music as it was a sign of elevated status and/or because they had been denied access to such a medium within the Brahminical Hindu religion. Furthermore, those occupying the top positions in the Churches have been and continue to be the non-Dalits, despite being a small minority amongst Christians numerically (Azariah, 2000). Approximately 15 million of the 20 million Christians residing in India in 1978 were of Dalit background (Azariah, 2000). A more recent claim by Lobo (2001) estimates that nearly 14 million of the 20 million, or 70 percent, are Dalits. Latest census figures show 24 million Christians in India, which is 2.3 percent of the population (Office of the Registrar General and Census Commissioner, 2007a). The number of Dalit Christians is no longer officially calculated, but according to P. Dayanandan (personal communication, October 15, 2007), the current estimate is between 70 and 80 percent. Suffice to say, many decades have passed with a Christianity comprised predominantly of Dalits utilising a style of music which is unrelated to traditional Dalit music. However, since the earliest signs of a distinct Dalit theology within Indian Christianity, which Azariah (2000) dates to 1978, a small number of voices has been announcing the need for a corresponding Dalit musical repertoire. One such advocate was Parattai, whose commitment to Dalit folk music and other aspects of folk tradition such as drama have been outlined in his book Folklore for Change (Appavoo, 1986), his thesis Communication for Liberation: A Search for an Appropriate Communication Model (Appavoo, 1993), American researcher Dr Zoe Sherinian's thesis The Indigenization of 
Tamil Christian Music: Folk Music as a Liberative Transmission System (Sherinian, 1998), and other publications.

\section{Folk Music for Change}

Folklore is an alternative communication system, which is used by the folk who are refused of [sic] active communication through the approved official communication media (Appavoo, 1986, p. 16).

In the context of this thesis, folk music in the Indian context means the indigenous music of those challenging the status quo, namely, Dalits. One may expect a negative response from some Christians to the notion of using folk music in church services. Dalit and non-Dalit Christians alike may be reluctant to introduce a style of music into their worship which is not only related to the 'bottom rungs' of society (from which some have 'risen up' and would like to forget), but is also somewhat casteist as it is associated with Dalitness. Many Christians in India are Christian because they or family members of previous generations have converted in an attempt to escape the caste system. However, the theology of Christianity differs from its practice. Casteism pervades all churches of India in much the same way that many forms of prejudice are present in today's 'politically correct' world: sometimes overtly but most often insidiously. Whilst it may not be politically correct to voice such prejudice, caste-based discrimination impinges upon the governance and day-to-day functioning of churches from every denominational background (Azariah, 2000; Sebastian, 2003b). Tamil Christians report the influence of caste on elections for bishops, church pastorate committees, the Student Christian Movement, staff and students at theological seminaries or institutions, and even admission into church choirs (Sherinian, 1998). Class intertwines with caste, so some discriminatory decisions depend upon both factors, such as who to eat with, while other decisions depend upon caste more than class, such as who to employ (Sherinian, 1998). Thus, some Dalit and non-Dalit Christians hold discriminatory opinions regarding music and other traditions with Dalit connotations or heritage. 


\section{Positive Responses to Folk Music}

Contrary to the opinions of elitists, folk music is understood by some as an appealing, clever and useful source of knowledge and communication. Arora found that folk music was more popular than film music among neo-literate rural Indian schoolgirls when employed in a karaoke format to reinforce and improve literacy (Arora, 2006). Arora's research took place in Kuppam, a village in Andhra Pradesh state near the border with Tamil Nadu. Folk song karaoke was favoured over film song karaoke by $96 \%$ of girls from government schools and $92 \%$ of girls from private schools (Arora, 2006). Appreciation of folk-style music is also found in Bollywood (Hindi) and Kollywood (Tamil) cinema. Instruments such as the parai drum and driving rhythms (both derived from folk music) are often incorporated into other styles of music to accompany the extensive dance scenes in Indian films. Parattai calls such music 'fakelore' instead of folklore, as it is produced in order to make money (Appavoo, 1993). He would similarly criticise Arora's definition of folk music, as it requires hardware (the karaoke machine), which costs money. Furthermore, fixing a written version of folksongs on a machine directly contradicts Parattai's definition of folklore as humanly transmitted creations which are free to metamorphose as required in new contexts and thus remain relevant and useful (Appavoo, 1986). However, Arora's research confirms the appeal of folk music to rural girls because as the girls reported, the songs are more familiar and easier to sing (Arora, 2006). The use of folk-style music in films also pays tribute (albeit inadvertently) to the strength and popularity of the music created by society's downtrodden.

In addition to their familiarity, folk songs may have been more popular in Arora's study because of the clever metaphors woven in which subtly question and resist power structures and dominant traditions (Arora, 2006). Such veiled messages rely on knowledge held by a specific subgroup, which in this circumstance was the females. Arora illustrates ways in which rural indigenous Indian knowledge has been passed down the generations through songs. Even sexual issues and sexual expression may be metaphorically knitted into the fabric of Indian folk songs and poetry (Arora, 2006). The skill of communication through song is not unique to oppressed groups, but has certainly been fine-tuned by those in situations where other forms of communication have been 
denied. Old African wisdom is transmitted to African Americans through proverbs and folklore (Frame \& Williams, 1996). The metaphors, imagery and symbolism in African American music are explored by Frame and Williams (1996), including those in spirituals, the blues, jazz, soul music, R\&B, rap and hip hop. In modern hip hop music, imagery such as that of the Underground Railway, in rapper Common's Pops' Rap...All My Children, metaphorically links hip hop to the Civil Rights Movement and Black Freedom Struggle (Alridge, 2005). Singers continuously bring new and pressing issues to the attention of the public through the use of clever language. Oliver Mtukudzi and other activist singers are currently doing this in the turmoil and devastation of Zimbabwe under Robert Mugabe.

Folk singers may also act as leaders, gathering oppressed peoples and providing them with hope through the messages and values which they espouse. This is the effect found by Nespor (2003) in research on Czech folk music from the 1960s to the 1980s which criticised the communist regime. In Nigeria, people from the Yoruba cultural area, the most active sector of civil society, used theatre, oratory and folk music to criticise Structural Adjustment Programmes and challenge the military during the authoritarian regime from 1988 to 1999 (Olukotun, 2002). Testimony to the power of poetry, plays and drum beating lay in the strong efforts by their opponents to actively suppress and outlaw these activities. The composition of poems and songs became a life-threatening activity and many anti-military protesters were persecuted, but the effects of their works on the people indicated that the action was not in vain (Olukotun, 2002). Songs were generally "couched in prayer mode" (Olukotun, 2002, p. 199) but carried satirical messages which were not overlooked by those in power.

\section{Religion and Spirituality}

How is spirituality relevant? Spirituality is one part of human knowledge.

Material science has advanced more quickly than spirituality, but we need a balance between material science and spiritual science... all branches of philosophy and knowledge are connected...the body is a spiritual scientist's 
laboratory—and unlike a physicist's laboratory, it costs nothing! (Swami

Sridharanandaji, 2007)

I use the words 'spirituality' and 'religion' somewhat interchangeably. While both terms refer to the existence of beliefs in some kind of superhuman force, the latter pertains more to organised, collective ritual and activity. Two common features stand out within the otherwise heterogeneous spirituality of African Americans. It is historically grounded in the quest for liberation from injustice, and it is inseparable from all other aspects of human experience or life (Frame \& Williams, 1996). African American spirituality includes the Church, formed during slavery, and other indigenous forms such as folk tales and music. Two aspects of African American spirituality mentioned by Frame and Williams also apply to indigenous Dalit spirituality or culture. Firstly, "the whole human, including the body, is employed in the praise of God" (Frame \& Williams, 1996, p. 19). The maximum number of human senses is engaged, and thus music and dance feature highly. Parattai emphasises the importance of using the human senses and the body for actions towards liberation, terming this Humanly Produced and Transmitted Media, or HPTM (Appavoo, 1993).

The second commonality between African American and Dalit spiritualities is that they are often underestimated or undervalued by those of the dominant groups in their respective societies. A large barrier to the respect and positive utilisation of the spirituality of African Americans is the religious persuasions of those (often 'white') people implementing the projects. Some people in this category come from a fundamentalist branch of a religion, usually Christianity, which they consider to be a superior form of spirituality. Some others are atheist or agnostic and have the same issues as the secular counsellors and psychologists described by Frame and Williams. These issues include disinterest, lack of respect, and lack of confidence or ignorance in discussing religious or spiritual matters. Dalit theology and cultural arts such as music are similarly hindered by elitism from some Dalits and non-Dalits, both Christian and otherwise. Rahnema (1992) claims that contemporary grassroots movements are often indifferent to dominant development ideologies because the dominant groups are insensitive to the crucial dimension of spirituality and its effects. It is not only in India 
that grassroots movements have a strong spiritual dimension and attach great importance to inner transformation, self-knowledge, and notions of God(s) (Rahnema, 1992). I am interested in the ways in which religion and spirituality function as assets of the people. Rahnema (1992) suggests that the operational efficacy of some groups is enhanced by spirituality because sharing spiritual ideals can create "new and contagious forms of enthusiasm and solidarity" (p. 171). Such strength is undoubtedly used in destructive ways by some groups, but in positive, peaceful ways by others.

\section{Music and Religion Combined}

\section{A Common Aim of Liberation}

It is common for songs to be sung, chanted or shouted during protests of all kinds, in every country. What is the advantage of using songs, and how does the protest differ when a religious or spiritual element is brought into the equation? Music and religion boast many of the same features; the ability to raise awareness of an issue, create unity within a group of people, communicate feelings, and prompt people into action. Arora (2006) makes the following statement:

...music does not merely reflect the social structure but creates it. Music is therefore a framework of beliefs, expressive symbols and values in terms of which individuals define their world, express their feelings and make their judgment (p. 161).

Arora's report focuses only on music, and yet her words here could easily be a description of religion or spirituality too. Her description does not rule out the possibility of change in beliefs and values over time. According to Morris (2007), "theology is the contemporary re-statement of the Christian faith." Both music and religion are strong contextual determiners of one's epistemology and may encourage unity. Thus, they may be used together as a robust force for change; either good or bad, depending on individual and collective standpoints. Whilst some may use these two global human activities for colonial-style proselytisation, they may also be combined to form a powerful tool for protest against hegemonic powers and social injustice. Examples abound of music and religion combined in struggles for liberation. The radical decision by the Catholic Church in the 1960s to allow local 
languages to replace Latin for masses, which enhanced communication with socially and economically underprivileged people, occurred concurrent to the birth of Liberation Theology (Scruggs, 2005). The description by Scruggs (2005) somewhat portrays local people as objects to be empowered and validated by some beneficent, more powerful group:

These forms offered an important potential to empower the popular classes by validating the worth of their culture (p. 96).

Nonetheless, as people started to campaign for social justice advocacy within the Church, new folk masses appeared in local vernaculars which reflected their ways of thinking, including the still-popular Misa Campesina Nicaraguense (Nicaraguan Peasant Mass) (Scruggs, 2005).

According to Gilbert, African freedom songs originated from a very popular style of music called makwaya (choir), which combines southern African singing traditions with Christian hymnody (Gilbert, 2007). Frame and Williams (1996) illustrate the close relationship between music and spirituality in African American culture, classifying music and dance as collective cultural and spiritual expressions of resistance to exploitation. Such expressions of liberation ideologies and racial solidarity have been in existence since the days of slavery, and continue still. An extensive collection of African American spiritual songs from slave days remain today, including Keep Your Lamps Trimmed and Burning. This still-popular song originally conveyed a message between slaves in the fields, telling each other to keep their lamps lit and stay awake on nights which had been chosen for escape attempts. Of the Nigerian Yoruba songs mentioned above, it was the religious songs, especially those in gospel style, which became very popular during the period of military reign (Olukotun, 2002). These songs served as a legal method of condemning oppressive leaders and were performed in the vernacular, making them harder to police and suppress (Olukotun, 2002). This, in addition to their nonreliance on money, allowed the protest to flourish and expand like the roots of a tree, bypassing the need for power or financial resources to reach the top branches. These features fit perfectly with Parattai's philosophy of liberation tools for Dalits, which should not only be inexpensive, but should also be difficult for those in power to control 
(Appavoo, 1993). Dalits already know their place in the vertical casteist scheme of society, so in order to claim control and challenge the dominance of 'upper' castes, they must focus on non-hierarchical links, or what Gorringe (2005) terms "horizontal mobilisation."

\section{Evolution of Theology Reflected in Songs}

Some branches of theology evolve surprisingly quickly, and these changes are reflected in song lyrics. I compare, for example, the hymns sung in the Church with which I am most familiar; the liberal Presbyterian Church of my home country, Aotearoa New Zealand. Older hymns such as 'Onward Christian Soldiers' (Appendix VI) have long been replaced with those by contemporary, local composers such as Shirley Murray's 'Who is my Mother?' (Appendix VII) and Bill Wallace's 'Hymn for 1990' (Appendix VIII). Murray's 'Through All the World' (Appendix IX) depicts Christ as a leper, a prisoner and a beggar, challenging the traditional church metaphors of lords and kings in much the same way as Parattai does through his positioning of God as a farmer (see discussion of song lyrics in the next section of this chapter). Mitchell (2007) provides a timeline of the changing images of Jesus in western countries, particularly in the liberal branches of the Presbyterian Church, and discusses the implicit theology which each respective image embeds in the human psyche when sung. According to Mitchell (2007), the image has moved from the divine Jesus to the conquering Jesus (as per 'Onward Christian Soldiers' and George W. Bush), to the judging Jesus, the accepting Jesus, and currently the transforming Jesus. Similarly, the religion and music of oppressed groups such as the Dalits provide an update as to where they are in their liberation journey. Given the considerable lack of written texts, musical compositions from Tamil Christians around the turn of the $19^{\text {th }}$ century provide a window to the theologising of Dalit Christians, despite their classical 'upper' caste musical form (Sherinian, 1998). Both the folk style and the lyrics of Parattai's contemporary music indicate the shift made by some Tamil Dalit Christians towards theology which represents their own Dalit identity, culture and traditions. In 2002, Sherinian reports that since 1999, TTS had been reviving neglected village congregations. This involved the use 
of Parattai's folk style worship and Oru Olai instead of the mainstream prayer books, hymnals and orders of service (Sherinian, 2002).

\section{Parattai for Change}

Parattai's assets-based approach is evident in his first norm of Dalit liberation media, "The Dalit liberation media should have only the hardwares [sic] that are inexpensive and easily available to them" (Appavoo, 1993, p. 41), and in his focus on Humanly Produced and Transmitted Media (HPTM). When people value and use their greatest asset, they are practising HPTM. This asset or 'hardware' is the combination of body, mind and spirit, and includes cultural aspects such as dress (Appavoo, 1993). After identifying this asset, Parattai then asserts that folklore, including folk music, is the best option for Dalit liberation. Folklore draws only on this asset possessed by all human beings, and does not require any special skills or expensive hardware, so anyone can participate. A characteristic of folklore espoused by Parattai is that its dissemination should be based on re-creation or (re)adaptation of the lyrics and tune to suit the inevitable changing circumstances of human lives and thereby maintain purpose (Appavoo, 1986). This flexibility allows folk compositions to remain useful. It also ensures participation in performance of the compositions not only contemporarily but also through time. The freedom songs of South Africa based on makwaya are an example of folklore as defined by Parattai, because:

They are created and sung collectively, are frequently modified as politics, attitudes and circumstances change, and are almost exclusively non-commercial (Gilbert, 2007, p. 426).

It is this flexibility that makes folk music such a powerful tool for change, because it evolves with the times and addresses the current struggles. Parattai's music challenges traditional Tamil Christian hymnody in three ways: the message is one of social justice and campaign rather than mere praise, the language used is the spoken (informal) Tamil used by rural people rather than the formal written Tamil, or English, and the music is in folk style rather than that of Western style hymns or indigenised classical music (Sherinian, 2002). The first of these facets may be understood from the English 
translations of Parattai's songs provided by Sherinian, such as Tāyi Tagappanārēe (Sherinian, 2002, p. 847):

\section{Tāyi Tagappanārēe (Oh Mother and Father)}

By James Theophilus Appavoo (Parattai)

\section{Chorus}

Oh Mother and Father who created everything,

Our Sami [God], we will worship you singing songs in Sen (pure) Tamil

We have no money so have not brought candles

Our Unity, Our Unity we offer to you.

\section{Verse 1}

We have forgotten justice and honesty.

We say (believe) that selfishness is Justice.

In the name of caste (jati) and religion

We fight and separate into pieces.

\section{Verse 2}

In January we have sweet pongal [a rice dish made and shared for the Tamil harvest festival of Pongal],

But father you are the life Pongal [the Eucharist] over flowing.

If we are true to that we will find the path to life

\section{Verse 3}

A mistake in tala [rhythmical pattern in classical Indian music] will spoil the song.

A disagreement will spoil our unity,

Salt crystals create thirst.

Your fellowship (relationship) will build our unity. 


\section{Verse 4}

They (Church leaders) make us their flock of sheep,

But then cut us up and make biriyani (a rice and lamb dish)

They fry us like a side dish and recklessly eat us.

$\mathrm{O}$ father, you are the only true shepherd

\section{Verse 5}

You offer only good things and won't let shame come to us.

You lead us near clean water and give us healthy grasses to eat

If bad tigers and wolves come you will attempt to save us

And lead us on the right path.

Although Parattai refers to God as 'father' several times, bi-gendered references, as in the chorus here, are common in Parattai's works. Parattai's version of the Lord's Prayer also calls to "Our Parent" (Sherinian, 1998, p. 834), as per the general international trend within liberal Churches towards inclusive language. Furthermore, many of Parattai's liturgical compositions posit God as a farmer, claiming "You are the one who breaks the gourd, removes the seeds and plants them!"... "You are the one who plows our hearts and removes the weeds"... "You are the farmer who makes it sprout"... "You are the farmer who makes them grow"... "O you who took up the plow and came" (Sherinian, 2002, p. 244). In this situation, the singers are "the over-ripe vegetables," "the land full of nerinji [herbaceous plant] thorns" and "the cotton fields that do not yield" (Sherinian, 2002, p. 244). This imagery creates a hierarchy which still places the singers in the lower position. However, it is a very powerful metaphor because it inverts the hierarchy of Indian society by placing farmers or agricultural labourers who use ploughs at the top, in the position of God, rather than at the bottom (Sherinian, 2002). For the musical scores, original Tamil lyrics and English translations of a collection of Parattai's songs, please see Sherinian's doctoral thesis (Sherinian, 1998). 


\section{Conclusion}

Music is a diverse part of every culture which has been used around the world not only for entertainment, but often specifically for protest. In situations of slavery and discrimination in Brazil and the U.S.A., music emerged as a tool for change. From African Americans to Zimbabweans, Nigerians, Czechoslovakians and Indians, it is the folk or indigenous music of the people which is usually employed for action. Whilst folk music is undervalued by many, it is also a popular and familiar genre for many of India's rural people. Therefore it has been recognised as an asset by a few Dalit Christians, such as Parattai. Spirituality is another facet of human life which is often used in struggles for emancipation, but is typically undervalued by the oppressors. Liberation theology and liberating music have often coincided around the world. The music of a religious group provides one avenue to understanding the group's theology and the extent to which this theology changes over time. I have given an example of the theological evolution of the liberal Presbyterian Churches in Aotearoa New Zealand through the eyes of their hymns. I have then placed Parattai in the context of the rapidly changing South Indian Churches, and explored the flexibility of form and cleverness of lyrics in one of his songs. 


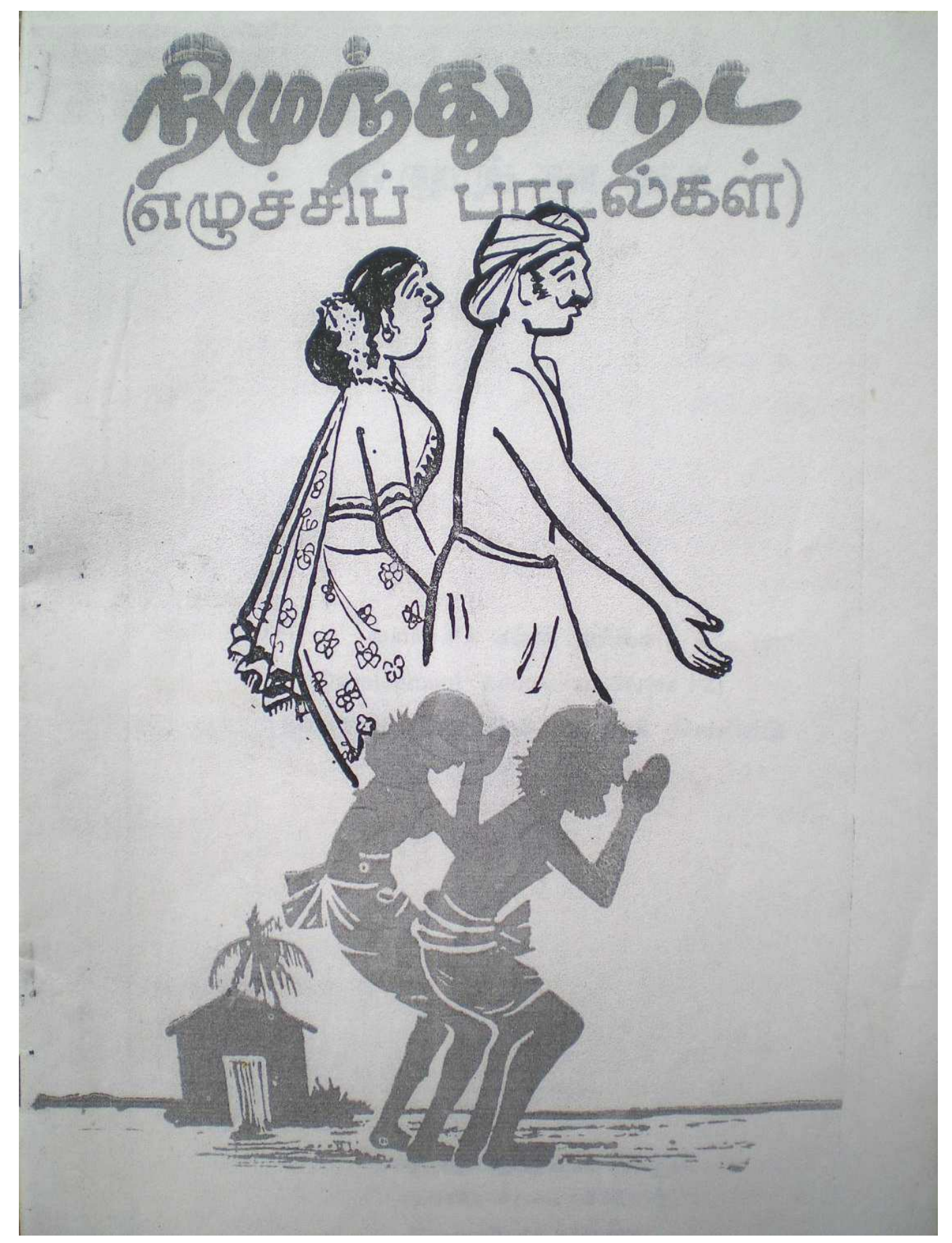

Figure 5: Introduction booklet for Parattai's cassette tape Nimundhu Nada

(Reproduced with kind permission of the illustrator, J. Augustine, TTS, Madurai).

The words appearing above the picture are the title, "Walk Tall," and the subtitle in brackets, "Uplifting Songs." 


\section{Chapter 5: Results}

Virundu Parimāruradu (Meal Serving Song)

Come, everything is ready!

Holy meal, the rare medicine that liberates.

It is not magic or illusion, not the feast given

In remembrance of the dead, or the rituals of "sastirams."

This meal is not redemption that comes through our own efforts

It is not a bribe given to attain the divine grace deceptively.

It is the best medicine, ground that day

In the upper room by the great native doctor,

Jesus the divine one.

It is the medicine "kaayakalpam" that gives everlasting life.

Its diet requires forgetting enmity,

sharing food and eating together.

(Parattai, Eng. trans. from Sherinian, 1998, p. 835) 
People who make music together can not be enemies, at least while the music lasts (Hindemith, cited in Hindemithon, 2007, para. 4).

\section{Introduction}

Parattai was born in 1940 and passed away in November 2005, during a teaching trip in the USA. He had lived almost half of his life on TTS premises as a teacher, after beginning his association there as a student in 1975. From his TTS base, he had many experiences and created songs, liturgies and street plays prolifically. A primary aspect which emerged from my interviews was that "People liked Parattai's music because they liked him" (Julie, March 26, 2007; Bibin, April 8, 2007). Thus, the chapter begins with an analysis of Parattai the person, in order that his compositions are understood as they were described to me: simply an extension of his extraordinary lifestyle. It was not Parattai's music but his messages which were "the main thing," stated Anthony (February 28, 2007). Music was one of the cultural tools or assets of the rural poor which Parattai used for conveying his messages, in addition to language, food and religion. This chapter considers the utilisation of these four interconnected tools in the promotion of equality. Between the sections on food and religion, I discuss the event which combined all these factors in a form of activism, Oru Olai, and its implications for gender and caste equality. I then review the advantages and disadvantages of Christianity as perceived by interview participants, and changes in these areas. The next section on spiritual equality considers the importance of Parattai's interfaith dialogue and action. Such interfaith suggests unity through caste rather than religion, and so I collaborate participants' opinions on the issue of promoting a separate Dalit identity and theology. The last portion of the chapter reports on the sustainability of Parattai's creative works and related action since his retirement from TTS and subsequent death. I provide participants' suggestions for the continued promulgation of Parattai's styles and messages, along with a section on the contributions of TTS. 


\section{Who was Parattai?}

\section{Parattai's Personality}

Although the questions on my interview sheet referred only to Parattai's compositions rather than Parattai himself, every participant began with a description of Parattai as a person. Most gave long lists of his talents, such as "He was a genius: he could sing, compose and direct, and he was a good trainer in drumming, theatre and puppetry" (Joshua, April 2, 2007) and "He was a good Christian, citizen, reader, singer and drummer" (Sudhakar, March 31, 2007). According to Jalastin (April 12, 2007):

Parattai was not a man, he was a culture. Culture means theology, communication, music, folklore and drama. He was a theology professor, writer, actor, poet, musician, chief examiner, HOD of communications at a university, Siddha doctor, very good cook—and a pastor.

Almost all participants proclaimed that Parattai was a good composer of music and plays, and the word "genius" or "born genius" featured several times. He was also described by various people as a messiah, a guru, a feminist, a radical, a very good communicator, a committed social activist, a "gifted one," a great motivator, a man with charisma, and a man with great presence. Perhaps the most suitable of these words is "activist."

Following Parattai's death, Dietrich pronounced him a cultural activist, claiming "Parattai was a cultural revolt as a person" (Dietrich, 2006b, p. 56). Parattai's activism was clearly the reason for participants" choice of adjectives for him such as "sincere," "genuine" and "authentic." Whilst he may have been too radical for some, those who loved Parattai did so very strongly because he "practised what he preached" (Diana, March 23, 2007; Pabitha, April 18, 2007). Preaching entailed the communication of a message, and for this, Parattai used a variety of media. Parattai preached his message of social justice not only in sermons but also through his songs, street theatre plays, classroom lessons, everyday conversations, and events such as Oru Olai.

Despite being unsolicited, the copious descriptions and information about Parattai brought the man alive for me. It enabled me to understand his messages and work as well as the impact he made on the lives of others. Upon hearing so many accounts of his 
talents and personality, I felt an incredible sense of regret at having missed meeting him by only one year. At the same time, I realised that I could get to know the essence of Parattai well through his compositions and the people he influenced. I knew that he had practised what he preached because the same adjectives used by some participants to describe Parattai's songs, plays and liturgies were used again by others when describing his personality. The songs were described as relaxing, fun, beautiful, direct, friendly, humorous, comforting, liberative, mocking (of traditional Christmas carols and of 'upper' caste people), and giving a satisfying feeling of venting anger. They were often about food, always in local slum or village dialects and very easy to both understand and sing. Simplicity was the key, with six participants using the term "simple language."

In congruence with the descriptions of his songs, participants variously described Parattai as an approachable person with whom you always felt comfortable, unlike a normal professor with whom there was usually a sense of hierarchy. You could question anything, he frequently told jokes, was humorous and friendly, and often called out to people to start conversations with them. He was not afraid of anyone, did not care what others thought about him, felt angry at the social and economic set-up of society and often composed when he was angry. He was also a loving family man and someone who understood the problems faced by people in poverty. Four participants said that Parattai lived a simple life and five said that he lived like a village Dalit despite the need to do so as a college professor. Participants reported that he only ever spoke in slum/village Tamil, ate kanjee rice ('poor man's food') every morning, ate meat every day (unlike the vegetarian 'upper' castes), chewed betel nut and drank arrack alcohol (practices looked down upon by many middle and upper class Indians, especially Christians), had a messy house, had an extremely messy appearance with his long un-oiled and unkempt hair (for which he earned the nickname 'Parattai'), and always slept on the floor or outside when staying in villages. Several participants explained that 'Parattai' was a derogatory term given to Dalits with untidy hair. One participant reported that:

My grandfather was a 'Parattai' - he had unkempt hair, so the missionaries cut his hair and made him tidy. Parattai [Appavoo] purposely made his hair like that to bring himself to a level of humility and be with the people who the Christians 
have left behind. People thought that was going backwards. Parattai tried to educate people about that. He was a radical. Not many other people agreed that the parai [a Dalit drum], Dalit language and the name 'Parattai' could be empowering.

\section{Convivial Poverty}

Many participants emphasised that Parattai faced poverty directly, never accumulated anything for himself, was very poor, and never saved money in the bank. He spent all his earnings every month on buying food to cook for others, and he or his wife Dorothy constantly cooked and provided meals for the many visitors who frequented their house. Jalastin (April 12, 2007) recalled that at the time of his death, Parattai had a mere 25 rupees $^{24}$ (less than NZ\$1) to his name. Several people commented that he did not have enough money to fix his own medical problems such as the bad leg which left him unable to walk unaided in the latter part of his life, and his weak heart. He did not take any care of his own appearance or health. Furthermore, he did not make any attempts to get more money. In keeping with his definition of folklore as a non-commercial and adaptable entity (Appavoo, 1986), Parattai purposefully did not assert his copyright for the compositions on his cassette tapes, and even wrote an introduction booklet for the tapes which encouraged people to adapt and change the words and/or tunes as they liked. Many participants in this study proudly related that aspect of Parattai and mentioned his booklet.

Amongst Parattai's radical actions was the adoption of a young adult daughter after she was rejected by her own family for wanting to marry a man of different caste. Girl children in India are seen as a financial burden because the parents must pay a large sum of money to get their daughters married and often pay a hefty sum in the stillprevalent practice of dowry. They then reap no benefits in their old age, as the girl marries into the boy's family and usually looks after his parents rather than hers. Thus, many families are dismayed or even distraught if no male children are produced. This has led to a severe situation of female infanticide and female foetus abortion, largely

\footnotetext{
${ }^{24}$ This sum is reported by Anbuselvam (2006) as 2.5 rupees.
} 
contributing to the situation of the 100 million 'missing women' in South Asia (UNDP, 2005). I saw a large sign inside a hospital near TTS stating in English that doctors in India are legally prohibited from telling expectant parents the sex of a foetus. Despite the fact that Parattai's two natural children were both girls and that he had no bank savings to rely on in his old age once he could no longer work, Parattai adopted another daughter! Many people advised Parattai against this commitment as neither of his natural daughters was yet married at the time. Suffice to say, all three women were duly married, with much help and cooperation from the family's many friends for the wedding day.

Parattai's purpose was to challenge inequality. The two inter-related forms of inequality upon which his opposition focussed were casteism and patriarchy. His messages were thus that "The higher caste people have no right to oppress us" (Pamela, March 29, 2007) and that "If we share our resources, there won't be any poor people" (Rajan, March 30, 2007). With regards to gender-based discrimination, Parattai maintained that "Girl children are equal" (Pamela, March 29, 2007), and "Saris restrict women physically... Women should use their long plaits as whips to change patriarchal values. They should fight patriarchy and not be submissive" (Jasmine, April 16, 2007). Parattai believed that "only cultural elements were powerful enough to bring change in people's attitude," declared one participant. I have identified four main cultural tools which Parattai used in his action towards social transformation: music, language, food and religion. The following subsections discuss these four inter-related facets respectively.

\section{Music}

\section{Carnatic Music}

What does it mean to sing and dance in this oral culture? This particularly useful question was posed to me by a long time foreign resident of Tamil Nadu when I asked about the influence of Parattai's music during a casual conversation. From that day on, I hung most of my thoughts and perceptions on that framework, trying to find what it meant to sing and dance as a Dalit Christian. Dance is highly significant for Hindus, as the very popular god Shiva is also known as Nataraja (literally, king or lord of dance). 
Many young Tamilians learn a South Indian dance called Bharata Natyam, and dancing is considered a way of entertaining both people and gods. Bharata Natyam takes many years of training to master and constitutes a form of worship. Carnatic (classical) Tamil music always accompanies the dancing and many years of practice is required for such musicians to earn respect as a professional. Carnatic music is at least as popular in South India as classical European music is Western countries, with a large proportion of people taking instrumental or singing lessons from childhood. According to James (January 2, 2007), TTS taught carnatic music to students in the mid-1980s because they wanted to reclaim musical forms which they considered to be Tamil in nature. Madurai had always been a centre for Tamil classical music, and politically minded TTS lecturers thought that by avoiding carnatic music or dismissing it as a Hindu practice rather than a Tamil art, Tamil Christians were denying themselves their own culture. Students used to study carnatic music for the entire first year of the BD course at TTS.

\section{Parattai's Role in the Change to Folk Music}

Parattai started his musicianship with training in carnatic singing and music. However, he moved during his life from classical to folk music (James, January 2, 2007). Three participants remarked on Parattai's ability in carnatic, folk and Western music, praising his talents with these multiple styles. Parattai was especially influenced by folk music while living and working at the TTS Rural Theological Institute (RTI), and was encouraged by TTS to write in folk style. In total, Parattai wrote 115 folk songs, 65 Tamil music songs, twelve specifically Dalit liberation songs, one or two English songs and three liturgies (Jalastin, April 12, 2007). ${ }^{25}$ Folk music had been used by Christian villagers during festivals for at least one hundred years, but by the 1980s it was almost extinct (Sherinian, 1998). However, this decade signalled large-scale Dalit activism around India and the beginning of folk music composition at Protestant theological seminaries, especially TTS (Sherinian, 1998). James (January 2, 2007) claimed that Parattai was one of the strong TTS supporters of the name change from 'folk music' to

\footnotetext{
${ }^{25}$ This is recorded in the first issue of the nineteenth volume of the TTS publication Arasaradi Journal of Theological Reflection (Anbuselvam, 2006), which features only articles about Parattai, as a tribute to the man who spent almost thirty years of his life in TTS.
} 
'Dalit music' in the mid-1980s. ${ }^{26}$ Within this context, the first published liberation theology folk song in 1988 and the first liturgy entirely in folk music style in 1994 were both composed by Parattai (Sherinian, 1998).

Implicit in most musical styles is not only the way of singing but also the instruments employed. The parai drum is most synonymous with Dalit (folk) music, due to its origins as an instrument compulsorily played by Dalits as a service to announce the death and perform the funerals of 'upper' caste village members (for a detailed account of this practice, see Clark-Decès, 2006). According to Diana (March 23, 2007), parai is the word used for the term "The Good News" in the Tamil Bible. A parai is made from the material available to Dalits, cow hide, rather than metal. Thus it is cheap, unlike instruments used in carnatic music such as the violin. According to Jalastin (April 12, 2007), Parattai introduced the parai to church worship and told people that they should practise folk worship, especially in South Tamil Nadu. Prasana (April 16, 2007) claimed that the parai was already there, but that Parattai revived all the other, forgotten instruments. He went around the villages enquiring about the local arts, asking people to play and then recording and registering their instruments.

\section{Appreciation for Parattai's Folk Style}

TTS comprises mainly students from either middle class urban Dalits or rural non-Dalits from low income families. Thus, whether from their own Dalit roots or from a rural setting, most students are familiar with the folk style of music employed by Parattai. Many participants related stories of the annual TTS Christmas carol service. During Parattai's many years as a teacher in TTS, he developed a ritual of composing one new song for the carol service every year. This was usually based on TTS's social justicerelated theme for the year (Jasmine, April 16, 2007), and was rather different from traditional Christmas carols. The carol service is attended by many groups from outside the campus such as villagers from around RTI and people from the TTS supported Arulagam women's shelter. Many participants told me that a large contingent would come to the carol service for the sole purpose of hearing Parattai's latest composition.

\footnotetext{
${ }^{26} \mathrm{I}$ have used the term 'Dalit folk music' in this thesis to distinguish it from the folk music of other peoples.
} 
Further indication of the appeal which Parattai's songs still hold for a certain sector of society was provided by one participant who is himself a well respected musician and has recorded many cassette tapes of music for sale. ${ }^{27}$ The musician told me laughingly that whilst he had produced tapes of his own folk songs, regular Christian music, and folk songs composed by Parattai, it is always the last of these three which sells the best. Parattai himself found that his folk tunes sold better than other people's songs sung by him (Sherinian, 1998). Almost every participant commented on the way in which Parattai's songs were loved by the village people because the style of music was their style. It was different from the foreign (mostly German) hymn music usually adopted by the Church, and the 'upper-caste' carnatic musical style with which they were equally unfamiliar. By using a musical style which belonged to the poor, Parattai provided an inclusive form of worship and expression in which any willing person could participate. Fernandez (March 26, 2007) termed this type of music a "participating art" in comparison with passive, carnatic music which he called "performing art."

Many participants said that village people do not know any Western style hymns or raga ${ }^{28}$ for carnatic songs and do not have church choirs like the urban churches. Therefore, folk music is particularly appealing and easy to implement in the village context. Casteism is more rife and yet less conscientised ${ }^{29}$ in villages, so many factors affect congregational response to caste-related musical changes. Those on the TTS campus who had known Parattai and understood him were clearly keen on his ideology and musical persuasion. However, many students expressed doubt about their own ability to translate a musical medium, albeit accepted (to varying extents) on the liberal campus of TTS, to their rural and urban congregations after graduation. Nonetheless, the Parattai style of music found favour with a large number of people in wider society. One elderly female participant in a slum told me that Parattai's music made people dance because it

\footnotetext{
${ }^{27}$ The sale of music on cassette tapes has only recently been overtaken by that of CDs in India, and cassette tapes still comprise a major part of the music market.

${ }^{28}$ Melodic scale

29 'Conscientisation' is a term coined by Paulo Freire, meaning "a process of awareness building, a method of awakening the conscience and the opening up of the innate potentialities [sic] and possibilities in individuals and groups of people. It is a process of true education, i.e. to draw out the potentialities of persons and groups," (Azariah, 2000)
} 
was folk music. As she recalled this, her whole face lit up into a big smile. Another person said that the folk rhythms made everyone feel happy, they clapped their hands and their heads moved. Yet another said that women danced when he sang one of Parattai's songs as a demonstration during a speech, and they petitioned him to come back. One participant reported that the folk rhythms were so good that she had seen a group of slum women who had professed a dislike of Parattai's songs watching one of his performances, feet tapping unconsciously in time to the beat.

\section{Resistance to Folk Music in the Church}

Resistance to folk music came from both Dalit and non-Dalit sectors of society. Two participants told me that some Dalits do not want to use music of Dalit heritage because they relate to it as a sign of oppression from the days when they were forced to perform at 'upper' caste villagers' funerals. Clark-Decès (2006) illustrates the recency of Dalits' liberation from this duty, finding that the well maintained tradition was only broken in the Viluppuram district of Tamil Nadu between 1990 and 1999. In 1999, they were "in the midst of freeing themselves from the stigmas of untouchability" (ClarkDecès, 2006, p. 265), no longer playing the drums or digging the graves. They now identified as 'Dalits' and rejected classification as 'Untouchables' or by jati names. One participant in my study said that there was even some protest against parai at Parattai's own funeral. Nonetheless, parai were played proudly on that occasion and many participants remarked that Parattai's folk music-filled funeral was a fitting portrayal of the man and his achievements.

In addition to individual Dalits' reservations over using a symbol of oppression as a tool for liberation, some urban congregations do not consider folk music appropriate for the Church. Certain people claim that the parai should be used exclusively for funerals, and that they only like organ music in church. Others consider church a place to simply praise and petition God rather than to seek change directly:

Some congregations don't want politics. They don't want change. They think you should pray for change, but not act upon it. So, these people want only the old 
hymns, ones which are not radical and not personal (Anthony, February 28, 2007).

On the other hand, sometimes congregations in cities such as Chennai and Vellore are more receptive to folk music. This style only became popular fifteen to twenty years ago, but urbanites are more accepting because they tend to have a higher level of political consciousness and have been exposed to the use of folk music in the secular world such as mainstream films (Johnson, April 6, 2007). The urban/rural divide is clearly pertinent to the use and efficacy of Dalit folk music in churches.

\section{Language}

\section{Vernacular Tamil}

Three main linguistic features of Parattai's creative works were attributed by participants to their popularity: the use of the vernacular, the topics and messages in the lyrics, and the linguistic techniques applied to the words. The majority of participants remarked that Parattai composed in slum Tamil, village Tamil, or "simple language." This meant that the songs could be introduced by pastors to villagers because they were relevant, easy to understand, easy to sing, quickly relayed their messages, and created interest. The use of such dialects broke down not only verbal but also written language barriers. Villagers who are illiterate or semi-literate have no access to the Tamil Bible because it is written in 'high' or 'pure' Tamil. Therefore, Parattai's songs provided a welcome change from the exclusive forms of Christianity maintained by other pastors and educated lay people. The less formal Tamil also made the music fun, relaxing, catchy and direct, addressing God in commanding ways such as "Hey God, come. You come here, man!" (Prasana, April 16, 2007). People felt that more emotion was able to be expressed through the use of this casual language, and thus feelings of anger and frustration could be vented. Parattai's music was described by some as comforting, and yet it also "went beyond sympathising" (Johnson, April 6, 2007). The use of the vernacular allows the easy provision to village Dalits of information such as the various benefits available to them (but not advertised) through the government. Compared with 
any bandh, ${ }^{30}$ protest or march, songs impart a message quickly and cheaply. "The information reaches the people quickly and then they act" (Sudhakar, March 31, 2007). For example:

After the songs and dramas reached the villages and towns, people realised that they were being oppressed by Hindutva and formed groups-mainly the Chennai and Cuddalore youths. They organised or joined protests and street walks using Parattai's songs. They started to question things, realise they'd been cheated. They had heard this before from other leaders, but not in their own language (Sudhakar, March 31, 2007).

When I enquired as to the results of these protests, the participant replied that they had pushed the government into action, providing some response and making certain oppressors afraid to continue oppressing people.

\section{Parattai's Messages}

The lyrics of Parattai's songs, street plays and liturgies provided cause for consternation by some who were less liberally minded than him. Participants mentioned that Parattai's lyrics addressed caste, attacked and boldly criticised Hindutva, and directly challenged the treatment of women by men. Bibin (April 8, 2007) stated that Parattai became more direct in his criticisms after moving into TTS, and Matthew (December 13, 2007) claimed that Parattai criticised Hindutva more boldly than anyone else ever in TTS has. This challenge of the status quo encouraged people to question their own circumstances and political issues. It also conveyed messages regarding social issues to the outside world where development organisations existed. These messages were otherwise hidden by Brahmins and without surfacing, no organisation would come searching for them (Sudhakar, March 31, 2007). Hearing Parattai's songs gave people a sense that "someone is listening to me, to my problems, because they're singing about women or caste or the environment" (Wilfred, January 12, 2007). The mere act of voicing the various social issues was empowering in itself, and because it was empowering, people liked it (Sundar, April 5, 2007; Pabitha, April 18, 2007). Parattai was always ahead of his time, proclaiming messages through his songs and plays

${ }^{30}$ Boycott/strike 
regarding topics such as globalisation. According to Prasana (April 16, 2007), India only started to get widely caught up in globalisation around 1998-2000, and yet Parattai's works had addressed and foretold the effects of this process as far back as 1985. For this, he was dubbed "a messiah."

Parattai combined the revelation of hidden stories and acknowledgement of oppression with messages of encouragement to the oppressed. The title of his 1985 cassette tape recording, 'Nimundhu Nada,' summarises his theme. Nimundhu Nada means 'walk straight' or 'walk tall' in English. The picture on the front of the accompanying introduction booklet (see Figure 6) leaves no doubt as to its meaning: the black and white image of a couple walking with straight backs is superimposed on a grey image of a couple bent over in submissive bows with hands pressed together in worshipful gestures of greeting. The woman in black and white woman wears a full, printed sari with blouse-piece and flowers in her hair, and the man wears a towel on his head. The woman in grey wears a cloth that does not fully cover her legs or upper body and the man wears his towel around his waist. Dalit women were "traditionally" (Rajawat, 2004a, p. 126) not allowed to cover the upper half of their bodies, and Dalit men were required by 'upper' caste villagers to tie their towels on the waist. Many participants mentioned the words 'Nimundhu Nada' during interviews, and their correlating effects. One said that it makes people feel like they are "somebodies rather than nobodies." Another said that it reduces fear and that he is no longer afraid of 'upper' caste villagers. This man declared that even when he is oppressed these days, he is not scared because he has a formal education. Parattai had taught him the importance of education. Many said that the messages in the songs and the command to walk tall produce a deep feeling of liberation, which then leads to a desire to help others liberate themselves too.

\section{Linguistic Techniques: Humour and Metaphor}

Parattai's lyrics were bold, humorous and sometimes subtly crass. One participant recalled the way in which people would get carried away by a catchy song and only later realise the subversive meaning of its lyrics. In one song about Gabriel the angel, Parattai repetitively used the word Annathe, which is actually a "vulgar" term used in reference to 
transsexuals. Parattai's intention was to provoke thought about society's male-female divide and what he considered the ridiculous debate in the Church regarding the gender of angels. However, Annathe is such a rarely used word that many singers were oblivious to its meaning. In fact, Hepsiba (April 10, 2007) claimed that it is such a rough word that people no longer sang the song after word spread about the otherwise happy, jolly sounding tune. The caste-based vegetarian/non-vegetarian divide in India was also ridiculed by the omnivorous Parattai, with the claim that "whatever you eat, it all comes out as shit anyway" (Joshua, April 2, 2007). Another commonly quoted song was one in which Parattai claimed that the reason why Dalits do not come from the head, shoulders, thighs or feet of Purusha, ${ }^{31}$ is that they come from the womb of a woman instead. Through the use of humour, singers felt empowered because they could ridicule and laugh off their oppressors. Parattai's courage in speaking out through his songs about caste oppression was considered by some as heroic and revolutionary but by others as dangerous or unnecessary. The real attraction of Parattai's songs, for Dalits at least, was that they "show the essence of Dalits" (Pamela, March 29, 2007; Matthew, December 13, 2007), and that he "revealed the greatness of Dalits through songs" (Matthew, December $13,2007)$.

Parattai also used humour when his street theatre style plays were performed. He wrote over one hundred plays and never repeated any, except for occasional adaptations performed to different audiences. Thus he kept the messages fresh and flowing. Parattai talked during his own plays, asking questions, getting answers and cracking jokes. This prevented passivity in the audience, keeping them alert and making sure that the message was being conveyed. He also interacted with the audience during plays written by other people when he moderated the annual Dalit Arts Festival held at TTS. No one minded when he interrupted. In fact, they grew to anticipate his comments and jokes (Prasana, April 16, 2007). One participant claimed that Parattai's strongest effect was through his plays rather than his songs. Parattai claimed that he would have been a film director if he had not become a pastor, as film is such a powerful medium of communication (Jalastin, April 12, 2007).

\footnotetext{
${ }^{31}$ As do people of the four respective varnas, according to the Manu Dharma
} 
As with the language and the messages, the rich imagery in Parattai's liturgies and songs is directly relevant to the lives of most rural Dalits. The use of familiar village objects as metaphors differentiated his liturgies from those of others. Parattai often referred to ploughs, fields, trees, birds, rivers and streams, which are all familiar objects that villagers can relate to, said Prasana (April 16, 2007). Many songs were about local food, claimed another participant, and therefore communicable to anyone in the region. Parattai used powerful lyrics to portray God as a farmer, and therefore farmers as creations of God (Sherinian, 2002). Farmers are the people who fulfil our most basic need by producing food, and therefore give life to all human beings. However in India, most farmers are very poor and obviously live in rural areas, so they are generally looked down upon by the city dwellers and the wealthy. As there is not such snobbery towards agricultural workers or extreme income disparity between rural and urban workers in my home country, I did not immediately realise the significance of Parattai's depiction of God as a farmer. It was only after living in India for some time that it occurred to me how radical such lyrics were, and thus their potential effects.

\section{Food}

Diary, December 20, 2006:

I got to visit Parattai's wife Dorothy today!! The difference of Parattai's house was immediate as soon as I sat down. Instead of just bringing me a cup of milky tea, she first asked me whether I'd like tea or coffee - and then whether I wanted it with or without milk!!! Of course I've been doing as the Romans do during my time in 'Rome,' but it was such a (welcome) shock coz I've been overwhelmed by hospitality and drunk a million cups of tea since I got here, but she's the first person to have asked me how I'd like it. I guess she just asked me that because I'm a Westerner, but actually it seems that in India people usually only drink black coffee or tea if they literally can't afford the milk. Typically, Parattai used to drink black 'poor-man's' coffee. I don't have any trouble emulating that! 
The most commonly uttered words relating to Parattai were that he was always feeding everyone. I was told over and over again that his house was open 24 hours a day for anyone to call in to and have a meal. This was described by participants as a major facet of Dalit culture. In his typical manner of proudly claiming Dalit traditions, Parattai would cook and eat beef (a 'lowly' food shunned by most non-Dalits and even some Dalits in India) every day. As Parattai lived for a long time as a staff member on the TTS campus, many of his guests were students of the seminary. Students are provided with three meals per day at the mess hall, but they preferred to eat at Parattai's where they could also be mentally stimulated and challenged by his conversation. They were also no doubt learning an important lesson in how to practise what one preaches. Parattai was inspired by Bible stories such as the Feeding of the Five Thousand, but he actually followed through with the sustained action of accepting and feeding everyone rather than simply thinking that it was a good idea and telling others to do so.

Outside his own house, Parattai also tried to spread the message of food equality during Holy Communion. He composed liturgies in which the traditional bread and wine or grape juice were exchanged for local food and drink in order to celebrate Tamil or Dalit traditions. He wished to validate the food ordinarily eaten by rural poor and show that it could be holy in the same way as any other food. This is particularly pertinent in a country where food or drink touched by a Dalit is still often considered irrevocably dirty and inedible. Participants told me of communions with kanjee rice, coconut meat, sweet ragi chapatti (millet bread), and coconut juice. In the same way that certain people despised Parattai's musical style, some also resisted change to the elements of Holy Communion. These more conservative Christians (usually urbanites who contributed a lot of money to the Church) considered Parattai's actions to be sacrilege, said Anthony (February 28, 2007). They valued foreign traditions based on the Bible story of the Last Supper over the idea of making Communion culturally relevant or appropriate, claimed another participant.

Parattai understood the power of food to both divide and unite. Examples abound of the societal divisions which are maintained when differences in food exist. These 
include the elitist attitude of 'upper' caste vegetarian Indians towards omnivorous Indians, and the variations in food consumption within every society due to income disparity. Parattai neatly illustrated the latter of these in the introduction to his book Folklore for Change: "A rich man in India spends Rs. 300 for his lunch in a five star Hotel. Whereas a poor Indian spends the same amount for two months, eating as little as possible to keep his life going on" (Appavoo, 1986, p. 2). However, along with this age-old world of inequality, there is an equally old ideology which suggests that by eating with someone, we break down hierarchy and discrimination. Thus, food has great potential as a tool for social change. From the development of the Round Table to the controversy caused by Jesus Christ when he ate with women and tax collectors, there are many stories which highlight the way in which the sharing of a meal by dominant and dominated groups reduces the hierarchy between them. By encouraging people to sit together and eat the same food, the power disparity can be reduced between a teacher and a student, a female and a male, a Dalit and a non-Dalit, a black person and a white person, and so on. Parattai took this one step further and said that people should not only eat but also cook food together. This was one way in which he attacked the gender stereotypes that force women to constantly provide meals for their husbands and children.

\section{Oru Olai: Music, Dancing, Food and Feminism}

Praise God with trumpets.

Praise him with harps and lyres.

Praise him with drums and dancing.

Praise him with harps and flutes.

-Psalm 150

A combined challenge to casteism and patriarchy was issued by Parattai when he started a monthly event at TTS called Oru Olai. The meaning of these Tamil words is 'One Pot.' This refers to a system whereby everyone contributes ingredients which are brewed together in a common pot that is attended to by all. The end product is then shared and eaten by everyone. The food cooked for Oru Olai at TTS is kanjee, a rice porridge considered to be 'poor-man's food.' It is made simply from boiling rice, dhal and water together. All members of TTS are divided into fellowship groups of approximately ten 
students and one faculty member, so each fellowship group boils their own kanjee in a clay pot and then all the contents are poured into a large common serving pot. The salt which provides flavour is added once all the kanjees are combined, as a symbol of unity. Everyone on campus then lines up to get a serving of this rather plain, basic kanjee and usually a spoonful of coconut chutney as a side dish. The meal is symbolic in several pertinent ways. It is a very plain South Indian dish as it contains no vegetables, so it reminds everyone of the restricted diet on which many poor are forced to survive. It is also a message to men that they should be participating in food preparation. I do not know how many of the male TTS members carry this practice back to their own homes. However, several participants claimed that Oru Olai was more popular with women as it allowed them a break from cooking at least one night every month. The ritual is also a direct protest against separation of people on caste or any other bases, and promotes unity through the basic processes of cooking and eating. Parattai was motivated to institute the Oru Olai custom at TTS after seeing the system at work in a village (Bibin, April 8, 2007).

I was unfortunately only able to attend one Oru Olai during my five months in Madurai, but that one experience left a lasting impression on me (see Appendix X for photographs of this event). On the way to the area where we were to cook the kanjee, I realised that I had forgotten my plate. One of the fourth year students offered to share his plate with me. I was pleased by this gesture, thinking that it was really in the spirit of Parattai to even share one's plate. However after we had eaten the kanjee and chutney, the student announced that he was going to go out for a real meal as the kanjee was too bland and he was not full. I was disappointed to find that the meaning of the evening had been lost on him. Perhaps the novelty of the idea had simply worn off because he had performed Oru Olai approximately forty times over his four years at TTS.

Oru Olai does not only incorporate the preparation of a meal. It begins with a procession by the students around the TTS campus, dancing and singing out to all the residents living on campus (garden workers, kitchen workers, teachers, gate watchmen, and the families of all these people) to come and join in the eating of the kanjee. The 
dance and song is very much village or Dalit folk style and is thus boisterous and lively rather than sedate. Parai are beaten with a deafening sound, voices sing loudly, people clap, and some members dance. I felt shy to dance at the start because I was completely unfamiliar with the style, but I was nonetheless unable to walk normally due to the rhythm of the drums forcing my feet to skip in time. The music was so intense that even a self-conscious dancer like me was literally moved to join in. However I realised that no other females were dancing, and not wanting to stand out as both a foreigner and a female, I tried to encourage other girls to move with me. I tried to coax the female staff, students and daughters of staff members, but not one would budge. I was aware that Tamil girls and women are generally loathe to draw attention to their bodies in public. However, I was also unable to believe that feminist Parattai would have accepted such a gender imbalance. Moreover, the music was driving me to move and I could not understand how other females could simply stand still and walk normally under such a demanding drum beat. This apparent contradiction between Parattai's focus on gender equality and the gender-biased behaviour I saw during Oru Olai became an issue which I discussed with each participant in my interviews. I wanted to know why it was that I had seen women dance both Bharata Natyam and traditional Dalit dances in guest performances on TTS soil, and yet the residents themselves would not dance for Oru Olai. I was also curious as to whether or not this was a trend which had developed since Parattai had stopped directing the event.

\section{Gender Justice: Easier Said than Done}

To the question of whether women used to dance in Oru Olai, I received the widest variety of answers. One participant said that he could not remember, some said that Parattai did not invite women to dance, and others claimed that he encouraged women to dance but they would not. Hepsiba (April 10, 2007) said that Parattai never actively invited women to come forward, but he did not criticise them if they did so. Another said that Parattai did encourage women to dance and they used to do so, but not anymore. Diana (March 23, 2007) believed that first year female students would dance if someone motivated them, but there is no one to do so now: "When Parattai was here, he would speak to you and you felt transformed and would go and dance." Moses (March 28, 
2007) claimed that only the most radical female students ever danced. Some women said that Parattai's eldest daughter used to dance and then other women would follow her. TTS women also joined in when "foreign women" were present, such as those from the annual group of visiting international Training in Mission (TIM) students.

Many participants explained to me that women are reluctant to dance because they are shy, or because they think their saris will come undone and expose their bodies. For specific dance styles such as Bharata Natyam, there are costumes which properly cover the body and allow free movement. There was a significant amount of regret from both men and women regarding the gender disparity in Oru Olai. People told me that women always join in the dancing in other states such as Rajasthan, Gujarat and the Punjab, and that "women dance in North India but not in the South. It makes me sad" (Joshua, April 2, 2007). One woman said that "Just because women don't dance, it doesn't mean that they don't want to dance or aren't given opportunities." Another said that she wanted to dance but did not know how. A further comment was that women dance only if they have talent, not for fun. Significantly, one female participant said that women would join in if it was proper traditional village-style dancing, as they do for the TTS Christmas carol service and the Dalit Arts Festival. However, she felt that Oru Olai dancing had become somewhat 'film-style' nowadays, and women did not want to portray themselves in such a raunchy way. Perhaps this was what one Sudhakar (March $31,2007)$ was referring to when he told me that women do not participate in unfixed dances where one "just moves in time to music vehemently." Most women explained the shyness of females as a cultural phenomenon, and yet many men defiantly declared that such gender inequality was the culture of patriarchy rather than the culture of Tamil Nadu. Three people mentioned that women always participate in rural kummi dances in Tamil villages. One male participant told me that Dalit culture is against patriarchy and that women themselves sometimes maintain patriarchy on campus. There is less patriarchy in the villages, he said, and the action is more collective there. However, the middle class female TTS students believe that dancing or even talking with males is "dirty" (Jalastin, April 12, 2007). 
On the other hand, a female participant pointed out that only a very small percentage of the TTS student body is female, and everything at the seminary is set up for men because until recently, that was all that was required. There are still dioceses in other states of India which do not ordain females. Women must be conscientised ${ }^{32}$ on every level regarding dress and bodies, she told me. This included making the difficult distinction between inclusion based on acceptance as an equal participant versus inclusion as a mere sex object. The gender-divided seating in the TTS chapel prompted interesting discussions. Whilst I saw first hand that the segregation was common practice in CSI, Roman Catholic, Pentecostal, rural, urban, large and small churches in Tamil Nadu, I had been surprised upon finding it even at TTS. Men were on the left and women on the right. A few male students or staff sometimes sat behind the females on the right, but I only saw one senior female student ever venture over to the left. Sherinian (1998) mentions that Parattai broke this seating arrangement in his services by encouraging everyone to sit in a mixed circle. A further surprise was the male students sitting on the opposite side of the chapel from the female students, wearing T-shirts with TTS's 2006 slogan "Gender Justice towards Equality" printed on them! I noted further that those very T-shirts were only able to be worn by the males, as the TTS girls all wore churidaas and saris instead of Western style clothes. I discussed this with staff and students, along with my reaction to the seating division. However, my thoughts on this seating formation were completely changed when one participant explained her feelings on the topic. She pointed out that in the absence of a gender divide, the default seating arrangement is to sit in families. However, she relished the opportunity to sit with all the other women instead of her own husband and children during chapel services:

In the chapel, it is nice to sit not in families, because I'm not then identified as so-and-so's wife or so-and-so's mother. It also means that the unmarried women are not sitting alone. It allows space for women's solidarity and gives me a sense of freedom, so I much prefer it (Rosy, January 4, 2007).

One participant considered Parattai "a peculiar feminist" because, she claimed, women were always pampering him. Nonetheless, his actions towards gender equality

\footnotetext{
${ }^{32}$ See footnote 29 , page 97 , for explanation of 'conscientisation'
} 
were unusually progressive, especially for a man. The idea of Oru Olai to share the work of cooking between men and women was revolutionary within his context. Furthermore, participants reported that he had a penchant for giving female TTS residents gifts of kitchen knives upon his return from the various places to which he travelled. Whilst a knife's pragmatic use as a cooking tool may appear to maintain the place of women in the kitchen, Parattai liked to explain its potential for women's empowerment. Parattai claimed that a kitchen knife could be legitimately owned by a woman and kept in the house, and yet also functioned as a weapon for self defence as required. He told the women to be like knives themselves and make men afraid of them (Hepsiba, April 10, 2007). Furthermore, he followed through the feminist messages in his songs by mixing up the female and male students in his classroom, telling the women to come away from the corners and contribute their opinions. Diana (March 23, 2007) said that Parattai's feminism could most clearly be seen in the raising of his daughters, to whom he gave "full liberation."

\section{Christianity: Education and...Casteism}

Diary, January 16, 2007:

Spent all day celebrating the big Pongal harvest festival in several villages. All the cows were being painted with bright spots of colour over their bodies, and the cows belonging to Christian families had great big crosses painted on their foreheads. Even the cows belong to religions in this country...!

In order to understand how Parattai used religion as a tool to convey his messages and why he stayed within a Christian framework at all, we must first consider the feelings about Christianity of the people whom he influenced. Many participants reported liberation or liberating feelings through being Christian. This was mainly attributed to the messages in the Bible and the education which was made available to them or their families at the schools established by foreign missionaries in recent centuries. Many rued the changes which had taken place since missionary times, claiming that Christianity was not so useful or 'real' these days. However, the main problem in the Church which was acknowledged by many Christian participants is the practice of casteism. The supposed castelessness of Christianity has been the motivation for millions of conversions by Dalits 
over time. Nonetheless, casteism is rampant in churches, but in a diluted form of that found within Hinduism. Christians I interviewed seemed hopeful that the Church will eventually eradicate casteism, and from there attempt to change the rest of society. Parattai's eyes were open to this potential too, and thus he focussed on not only oppressed rural Dalits, but also pastors in training.

\section{Perceived Advantages of Christianity for Dalits}

Many Christians I interviewed felt that they had benefited in a variety of ways from their religion. Diana (March 23, 2007) said that Christianity provided a new identity alternative to that as an 'Untouchable.' Christianity provided schools which helped Dalits get an education, increased self-understanding and led to empowerment. Others said that "When Hindus become Christians, they naturally get the liberative concepts" (Julie, March 26, 2007) and that "Development comes from the basic ideas of egalitarianism and equality found in Christianity" (Joy, March 29, 2007). I must stress here that three participants specifically stated that Dalits are not Hindus, as Dalits' own indigenous Dravidian religion is separate and different from the Brahminical wing of Hinduism. Thus, the issue for Dalits is not necessarily one of identifying either as Hindu or Christian. However, many village Dalits identify as Hindus for various reasons (self-imposed and otherwise), and many of the comparisons made during interviews and in general conversation referred to Hindu Dalits versus Christian Dalits. The theme of educational benefits was common, as in these two examples from female participants:

I'm not hating Hindus. My parents are Christians, that's why I am. My grandparents were Roman Catholic but became Protestant. My father and I were educated in Protestant schools. Definitely, I could not have this much education or opportunities if I was a Hindu. Father studied to be a teacher because he was Christian. Missionaries put him in teacher training school. I also was put into hostels from my $6^{\text {th }}$ standard through to college. I liked it (Hajira, April 12, 2007).

The advantages of being a Dalit Christian-you know, a lot of things—you can study a lot of things, read a lot, my husband did his $\mathrm{PhD}$. He couldn't have done that if he was a Hindu Dalit. You can get education and knowledge and can go 
and liberate others-poor Dalits. So it's useful to become a Christian. Hindu Dalits have no awareness. My children know their caste but they're proud of itthey have come out of the system (Rosy, January 4, 2007).

Despite my observation that women and men sat segregated in every church and chapel I visited, one participant claimed that Christian churches brought people together and were less segregated than Hindu temples. Furthermore, the associated Christian scriptures advocate this anti-hierarchical ideology. "Certain [Bible] verses say that you aren't worshipping God if you're discriminating against me," and "God claims the suffering as his people," stated two participants. "Christians know that God is interested in them and they are a part and parcel of Creation," said another. Reasons given for people coming to Christianity were that they felt it was liberating, and believed that change would take place. Deepa (December 13, 2007) claimed that:

You get more out of Christianity because you see people suffering for the sake of the poor and attempting to eradicate poverty. Jesus Christ is a good role model for that. Pastors are always helping people.

"Why else would people have converted by the tens of thousands?" asked Johnson (April 6, 2007), continuing with this statement:

It was an active decision by Dalits because what the missionaries told them was good and genuine, and they could see their own children reading thanks to the schools. Hindus also think that what Jesus Christ and the missionaries did was good with their building of schools. Some Hindus go through the Christian schools. That's why Hindus respect Christians more than Christians respect Hindus. The cross is very highly respected by Hindus and even seen as a sign of protection when worn around a girl's neck.

This was the only statement uttered by any of my predominantly Christian interviewees which specified a positive view of Christians by Hindus. It is interesting to compare this to a comment in an 1896 missionary's report that "Though his own sons may study in the Mission High School, the Hindu land-owner will do his worst to prevent his Pariah [Dalit] serfs from getting to the spring of knowledge" (Clarke, 2003, p. 343). 
Johnson's opinion regarding the genuine appeal of Christianity was shared by another participant:

The advantage of Christianity over Hinduism is that it unites and shares. The missionaries shared their own God, the same God with Dalits. There were no separate deities for Dalits to worship. The common god came in addition to education, health and social uplifting. If it were fake or people were only converting to get rice, it wouldn't have worked so well. However, it's different these days with the Indian bishops as they are and the singing, swaying, Hallelujah-shouting American-funded current day evangelicals. All the schools for Dalits set up by the missionaries have been overtaken. We should go back to the missionary times for real theology. ${ }^{33}$

\section{Perceived Disadvantages of Christianity for Dalits}

Jesus came proclaiming the kingdom of God and what we got was the Church (Geering, 2007).

Many participants spoke of the foreign missionary times, claiming that it was good to be a Christian in the past but that there are not so many benefits these days. This was mainly because the old advantage of access to education was now either irrelevant or compromised by their religion. Being Christian is of no particular advantage anymore, claimed Joy (March 29, 2007), because the number of government schools has increased since Independence, so Christian schools are no longer the sole option available to Dalits for education. In the past, Christians had more access to money from the Western countries, but despite the sharp decline in these financial resources, the government has not adjusted its policies accordingly, said Pamela (March 29, 2007). "This sometimes leads to re-conversion by the very poor, in order to meet their basic needs such as food" she added. If Dalits become Christians, they lose special access to food rations and houses, according to Hajira (April 12, 2007). At the time of interviewing, the quota of reserved seats in universities and government jobs was smaller for Dalits identifying as Christian (or Muslim) than those identifying as Hindu. "That's the cost of being a

\footnotetext{
${ }^{33}$ The missionaries to whom this participant refers are the Western missionaries of the $19^{\text {th }}$ and $20^{\text {th }}$ centuries, rather than current day Indian missionaries.
} 
Christian," one participant observed. Later in 2007, the state government of Tamil Nadu improved the situation, stipulating that $3.5 \%$ of the quota must be filled by Christian Dalits, and 3.5\% by Muslim Dalits. Other states have yet to follow suit. This policy change was described by Tamil Nadu Chief Minister, M. Karunanidhi, as a "gift" (cited in TN juggles quota, 2007, para. 9). However, the Indian student loan scheme still does not extend to qualifications undertaken at theological seminaries.

The Churches have more responsibility nowadays because people convert and then get problems but their panchayat (local council) tells them to get money from the Church instead of helping them, claimed Pabitha (April 18, 2007). There is another disadvantage of being associated with the West: "When a Hindu converts to Christianity, they benefit a lot, but they also suffer because Christianity is a foreign religion," said Julie (March 26, 2007). "You' re not covered by the Atrocities Act if you're a Christian, but even so Dalits are still converting to Christianity!" exclaimed Joshua (April 2, 2007). One Chennai resident claimed that:

The only benefit for people in being a Christian is knowing the Lord; being proud and happy about knowing the Lord Jesus as their liberator. There are meagre benefits related to the Church, for example, you can put your son in a boarding school, get positions at nursing homes, etc. Even then, only rich, urban, Dalit Christians can get this access to education. There's more discrimination in the villages than in cities. Even though I've got a Masters degree, I still can't walk with shoes on through the streets of the village where I grew up. They won't beat me anymore but they do ridicule me and call me arrogant. So I walk through the fields to get there instead. I'm not ashamed by those experiences anymore, but I am wounded. It hurts.

"The Churches say that everyone is equal but they are practising casteism too," stated Matthew (December 13, 2007). Many participants claimed that there was casteism in the Church, in addition to a lack of unity between dioceses and denominations. Dalits are sometimes denied positions in the Churches. This is very different from the Christianity which the missionaries brought, noted one participant. 
However, another participant claimed that some groups of Catholic missionaries maintained caste, citing the Catholic cemeteries in Tuttikorin which have twelve segregated, caste-based entrances. You only have to look at the newspapers claimed another, where you find men searching for a "Nadar ${ }^{34}$ Christian wife." The casteism problem was not between Brahmins and Dalits, but between Sudras and Dalits, said one participant. I certainly found this to be true of the casteism about which I was told within the Church and TTS itself. This is because it is mainly people of Sudra and Dalit backgrounds who are Christians. "Even the students have caste knots in them which can't be undone," remarked one participant.

Another participant reported that in Madurai, Dalits can not register as members in non-Dalit churches, and that some non-Dalit pastors will tell Dalits to "go to the Dalit church over there, you can register over there." One TTS-graduated pastor had been attacked by his Nadar congregation for using Parattai's songs with his congregation because it was the first time the caste structure within the church had ever been challenged. According to one participant, there is more casteism in city churches because the congregations are mixed groups which have migrated from various areas. In rural India, missionaries originally built churches only in Dalit areas, so the congregations there tend to be more homogeneous. The most blatant casteism I personally heard from a Christian was a former town girl aged 20 who had moved to a village. Upon attending my first church service at her tiny village church, I was immediately befriended by this smiley, English-fluent girl. I went to her house after the following week's church service and was treated to great hospitality by her whole family. With an incredibly full stomach and sari wrapped around myself, I was taken all around the village and introduced to everyone she knew. Whilst on the rooftop of one neighbour's house, she pointed out "the SC [Dalit] street" only about 100 metres away, so I asked if we could walk down it. She said that they did not usually go down that street, but took me there regardless. To my question of why they did not go there, she replied that "People behave very differently there, in unacceptable and bad ways." As we walked down the street, she pointed out with disdain the people washing clothes and dishes "right here on the street."

\footnotetext{
${ }^{34}$ A Sudra jati.
} 


\section{Changes Brewing}

A strongly proffered opinion was that casteism exists in churches but in a less harmful form than the Hindu variety. Participants suggested that casteism in the Church was less Brahminical, less accepted, and never openly promoted. Unlike Hindus, Christians could talk about caste problems, and Dalit Christians had a voice in these discussions. Although casteism was practised, the basic ideology was one of equality, and Christians were trying to break casteism while Hindus were trying to maintain it, said Sudhakar (March 31, 2007). People felt that there was more chance of egalitarianism within Christianity than within Hinduism. Signs of hope for change were apparent, as in the comment by Rajan (March 30, 2007) that progress has been made and people were starting to accept pastors of different caste backgrounds now. Prasana (April 16, 2007) felt that caste will eventually be abolished from India completely but it will be some time coming because Dalits only "came up" in the 1970s to 1980s:

It will take a long time, but things are set so that even upper castes know that caste will be abolished. That's why they're trying to hold on to it for themselves. Otherwise it would be quicker.

Some participants appeared to have given up on Christianity as a path to caste freedom, claiming that people should convert out of Hinduism but not into Christianity. Said Deva (April 13, 2007):

Some students feel that they got the chance to study and become pastors because of Christianity, but people shouldn't have to convert to get an education! Another felt that the rich Dalit cultural traditions get lost when Dalits convert to Christianity. He said that Dalits want to leave Hinduism because it is hierarchical and anti-women, and that they should convert out of Hinduism but not into anything new. The influence of Dr Ambedkar was evident in comments by participants who felt that Buddhism had the best potential for a caste-free life. One stated that the Church wounds people with the hypocrisy of its ideology versus its practice, and that the wounded Christians are now turning to Buddhism. 


\section{Spiritual Equality}

Spiritual equality is more important than social equality, but the government can only work on the latter, claimed one participant. Parattai awakened Dalits' potential for spiritual equality. "If God sees us as equal, then why don't the people?" the participant asked. Some participants saw liberation as a separate entity from spirituality, claiming that Parattai's songs were "spiritual but also about liberation." Others said that Parattai's songs were not just about spirituality or ministry, but also focussed on social action or personal action. However, it is clear that Parattai considered liberation, spirituality and activism as essentially one and the same entity. Parattai broke away from the traditional way of viewing God and allowed people to approach a personal God, said Moses (March 28, 2007). "Parattai empowered people with the Good News about themselves!" (Deva, April 13, 2007). For some village Dalits, Parattai was the first person to ever suggest that they were also made in the image of God. "Parattai was a rare follower of Jesus in his expressing of solidarity with the non-developed through his songs etc.” (Bibin, April 8, 2007).

\section{Parattai's Christian Framework}

In the modern context of churches unable to purge themselves of casteist practices and some people giving up on the Christian faith altogether, why might Parattai have bothered to spend so much time to persuade Christian theological students into true egalitarianism? Deva (April 13, 2007) claimed that it was best to start with the Christians for protest against casteism, because they are the ones who have already expressed a dislike of caste and are speaking out about it. This person felt that the problem would never be fully solved however, because Christians had not addressed the issue to a sufficient extent. Parattai inspired students to act by relating various problems to theology. He taught them that as a Christian pastor or theologian, they had a responsibility to be concerned about the people and make an effort to help solve the problems. Many participants referred to the responsibility of Christians to other people. One mentioned the inter-related problems of caste and patriarchy:

Christianity as a religion is more middle class oriented and patriarchal. True Christian principles are liberative but they are not possible (to practise) because 
we are human. It is always a daily struggle against patriarchy, but Christians have more responsibility than Muslims or Hindus.

In the same way that Parattai challenged TTS students to remember the limited food available to the poor through Oru Olai and alternative communions, he focussed people on the villagers' theology too. Parattai integrated what he learnt from other religions, especially in the villages.

One of Parattai's songs is about a folk god of the cobbler community [one jati of Dalits], Ondi Veeran. He did not restrict himself to the Christian God (Jalastin, April 12, 2007).

From villagers, Parattai learnt about the female Dalit deities who had been martyred for the cause of overcoming caste. He found that village deities unite people and are part of the people, mirroring their joys and sorrows. When the people felt weak, they said that their God was weak too, and vice versa in happier times. "After seeing Parattai's plays, people had a positive view of the poor" (Rajan, March 30, 2007). One way in which he achieved this was to put himself in the villagers' shoes:

He saw the way that they [the villagers] sang which was very different from the educated people, and he wanted to make a liturgy which matched their way of singing. So he made a whole liturgy in village style, and that makes students to think [sic] about how villagers worship God and understand God (Prasana, April $16,2007)$.

Thus Parattai used the musical and linguistic styles of the villagers themselves, but concocted liturgies, songs and plays peppered with messages of encouragement and liberation from oppression. One participant said that Parattai and his works "help Christians to remember the Dalit brother and sisters we've left behind." These "brothers and sisters" were all the poor Dalits who had not received the benefits of education or uplift from Untouchability and caste oppression. "There are even many Christian Dalits who are uneducated and living in villages," said one participant. 


\section{Parattai's Interfaith Outlook}

This is one of the most important features of Parattai's work: because he focussed attention on the plight of the poor and suffering, he encouraged unity amongst all Dalits across religious boundaries, countering the elitism displayed by some newly liberated Dalits. Christian Dalits have now been living in cities for two or more generations. Whilst these young urbanites may have experienced some discrimination due to their heritage, many have no idea about the Untouchability still practised in villages. This was brought to my attention during the Student Christian Movement of India (SCMI) national conference on "Challenging Dalit Women's Status amidst Globalization," held in TTS over the New Year break. I participated in the conference and went on exposure trips to villages where we specifically talked to Dalits about the practice of Untouchability. In one area, we met the panchayat president. He was a Dalit and had reached the position of leader due to the government stipulated reservations for Dalits. The existence of any president in the area was a recent victory, as the non-Dalit people had prevented elections from being held since the reservation policy was put in place ten years earlier. However, the room for further abuse of such policies was evident, as the non-Dalit vice president accompanied the Dalit president everywhere and answered most of the questions for him. The other SCMI conference participants were from states all over India, some of which are more than 90 percent Christian (Northeastern states), and others with similar or lower rates of Christianity than Tamil Nadu. The SCMI is a social action oriented movement but is, as the name suggests, comprised of students, mostly at the university level. Thus the members were all highly educated people predominantly from urban, Christian families. Their shocked reactions to the conditions of inequality in the villages were not dissimilar to my own. The urbanites' lack of awareness regarding issues of rural people in their own country alerted me to the gaping differences in lifestyle between these people (many of Dalit background) and the poor rural Dalits.

Parattai had a very interesting position on religion. Surprisingly, despite his anger against the Manu Dharmins, ${ }^{35}$ he was not anti-Hindu. He even concedes that

\footnotetext{
${ }^{35}$ The 'Laws of Manu,' scriptures which specify the caste system
} 
early Sanskrit religion was not oppressive. It only had gotra ${ }^{36}$ but not caste, and gave women prominence. It became oppressive in encountering the city States.

(Dietrich, 2006b, p. 62).

No doubt the Dalit affiliation was a factor in Parattai's good friendship with 'Hindu' Dalit politician Thirumaavalavan. Two participants recalled the Biblical, political, feminist and Liberation theory-related influences that Parattai had on this man. He had also given the politician his very first cellphone after receiving it himself as a gift. "The Bible is not only for Christians, Parattai would say" (Sundar, April 5, 2007), because Parattai saw the Bible as a liberative tool and believed that liberation should not only be for those of the Christian faith. Parattai claimed that the Bible should be used for social change because that was the essence of the stories. He showed that Jesus' message was to mingle with the ordinary people and that Jesus was a great example of a protester (Julie, March 26, 2007). There were many stories in the Bible which could be paralleled with the situation in India: the Samaritans were the 'Untouchables,' people who others would not eat with, people who could not tread on forbidden land. Jesus himself was a villager, and seven of the twelve disciples, Jesus' closest confidantes and fellow imparters of knowledge, were illiterate fishermen (Deva, April 13, 2007). Parattai's songs were not only for Christians, and he never forced Christianity on anyone. Rather, he identified problems which were common to both Hindus and Christians, such as the oppression of women, claimed Wilfred (January 12, 2007). His secular songs are still used now by women's movements at many gatherings. His Christmas carols were full of messages about the environment and nuclear problems instead of simply the literal coming of Jesus (Sudhakar, March 31, 2007).

\section{Dalit Identity as a Separate Entity}

Though he was a born Christian, his Dalit identity made him to act [sic] extraordinarily...His Dalit religion protested the existing institutionalized Hindu, Christian and Islamic religious perspectives about Dalits (Anbuselvam, 2006, p. 13).

\footnotetext{
${ }^{36}$ The assignment of lineage or clan to a Hindu at birth, originally only practiced by Brahmins.
} 
One participant warned me to carefully distinguish religion from culture. He explained that the British colonists had not done this and simply thought that everything was religion. On the other hand, several participants threw these two concepts together. One said that religion and culture can not be separated out. Dalit culture is common to all Dalits and thus Hindu Dalits and Christian Dalits are very similar, claimed Pamela (March 29, 2007). Another said that Parattai knew the power of religion and culture for forming identities. He also understood the relation of education to religion, and the importance of education not for better jobs but for uplifting a person and allowing them a more positive identity. This was affirmed by the many people who commented that caste is stronger or more relevant than religion. "Parattai was very respected by secular Dalit movements because he criticised 'upper' caste values," commented one participant.

The issue of exclusive Dalitism was brought into the interviews by more than one participant, and pointed to an important argument regarding the abolition of casteism: does the encouragement of a separate Dalit identity help or hinder? One participant recalled Parattai's message that "We are Dalits, we should use our Dalit culture." Parattai's focus was on the poor and the uneducated; the victims of Untouchability. Two participants claimed that it was mostly only Dalits who listened to Parattai's music, because he focussed solely on them. Therefore alliances between castes were difficult, acknowledged one: "Why should non-Paraiyars ${ }^{37}$ learn the parai?" she queried. One person felt that 'folk' was a better term than 'Dalit' for Parattai's songs. "The music should be for everyone, not just Dalits," he said. Others claimed that Parattai's style of worship broke caste barriers. "He helped Dalits to understand what they have, with the parai, street theatre, messages, etc," said Pamela (March 29, 2007), continuing:

He reached out only to Dalits, but that was okay because Dalits have an amazingly negative self esteem, the wounded psyche. Parattai was intelligent, so he could discuss topics apart from just Dalit issues. We should move on from the affirmation of Dalits in order to completely get rid of the caste system.

\footnotetext{
${ }^{37}$ Paraiyar is a Dalit jati.
} 
"Why only Dalits? [Because] others have problems too, but no one else is coming forward to help the Dalits. That's why," pronounced Sudhakar (March 31, 2007). A further participant declared:

Polarisation is a necessary stage of liberation. We must get to the point where Dalits don't feel threatened anymore. Then we can go back to classical music and enjoy its heritage...For liberation, you must first be conscious of oppression and become caste conscious. Now, students ask me for my caste [on the TTS campus]. They didn't do that before... Your identity affects your epistemology.

The strong drive for Dalit identity did appear to have created strong divisions at TTS. There were hot debates and accusations of caste-based prejudice amongst students during the men's hostel secretary elections and the regular General Body meetings. Most of the TTS student population is Christian by birth rather than by conversion, approximately half with Dalit roots and half with non-Dalit roots. The non-Dalit students are generally from Nadar or Thevar backgrounds, castes which are at the bottom of the hierarchical caste system but still therefore in a slightly 'higher' position than Dalits, who are 'beneath' the system. Evidence of casteism within the Church is apparent at TTS because everyone knows their own caste and that of everyone else, despite the aim to unite as Christians and eradicate caste from the supposedly egalitarian religion. Students from villages are generally aware of their caste before coming to TTS, but many from large metropolitan areas such as Chennai said that they were not conscious of their own caste before studying at the seminary. These students were invariably Dalits who had enjoyed a lower to middle class upbringing in the city. In these urban areas, families were more anonymous and thus had not suffered from practices of Untouchability. The students were all highly sensitised to caste discrimination after learning at TTS that it is acceptable and even good to talk openly about caste issues. The castes of the previous and current principals (non-Dalit and Dalit respectively) were especially significant.

\section{Sustainability of Parattai-inspired Actions}

If he [Parattai] lived longer, we could learn more from him. He had so many ideas in his mind (Julie, March 26, 2007). 
A major objective of this research was to ascertain whether or not Parattai's cultural contributions towards the emancipation of Dalits have continued to function usefully since his death in November 2005. My interviews also investigated the perceived survival chances of his contributions. This subsection considers how Parattai's songs, Oru Olai and other works have been maintained, and by whom.

\section{The People}

According to one participant who was a senior faculty member at TTS, more than 75 percent of pastors in Tamil Nadu are graduates of TTS because it is the only regional college where classes are conducted in Tamil rather than English. Everyone at TTS between 1979 and 2005 was influenced by Parattai, and thus there are potentially thousands of students from over Parattai's many years of teaching at TTS who will maintain his work. During the second year of study, TTS students reside in slums as a form of exposure, so they can spread Parattai's songs and messages there, suggested Moses (March 28, 2007). One participant said that the songs work in both rural villages and city slums, although another said that they are more effective in the former than the latter. In the third year of study, TTS students reside in villages. I visited the village of the 2006 third year students on the day of an anniversary celebration commemorating the establishment of a church in a nearby town. The third year students were heavily involved in the organisation of this event, and sang three or four of Parattai's songs during the celebration. Some students in every year level at TTS are writing songs in the Parattai style, especially for the Christmas carol service. That is the key to the survival of such music and ideology, claimed one participant. Such songs and skits previously popularised by students are now employed by some pastors and NGO workers because they have been proven to quickly and easily convey messages of self-worth, remarked one participant.

Jasmine (April 16, 2007) claimed that Parattai's songs are still sung by former female students in rural churches and women's meetings: 
Women ask for Parattai's songs because only his are lively. The others are dull. We need this liveliness because our climate is hot. We sing to prompt people to wake up and think.

After graduation, students take Parattai's colloquial customs back to their churches, where they are accepted by the congregations, claimed one person. She added that if the songs are not spread, then it is the students' fault because they are too scared to put the theology learnt at TTS into practice. One final year student told me that Parattai's songs were the first social transformation songs he had ever heard, and that he has now introduced them at the church in which he is training. The congregation know and like the songs because they want change, especially the youth. He has not tried Oru Olai yet but intends to do so when he has his own congregation next year. Pabitha (April 18, 2007) summed up the common opinion of many regarding Parattai: "It is our duty as TTS students to continue his work, propagate and practice his ideology and concepts. It's in our hands."

In addition to TTS students and graduates, I was told that Parattai lives on both in his daughters and in some of the great Dalit political leaders. With regards to his family, I certainly felt an enormous sense of loyalty and continued commitment to social justice when I spent time with his two elder daughters. Upon visiting wife Dorothy, whom I met first, the words which flew around my head were that of the famous slogan: "Behind every great man, there is a great woman." Parattai now has grandchildren, and so there is hope that his message will be carried down the generations by his immediate family as well as the greater family of friends, students and acquaintances. Furthermore, his cassette tapes would keep the music alive. The tapes caused "a great shaking around Tamil Nadu," claimed Moses (March 28, 2007). The vigour and action continues, said another person. In addition to the tapes, the Christian Literature Society (CLS) and TTS hymnbooks such as Puttuyir Pädalhal carry Parattai's songs. I was told that every CSI hymnbook carries his songs, and found this to be true upon opening the hymnbooks in various churches which I visited. 
The other place where Parattai's sentiments were found was in the participants themselves:

Parattai's thoughts are not dead. They are living in me. We use his socially themed songs every year on Ambedkar's birthday, April 14 ${ }^{\text {th }}$. Parattai's alive in my thoughts. I teach his songs and ideology to my children, so it will go down the generations (Sundar, April 5, 2007).

"His voice lives on in his music," claimed Pabitha (April 18, 2007). "It is still encouraging to us to hear his music, his voice, read his books and articles. Like a ghost, he still gives us energy," said Julie (March 26, 2007). "His concepts are living in my mind" was a common statement. Perhaps the most eloquent quote was from Jasmine (April 16, 2007): "The tip of every leaf of every tree will sing his songs. Nature knows his intention for social change." Parattai's music was clearly regarded as a strong medium for communication, as illustrated by such comments as: "His songs will have their own effects on people for one hundred years-[they] will have an impact on people because the words are so complex and deep;" "Music has no beginning or end;" "The songs themselves give life to his concepts and even if we forget the man, his songs will keep doing his work."

\section{Maintenance of Parattai's Songs: A Mixed Response}

Four people specifically said that Parattai's songs are still being used now, citing reasons such as "Because they're good," "Because people like them" and "Because people love to sing his music." One person said that the effects of the music are only now coming out. He expected the songs and the messages to spread all around Tamil Nadu, but the process would take time. Various people asserted that Parattai's songs were still used on the radio, for functions, church services, workers' union meetings, youth meetings in villages, diocese meetings, the in-service training programme for graduates, by women's movements, RTI, TECCA (a training group for rural laity), and the TTS preschool. One participant mentioned that the songs were sung enthusiastically at the diocese level by Madras Diocese ${ }^{38}$ graduates in Chennai. Several people spoke of the

\footnotetext{
${ }^{38}$ Despite the city's name change from Madras to Chennai, the name of the Madras Diocese has not changed.
} 
higher rate of use in Chennai due to the Madras Diocese students' affiliation with Parattai. ${ }^{39}$ Another remembered that the songs were used and the folk style of worship was introduced in Trichy at the synod and diocese levels, with one youth programme consisting of 300 to 400 participants. Participants claimed that the songs were used all around Tamil Nadu and also in Bangalore. ${ }^{40}$ One participant recalled using Parattai's songs most recently in 2000 when still working as a pastor. He interpreted and discussed the words of the songs in his sermon, "and people liked it."

However, not all participants were confident of the sustainability of Parattai's works. One participant felt that the songs were not used in the Madurai area (outside TTS) or Tirunelvelli, where Christians are predominantly of Nadar background. She claimed that "Nadars won't allow them to use the songs, and Dalits won't appreciate them." Pabitha (April 18, 2007) noted a lack of popularity in Chennai due to the mixedcaste congregations and resistance towards change. "The songs are sung only by a few of Parattai's boldest students, and only in Dalit-only congregations in this area," he claimed. A female Muslim participant felt unable to spread Parattai's songs for a different reason: "I get no chance to teach others because I'm not a man so I stay inside (the house), but I sing them to myself." One student participant felt that Parattai's songs are only used ornamentally now in TTS and so people do not accept them. He reasoned that the songs must be used in context. "TTS should make a conscious movement, otherwise Parattai's works are unusable," he said.

Perhaps the lack of positive change and tailoring to the context was indeed a major reason for the reduced appreciation or use of Parattai's songs. Despite Parattai's open invitation to make changes to his music, three participants claimed that no changes had been made to his tunes since his death. One person claimed to have changed some pieces of his musical liturgy: "It depends on the students conducting it. It's more difficult for non-Dalits to do the folk style so sometimes we change it." Another had changed a few words to more inclusive or politically correct terms for God, women, and visually

\footnotetext{
${ }^{39}$ Parattai's home diocese was the Madras Diocese.

${ }^{40}$ Capital of the neighbouring state, Karnataka. Some students come from Bangalore to study at TTS.
} 
impaired people, both before and since Parattai's death. Pabitha (April 18, 2007) claimed that Parattai's Nimundhu Nada songs have widely spread and are used by various movements. She claimed that some of the songs are now so well integrated into the protest culture that they are commonly owned, and people sing them without knowing the name of the composer. Another participant said that Parattai was the main person involved in executing village arts, but people do not remember him for that:

Only the TTS and Christian circles know him. He had a lot of contact with movements but didn't get that much opportunity because he was a Dalit. One participant gave the following opinion:

Parattai will have less influence over time because he will be minimalised [sic] by those who were jealous of him-both Dalits and non-Dalits. I worry that he will be forgotten. People may use his music, but it won't have the direct influence on students as it did when he was alive. Parattai did and still does operate in this casted [sic] Christian church.

\section{Maintenance of Parattai's Other Works: Liturgies, Plays and Oru Olai}

Whilst the comments regarding the sustainability of Parattai's songs were mixed but overall hopeful, his other forms of expression had not fared so well. Several people said that Parattai's liturgies are still used in churches, with one claiming that the liturgy with the coconut Communion was still practised. However, others were more familiar with churches where this was not possible, relating stories of congregations which would not allow the elements to be changed. "You can do it in TTS but not outside in the churches," she stated. Parattai's liturgy is conducted once a month at TTS, explained several participants. I attended a very memorable Parattai style Communion service created and conducted by one fellowship group within TTS. Photographs of the chick peas and black ginger coffee served for this Communion are available in Appendix XI. Parattai's liturgies are not often conducted outside TTS. His plays are not often reproduced at all, despite the relevancy which their intertwined messages still hold today. Participants explained that all the scripts remain, but the plays are difficult to perform now due to the long scenes and lack of their original director. However, by far the 
strongest criticisms regarding maintenance of Parattai's works were those pertaining to Oru Olai.

Some cases of the practice of Oru Olai by former TTS students with congregations outside Madurai were described. One participant claimed that Oru Olai was taken into villages by students, and especially employed in times of celebration. A former TTS student who conducts Oru Olai with his village parish was identified. Wilfred (January 12, 2007) said that he holds an Oru Olai style shared meal wherever he goes, sometimes for groups of between 600 and 800 people, and including local Muslims. Another participant had initiated the practice in a parish and this was being continued by the women's fellowship. The food was distributed to Hindu families in the area too. "People like Oru Olai because they don't have to give money for it, only food," this participant said. She felt that Oru Olai would not work in a town or city church because people may just try to give money instead of getting into the spirit of the event. It was more important to do such a thing in cities because there is more casteism there, but it is also more difficult, she said. Joshua (April 2, 2007) reported that Oru Olai was conducted every month by the Perangapetai Lutheran Church. Another participant claimed that Oru Olai was only happening in TTS now, and that he knew no pastors instituting the event in Chennai apart from the husband of Parattai's second daughter. "Therefore it is hard to know how long it will last," he said, considering Oru Olai more a part of pastor training than something to carry to congregations or communities.

Many negative changes were perceived by TTS dwelling participants in the execution of the monthly TTS campus Oru Olai since Parattai's absence. The main problem reported was a lack of enthusiasm amongst both students and faculty.

Participants complained that the event was now shorter, slower and less exciting. "Before, people gathered to eat and talk about their problems. Now they're divided," said Edward (December 13, 2007). "Before, all families participated in Oru Olai keenly. Now they only do it because they have to," claimed Anthony (February 28, 2007). A major source of disgruntlement was the lack of participation by faculty members, with one participant claiming that twenty of the teaching staff no longer attended, and another saying that "the 
Oru Olai we do now is not the true one because faculty don't come. It will completely disappear when [one particular staff member] leaves." There appeared to be reluctance by students to attend the event as well. Students apparently viewed Oru Olai as "a chore" and only participated because it was compulsory. "They must be pushed to attend, and are questioned if they do not come," said Sundar (April 5, 2007). Confusion over the meaning of the event appeared to be the reason for this disinterest, as "some students think that Oru Olai is only for Dalits or only for staff" (Jalastin, April 12, 2007). One senior student lamented the fact that "Oru Olai is the only way of today's students to know Parattai, but it isn't promoted enough." This thought was echoed in the following statement by another participant:

Students don't like Oru Olai because they don't know about its significance or origins and they don't want to know or think about the concepts behind it. It's not because Parattai isn't here, it's because they're too busy with so many activities.

Joy (March 29, 2007) claimed that students were no longer motivated on the inside towards action or change. "Parattai could motivate them because he got to know people," she said.

Participants criticised the lack of maintenance by the seminary's senior faculty members, but also attributed the change to the loss of Oru Olai's creator, with comments such as: "Now it's a bit institutionalised. It's not evolving. We need a new leader," and "It's a bit difficult to do Oru Olai without the leader, but it is possible." Several other comments about the lack of leadership were made in general regarding the survival of Parattai's theology, ideology and actions: "We're all missing him. There is no one to replace this genius" (Jasmine, April 16, 2007), and "I don't think we can have another man like Parattai" (Pabitha, April 18, 2007). A significant number of participants were teaching staff themselves, and they generally seemed disappointed at the demise of Oru Olai but displayed little hope of any change in the situation, which may explain the decline in numbers attending. 


\section{The Role of TTS in Musical Activism}

The most obvious platform for the promotion of Parattai style activism is TTS; the college from which Parattai graduated at age 38 and then worked at for most of the rest of his years. Whilst some participants claimed that no activist would ever fill Parattai's shoes, there is a clear intention at the college to encourage an active form of theology. The main aim of TTS appears to be an awakening in students of the need and will to fight societal injustice. Rather than focussing on evangelism and proselytisation, the seminary teaches liberation theology. The holistic teaching style increases students' awareness of caste issues, patriarchy, ecological damage, globalisation and mass media. Each year a new theme with an accompanying picture is chosen by the seminary, displayed during annual campus events, and printed on T-shirts which are purchased by students. The theme for 2006 was 'Gender Justice towards Equality,' and for 2007, it is 'Spirituality towards Conservation of Resources.' But how can such liberative ideology be put into practice? Students may spread a hopeful message in their assigned churches after ordination as pastors, but if none practise what they preach then real change for Dalits, Christians, and women (and, especially, Dalit Christian women) will remain simply a nice idea. However, TTS combines liberation theology with music and other forms of art, providing a hands-on, action-oriented method of teaching and learning. A striking poster created by TTS's Dalit Resource Centre (DRC) proudly announces that 'Dalit Arts are Weapons for Liberation' on a black backdrop with a man beating the parai drum (see Figure 2).

Music is an integral part of TTS life at every level. The music is not exclusively folk style, but rather covers a variety of genres. Students not deemed ready to start the B.D. course undertake a one year music course which involves tuition in singing, parai drum playing and other musical pursuits. Music classes accompany other courses on Indian society, politics, history and communications in the B.D. curriculum, and violin lessons may be taken as an optional extra-curricular activity for no charge. After all the other classes and exams are finished, first year students complete a two week training programme in parai drumming, dancing and other Dalit arts in the countryside at RTI. The main events of the TTS year involve singing, acting and dancing; from the daily 
morning chapel service often featuring special items sung or performed by students, to liturgies which are entirely sung rather than spoken, to Oru Olai. In addition to these regular activities, there are also special entertainment evenings put on by the respective women's and men's hostels to celebrate Christmas and the end of the academic year in April, and separate men's and women's Christmas carol rounds led by a Santa Claus. Major annual events involving the public are held too, such as the TTS Christmas carol service and the Dalit Arts Festival. Furthermore, TTS has its own recording studio and releases cassette tapes and CDs of music composed, sung and played by staff and students. These are only the ways in which I saw music incorporated into the life of TTS between November 2006 and April 2007. There are even more events and practices during the rest of the year which I was not able to experience.

\section{Participants' Suggestions for Sustainability}

No participant specifically named a new leader or a way of reviving Oru Olai, but several suggestions for improving the sustainability of Parattai style composition at TTS were made. One person said that students should be trained to write like Parattai, especially prior to the Christmas carol service. Another claimed that TTS should employ a full time folk music tutor and invite people to come and compose at TTS, using Parattai's music as a model. A different kind of suggestion was to establish a trust or annual seminar on Parattai at TTS. One participant's idea of the best action was to take a step by step approach:

First, we should create awareness in the churches, then form a society-oriented action group and give them orientation about society and caste. Do this with the youths because they are the pillars, they can be moulded. Make it go further, that is my aim - and to create a human rights organisation in every church. The

Church should be directly involved as a social force and indirectly involved as a political force. That's my intention. Then it's easy to involve people in social activities (Prasana, April 16, 2007).

One participant had begun taking part in protests and started a movement of his own as a result of Parattai's influence. This man also emphasised the important role played by educated youths in his movement. Young people could explain the circulated pamphlets 
regarding the ways to fight against deprivation of basic facilities in villages such as water and graveyards, incorrect documentation of land, and forms of Hindutva oppression. My overall impression from the interviews was that Parattai's students must pass on Parattai's ideology and tools to the adolescents in their churches. If this process is not carried out, then Parattai's message will not reach as far as it otherwise could.

\section{Conclusion}

Parattai's influence on the people around him was made clear by the mere fact that each participant had so much to say about the man. Twenty five of the twenty six interviews lasted over an hour, with the participants talking freely about Parattai's tools for change, themes, messages and lifestyle. The descriptions of Parattai's 'simple' lifestyle and the style of his compositions corroborated each other. A picture of a clever and respected pastor who sustained a voluntary life of poverty was brought to life through the many details related to me. The songs were popular and communicable to the rural poor because he used the familiar elements of rural Dalit life: their musical style, language, food, religions and philosophies of life. They were also appealing to many members of the TTS population, and served as a reminder of their more oppressed sisters and brothers in society. The dancing, singing dinner routine of Oru Olai encapsulated Parattai's messages of caste and gender justice, but also provoked questions from me regarding gender equality in casual, celebratory dancing. I found willingness in the words of both men and women at TTS with respect to women dancing, but not in the reality of Oru Olai. I have also shown that much criticism of casteism within Christianity was expressed. Nonetheless, the majority of participants felt that Christianity held more potential for reducing casteism than any other option. Spiritual equality was highly important to Parattai, so he concentrated on breaking down not only caste barriers but also religious barriers. Through these actions, he fostered an intra-Dalit unity which became a new issue of division between Dalits and non-Dalits.

A major aspect of this research was the sustainability of Parattai's style. Views regarding the ongoing employment of Parattai's works were varied. This reflected the urban/rural and caste divisions, and the wide variety of responses to Parattai's radical 
messages and actions by people all over Tamil Nadu. Some participants felt that this special man and his egalitarian messages would live on forever in his songs, through his students, and in people's hearts. Many examples of the continued utilisation of Parattai's songs and liturgies were provided. A smaller number of people displayed pessimistic views, knowing that the deeply ingrained casteism within the Church may be able to topple Parattai's theology now that the leader is gone. Many TTS members criticised what they considered an inferior version of the Oru Olai ritual which now takes place at TTS due to the lack of leadership for this monthly event. TTS plays a critical role in involving future CSI pastors in music. I experienced many musical components of TTS life in my five months on campus, some folk and some otherwise. The musical style and associated theology of CSI pastors tend to emanate from TTS. Therefore, suggestions for the maintenance of Parattai's essence included a stronger focus on composition of folk music at TTS, with Parattai's songs and liturgies as examples. Like me, the local students who now come to TTS can no longer meet Parattai in person. However, as I have discovered, his music and words still speak for him. 


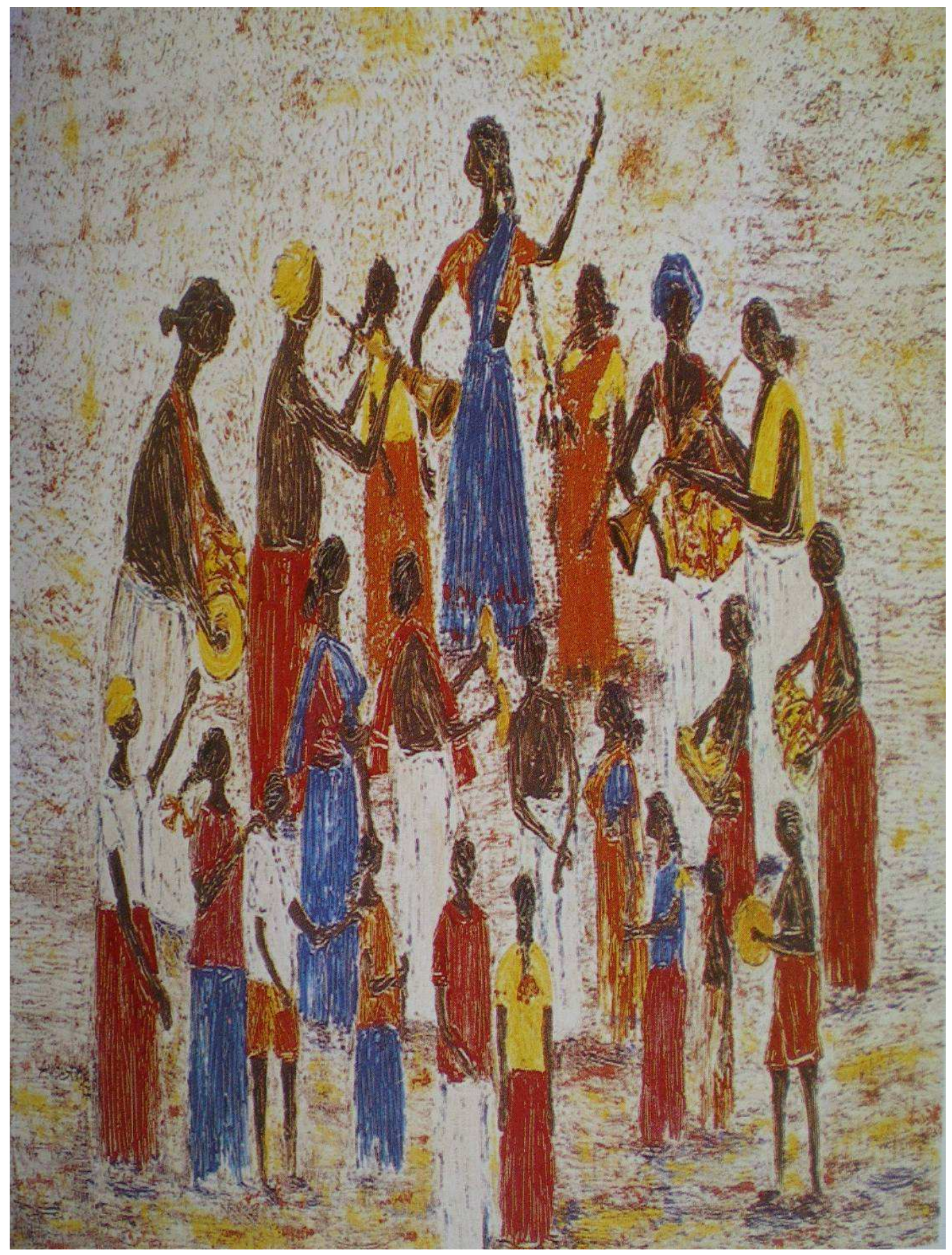

\section{Figure 6: Celebration}

(Original work by Augustine Annadurai, appearing in Larbeer, P. M. and Alexandar, V. (2000). Permission to reproduce kindly granted by P. M. Larbeer). 


\section{Chapter 6: Discussion and Conclusions}

He's not a Brahmin who abhors

The touch of a Mahar.

What retribution can he pay?

He won't throw his life away!

A Chandala drives him wild,

It's his heart that is defiled.

Tuka says, his caste is defined

By what fills his mind.

(Bhakti poet-saint Tukaram, Eng. trans. from

Zelliot \& Mokashi-Punekar, 2005, p. 26) 
Everything is in a state of flux, including the status quo (R. Byrne, cited in Marsh, 2004, p. 5).

\section{Introduction}

From November 2006 until April 2007, I lived at TTS in Madurai, South India. I interviewed twenty six people, including twenty residents of TTS. My questions pertained to the significance of the folk music compositions by former TTS lecturer Parattai and the sustainability of these works since Parattai passed away in 2005. In addition to the results of these interviews, I reviewed secondary sources which I accessed both in Aotearoa New Zealand and in India. My main objectives were to learn how Parattai's music changed life for Dalits and the extent to which his style of music had been sustained at TTS and in wider society. This chapter combines the results of my primary and secondary sources in order to address these objectives. The first section reports my findings that Parattai's music was effective due to his multifactor approach to liberation and his focus on internal factors such as the psychological and spiritual. I also show that his approach worked for many Dalits because it celebrated and promoted Dalit identity. The next section discusses the place for a separate Dalit identity as a necessary step towards castelessness. I then relate India's issues of diversity versus uniformity to those in my home country, Aotearoa New Zealand. This is followed by a summary of results pertaining to the sustainability of Parattai style Dalit activism. After that, I consider the changes which I underwent myself by living and conducting research in South India, before concluding the chapter with the limitations and future directions of my research.

\section{A Multi-Faceted Approach for Effective Change}

The secondary data shows that Dalit movements have emerged and enormous changes have occurred since the time of Dr Ambedkar. However, millions of Dalits still suffer in poverty. This poverty manifests itself as inequality, prejudice and discrimination. The discrepancies in quality of life both amongst Dalits and between Dalits and other Indian citizens go far deeper than simple reasons of monetary income. The poverty of 
Dalits encompasses at least the eight components of Parattai's EPSI PEGS; Economic, Political, Social, Ideological, Psychological, Environmental, Gender, and Spiritual factors. Thus, a medium which addresses such a range of factors is most useful in attempts to eradicate casteism. I briefly review the limited successes of the eight EPSI PEGS factors when attempted in isolation, as reported in the literature and interviews of this thesis. In particular, I highlight the importance of including spiritual factors.

\section{$E, P, S, I, P, E$ and $G$}

Improving the economic situation of Dalits does not guarantee a life free from caste-based prejudice. Neither does the simple adjustment of political policies to allow a few more Dalits higher education and public sector jobs, nor social stipulations against Untouchability built into the Constitution. As indicated by participants in my interviews and by the reviewed literature, changes de jure have not proven their worth de facto. Most importantly, the changes which have occurred are not yet widespread. Parattai constantly reminded his fellow Indians of these limitations, and UN data on the MDG progress and CERD analyses reflect this reality of continued oppression. Legislative changes in India are essential but not sufficient.

Casteist ideology runs thickly in the veins of all Indians, and is deeply embedded in the psyche of every person. Initially frustrated by the lack of direct answers regarding the specific actions which Parattai's songs had promoted, I later came to realise that it was the internal components of casteism for Dalits which Parattai had been most effective in influencing. The insidious nature of casteism is that even Dalits themselves came to believe that they were not equally human with caste people. At the other end of the caste spectrum, an assumed position of superiority is soldered into the Brahmin psyche from a young age (Ananthamurthy, 2005). Parattai's songs with their liberative words and style burrowed into the wounded psyche of Dalits and found a place to start the transformation of Indian society. Other methods which advocate equality but neglect the psychological aspects of casteism are unlikely to succeed. A Dalit liberation medium attacking caste without consideration to the environment is also useless. The practice of Untouchability has physically segregated Dalits into inferior living areas and openly 
restricted their access to basic resources such as water. The addition of pollution to India's environment by multinational companies further aggravates the problem, and most negatively affects the millions of Dalits who work as agricultural labourers. Gender discrimination adds to the oppression of Dalit women. I have illustrated the inter-related caste, class and gender factors reported in academic literature on education, and also in my primary data on women's reluctance to dance during Oru Olai. Due to the added burden of patriarchy on female Dalits, any attempt to reduce caste-based prejudice which does not involve equal leadership and participation by women is less effective.

\section{The 'S' for Spirituality}

As with the other EPSI PEGS factors, spirituality can not act alone to transform the lifestyles or the treatment of Dalits. Azariah (2000) claims that a religiously sanctioned negative identity requires a religiously sanctioned (Dalit) theology to legitimise a positive or equal identity. However, caste is not simply a religious phenomenon. The system may have originated from ancient religious texts, but since then it has become an all-encompassing part of life in India and a number of other countries. Thus, even following a supposedly casteless minority religion such as Christianity or Islam does not immediately dissolve all inferiority and superiority complexes. It is clear from the literature and from my interviews that casteism is alive in the churches of Tamil Nadu, albeit in forms which my interview participants perceived as revised and somewhat lesser than that within mainstream society. Messages of egalitarianism in the Bible or the Qu'ran may be ideologically kosher, but difficult to apply practically. Nonetheless, the spiritual aspect of equality must be addressed in association with other factors, in order to combat caste in a country where $99.9 \%$ of citizens profess to be of one religion or another. India's official political status as a secular country is vital for minorities, and yet the spiritual realm plays a large role in the public and private lives of all citizens.

I have demonstrated in my literature review that many minority religions and sects of Hinduism have sprung up in India over the millennia as responses to the Brahminical caste system. As Anthony (February 28, 2007) stated, equality in the eyes of 
God may have a more positive influence than economic or social equality on the deeprooted psychological aspects of caste such as self respect. Laws prohibiting segregation in places of worship and other public arenas are flouted routinely, as is much other legislation pertaining to equality. In a similar vein to many of my Christian participants, Leftist Brahmin Hindu Ananthamurthy (2005) sees spiritual equality as the key factor to castelessness:

To this day, I am convinced that untouchability will be eradicated only when

Dalits can walk in and out of any temple with ease. When this happens, it will also be possible to drink water from the same well and to eat together (p. 21). On the other hand, M. C. Raj (2006b) states that Dalits will stop going to different religions and parties in search of their space when all Dalits have united as one by forming Dalit panchayats (village councils). I have learned from Parattai and the literature on liberation music and theology that it is affirmation of the identity of oppressed peoples which is the key to equality. Thus, whether through religion or through panchayats, the assertion of a positive Dalit identity is most pertinent to large scale change towards equality for all Dalits in India.

\section{How Parattai's Dalit Music Transforms People}

As with Dalit theology, Dalit music expresses a Dalit identity of strength. Theology evolves when people within a religion challenge the status quo and push for transformation. Contemporary music reflects current status quos, both those pertaining to religion and to other spheres of life. I have illustrated a miniscule proportion of the world's history of music which echoes the various protests and revolutions against oppression. The lyrics of any songs sung by a particular faith group provide an indication of the group's theology, and the changes over time therein. Parattai's music remains a significant contribution in this flow of musical and religious history. I have reported participants' views that his songs were popular amongst rural Dalits and some urban Dalits not only due to the religious elements, but also due to the Dalit folk style of his music, the village or slum styles of language, clever linguistic techniques, liberative messages, and relevant imagery and symbolism such as that pertaining to village food and agriculture. The many people who responded so favourably to Parattai's music did so 
because it announced a positive, proud, unapologetic Dalit identity. Most significantly, Parattai's works were popular because his lifestyle was an active expression of the messages which he communicated through his lyrics. Parattai's life of convivial poverty ${ }^{41}$ was his answer to the unequal, elitist, casteist, Earth-destroying Industria which he found himself surrounded by. As Rahnema (1992) indicates, convivial poverty is common amongst grassroots movements as resistance against the dehumanising forms of imposed poverty which devastate all forms of life. Nonetheless, Parattai's intentional descent down the ladders of wealth and status was radical and genuine. This was especially so amidst the rapidly polarising lifestyles of educated urban Dalits and uneducated rural Dalits.

\section{The Importance of a Separate Dalit Identity}

\section{Dalit Pride}

Is pride a luxury that only the rich are entitled to? (A. Roy, 2002, p. 106). According to Zelliot (2001), social movements thrive on pride, and the name 'Dalit' in itself indicates pride as opposed to former names which symbolised pity or submission. However, in any attempt by an oppressed group to reclaim its heritage, culture or arts, the group risks becoming as exclusive as those dominating it. Indeed, the question has been asked in relation to specifying art as 'Dalit' art; "Was it not a sort of communalist ${ }^{42}$ mistake to even consider such a category?" (Tartakov, 2000, p. 20). On the one hand, unity may develop within this identifiable group and serve as a strong basis for collective protest and action towards claiming human rights. Furthermore, inner strength and self respect flourish under positive recognition of a person's identity. These processes are certainly evident at TTS. One interview participant remarked that TTS "roots out Dalits' feelings of lesser worth." On the other hand, such casteism segregates Dalits and nonDalits. This problem is apparent in TTS as well, as evident from interviews and casual conversations on campus which I had with people of both backgrounds. Thus, Christians fall into the trap used by Brahmins to control 'lower' castes, Dalits and tribal peoples,

\footnotetext{
${ }^{41}$ Voluntary or moral poverty (Rahnema, 1992)

${ }^{42}$ In the Indian context, the word 'community' is used to refer to one caste group, and thus 'communalist' is a term with negative connotation pertaining to exclusive, casteist activity.
} 
and also by the British to control India before Independence: the divide and rule mechanism.

Parattai held high hopes for sufficient liberalism in the Christianity of students at TTS, and certainly functioned as a role model of such a stance. He focussed his messages on the educated Christians for a good reason: these were the people with the potential to bridge the gap between their lifestyle and those under extreme oppression. If both Dalit and non-Dalit Christians could accept the idea of parai drumming and folk songs in rough, village vernacular as an asset of the poor to be emulated and celebrated, then prejudice could be reduced. If literate Dalit Christians really treated the uneducated village and slum-dwelling Dalits as their brothers and sisters, then action towards liberation of all would occur. It is here that the validity of a separate Dalit identity becomes apparent. When less oppressed Christians of Dalit background wash their hands of Dalit customs, they lose their best skills for countering the casteism suffered by themselves and other Dalits in India. Parattai functioned as a check and balance for the Christian struggle towards eradication of the caste system, Untouchability and other associated prejudice. He could see that in order to be treated equally as a Dalit, the first step is to proudly be a Dalit. Parattai believed that the Dalit identity should be maintained, but claimed with self respect rather than serving as a source of shame. Whilst Parattai was more locally focussed, his opinions complement those of another Dalit leader, former President of India, K. R. Narayanan (cited in Thekaekara, 2005, p. 17):

Revolution has to come from below - through education and through protests from the oppressed people. We need to gather much more momentum, from world opinion, human-rights groups, etc. We need to give up the bitterness and move on. To be proud of being Dalits. Learn from the Black Panthers, the Black is Beautiful movement. Assert Dalit pride. Only then will we learn to express and assert ourselves. I believe that ultimately we will overcome.

I have explored the Dalit theology and Dalit culture which are gaining popularity as tools for emancipation in the liberal branches of Indian Christianity. As with general politics, however, there is a difference between the word and the reality. The theology 
espoused by the Church offers hope to those who know that they deserve the same respect and dignity as all other human beings. The great challenge now is for Christians, especially the pastors in their leadership roles, to practise what they preach, à la Parattai. Dalit theology may appear exclusive at first, but it is instead a giant step towards the inclusion of Dalits in mainstream Christianity and society at large. If the Church wants to break down caste barriers and unite all members and pastors under the one religious banner of Christianity, it must recognise and celebrate Dalit arts. While Christian Indians are still prohibited by their families to marry inter-caste within their own religion, there remains a long way to travel along the path towards equality. Due to the co-existence of Dalits and non-Dalits at TTS, attitudes regarding caste-affiliated marriage were changing. Some of the male and female students I talked to were forbidden by their parents to marry a fellow student of different caste background, but claimed that they would let their own children do so when the time came. Both Dalit and non-Dalit students felt that their parents' views were rather antiquated. Only time will tell how widespread such attitudinal changes will become. Already there were examples of TTS or ex-TTS members other than Parattai's daughters who had married inter-caste and/or inter-religion. Those I met tended to be Dalit Christian men married to Brahmin Hindu women. Most women and some men had been disowned by their families. These bold couples highlight the slow but steady countering of casteism.

\section{Uniformity or Diversity for Equality?}

I am grateful to a student of Gurukul Lutheran Theological College in Chennai who challenged me with the following question regarding my thesis: "How are you going to relate that to your own context?" As in India, there is a wide gap between the situations de jure and de facto in my home country of Aotearoa New Zealand. We used to describe the country as a 'melting pot,' where people of many different ethnic and cultural backgrounds live together in an integrated manner. For example, the indigenous Māori do not live in separate, designated areas as do some Dalits in India and indigenous peoples in other countries. The residents of Aotearoa New Zealand include a significant number of people of Pacific Island and Asian descent, and a small number of people with African and Middle Eastern backgrounds. However, someone pointed out that if we melt all the 
different cultures and colours in one pot, then the end result will be dominated by the flavour of the majority-dominant group; known variously as the Pākehā, tangata tiriti, European or 'white' New Zealanders. Thus, a new term 'mixed salad' came to replace the melting pot image. The ingredients of a salad need not dissolve and merge into one homogeneous mass. Rather, they may co-exist but each distinctive taste is savoured; diversity within unity.

A mixed salad is not the current reality in Aotearoa New Zealand, but an ideal situation to which we are slowly heading. Those who still advocate for the melting pot are the biggest threat to equality. Certain New Zealanders believe that the melting pot is the best method. Such people claim that uniformity is required rather than diversity, so the establishment of a separate Māori identity compromises equality (for example, see former National party leader Don Brash's speech on 'racial separatism,' (Brash, 2004)). It is in this way that I can well relate the situation of my country to India's Hindutva organisations which promote unity through a Brahminical Hindu 'One India,' and to the Christian Indians who desire a uniform Christian identity. The transformation of oppressed peoples in India differs from that in Aotearoa New Zealand particularly in its extreme belatedness. Oppression of Māori people began when the British arrived in Aotearoa New Zealand in the $19^{\text {th }}$ century, whereas caste-based prejudice in India has survived for hundreds of centuries. Thus, the changes originating in the mid- $20^{\text {th }}$ century and propelled forwards by Dalits in the last two decades are momentous and vital to the continued transformation of India. Dr Ambedkar and Parattai are no longer here in their Earthly forms, but other people must continue to embody the equality through diversity to which these two men dedicated their lives.

\section{Sustainability of Parattai-Style Activism}

Of all Parattai's creative forms, I found that his songs had been the most popular and well maintained. The messages conveyed through his songs had also been sustained. Parattai's main message for the Christians of India was clear; unity between Dalits of every class, geographical area and religion should be established. Urban Dalits should not forget or shun Dalit brothers and sisters who still suffer from severe casteism in the 
villages. Parattai's musical style is Dalit rather than Christian, which allows more room for interfaith unity across Dalits of all religious and spiritual groups. Dalit music is not specifically Christian, and yet the embrace of such traditions may be considered by some as the very Christ-like concept of standing in solidarity with the oppressed. Thus, the promotion of Dalit folk arts and spirituality as exemplified by Parattai is a key method by which Dalit and non-Dalit pastors can put into practice their messages of equality. Dalit folk music is the key to a true Dalit Theology. Parattai's EPSI PEGS stipulations (Appavoo, 1993) provide guidance for creating folklore.

The particular tunes or types of folklore to use can not be prescribed. Parattai appreciated the ever changing diversity of human beings both across space and time. Therefore he taught that the messages and the music or other folk forms must evolve as the people evolve. Only two aspects of such compositions should remain the same: they should be created with the tools or assets of the people themselves, and the goal must be liberation (Appavoo, 1993). Therefore, the most effective song or play for a contemporary context may not be those composed by Parattai himself. Rather, adaptations or original compositions are the best way to carry on Parattai's legacy and transformation of society. Participants in my interviews reported limited progress in this area. However, if such action is embraced, then Parattai's message and style will be sustained long after his name is forgotten. I will hazard a guess that he would be quite happy if that happens. Parattai regretted the publication of his songs in print and audio forms because he felt that this had prevented their re-creation or evolution, and was therefore detrimental to their flexibility and efficacy for new environments (Sherinian, 1998). However, his leadership was critical for the introduction of folk music as a form of activism into TTS and the CSI in Tamil Nadu, so examples of his songs and liturgies are invaluable for communicating the medium to all present and future students. It was these students, the upcoming pastors of Tamil Nadu, in which most participants held hope for the survival of Parattai's theology and artistic style. Therefore a great responsibility lies with the faculty and senior students of TTS to pass on the meaning and the methods of Parattai. 
Participants reported that Parattai's music was not accepted by everyone. However, the overwhelmingly positive responses regarding Parattai and participants' strong convictions that TTS students will sustain his activism have led me to believe that Parattai was not merely "a voice crying in the wilderness" (Dayanandan, 2005, p. 10). TTS could facilitate the process of an enduring focus on Parattai's style by fulfilling the suggestions provided by participants in this study. The participants were, after all, predominantly members or former members of TTS. Seminars on folk music composition would certainly make an impact, as would a full time Dalit folk music teacher at TTS. Such a teacher need not replace the current music teachers but rather could complement them. The whispers I heard of an affiliated Dalit arts college to be formed in Tamil Nadu indicate that TTS may be going in this direction. The results of my interviews show that as time goes by, it is TTS's monthly Oru Olai which has suffered the most from the loss of its leader Parattai. Leadership is essential for a positive evolution of Oru Olai, the Parattai-inspired festival which combines dancing, singing, cooking and eating. If all the male TTS participants who bemoaned patriarchy and the lack of dancing by Tamil women would encourage women to dance, starting with their own wives, then Parattai's feminist ideology would be realised. The women themselves could also choose to challenge gender discrimination by dancing during Oru Olai. This procedure would probably require leadership from female faculty members. At present, the TTS faculty is dominated by males, but in offering placements and lower fees to female students, the seminary is paving the way for more equal gender ratios amongst future faculty staff.

The answer to what people around the world can do is less definitive. How can we support and work with Dalits towards attaining equal treatment? Smith (2005) advocates for the International Dalit Solidarity Network (IDSN) and increased pressure on the Indian government in high-level contexts such as CERD meetings. Action at this level is necessary but must work in combination with that at all other levels. Prabhakar and Kwon (2006) claim that every society becomes more truly just in proportion to the amount of collective effort towards change made by the large numbers of people at "the bottom” (p. vii). In Parattai's words, “...change is an internal aspect. It can not be preached or thrust on people. It should come from the poor people themselves" (Appavoo, 
1986, p. 123). My research has shown that it was the levels of internal motivators such as self respect, self dignity and pride in Dalit identity which Parattai's music most significantly transformed. The assets of an oppressed people are often overlooked by outsiders. However the skills, heritage, food, music and language are the greatest tools with which Dalits are equipped to fight the caste system. So are the religious and spiritual aspects of their lives: Christian, Dalit, and otherwise. "Caste is the oldest surviving social hierarchy of the world," claims the IDSN (2007) video. We are at a crucial time in history, when Dalits have thrown open the door to their own emancipation from segregation. A great role model for activism within the South Indian Christian context was Parattai, the one who was "truly beyond hierarchy" (Dietrich, 2006a, p. ii).

\section{Transformation of the Researcher}

I was on the ten hour train ride from Chennai to Madurai to begin my stay at TTS when a chatty older married couple enquired as to my religion. Upon answering 'Christian,' the man enquired as to whether I was a missionary. I answered somewhat defensively that I certainly was not. My heart sank as I realised that my skin and eye colour identified me with the foreign missionaries who used to come en masse ${ }^{43}$ to proselytise in India. The couple themselves were Roman Catholic Christians and their tone of voice indicated that perhaps they would not have minded if that was indeed my purpose in India. However, I spent the rest of the journey wrapped in a shroud of postcolonial guilt. I was embarrassed and disappointed that people of my ethnicity had come and tried to change the way Indians lived their lives. With complete disrespect for such an intimate and personal aspect of life as the local spirituality and religions, these 'white' people had presumed to know what was best for Indians. Such arrogance directly contradicted the messages I understood from the Bible about accepting differences, treating other people as equals and showing peace towards one's fellow human beings. Upon arriving at TTS, I was taken to the guesthouse which was dedicated to influential European missionary Ziegenbald. Despite the liberal theology taught at TTS, I saw more plaques on campus with the names of foreign Christian missionaries, and heard a lot

${ }^{43}$ And still go, but to a lesser extent 
about them while amongst Christians in India. Realisation dawned that many Dalit Indians were actually grateful for the part played by missionaries in their country.

Certainly, the history read by church sponsored Dalit school students was written by the missionaries and is therefore biased, as is all human history in some way. Nonetheless, as revealed in my interviews, many Christians feel gratitude to foreign missionaries for having granted them the basic human right of education. In my desire to respect other religions such as the various forms of Hinduism which existed before the era of mass foreign missionary influx, I had completely disregarded the intelligent, active decision-making abilities of Dalits and other Indians who converted to Christianity. Some people were forced to convert in certain times and places, but many others chose to receive education and integrate the new schemes of values and religious practices into their lives. Christians who I interviewed felt more oppressed by the Indian caste system than by their religion which had originally come into India from external sources. Furthermore, in my horror at the idea of Western proselytisation, I had not appreciated the different dynamic in the relationships with gods between some Indians and myself. People I met or observed in financial hardship who could never rely on money for their basic needs tended to rely strongly on deities. I came to see that people who can only depend on their gods for daily survival choose the $\operatorname{god}(\mathrm{s})$ who they believe understands them and listens the most. Several converts who I chatted to on public buses told me that they had chosen Jesus (or the Christian God) to pray to because he seemed better than the other gods whom they had been worshipping. They considered Jesus to be the most useful for their purposes. It is not correct to say that conversions to minority faiths have always happened as conscious protest against the caste system (Bayly, 1989). However, if the alternative ideology and actions of these relatively small minority groups of Indian citizens posed no challenge to Brahminical Hinduism, why would the fundamentalist Hindutva groups expend such effort on enforcing a homogenised, 'One India'?

Despite my family's religious orientation, I am a product of the secular, scientific education and political systems in which I was raised. Therefore, a post-secular worldview was necessary in order to fully grasp the assets-based approach to research. In 
recent decades, there has been a resurgence of conservative Hinduism, Islam and Christianity, all propagating exclusive, fundamentalist mentalities and actions (Almond, Appleby, \& Sivan, 2003; Morris, 2007). Nonetheless, peaceful theology and activism which promote the respect of other people and the planet are simultaneously found in the name of most religions. Liberation theology constitutes one form of the latter of these, as does Parattai's active theology. Some people may 'throw the baby out with the bathwater' in regards to the role of religion in human life. However, respect for those faith paths which do advocate heterogeneous inclusiveness may reveal a useful tool for action which has been suppressed by the oppressors in certain contexts.

\section{Limitations and Direction for Future Research}

Parattai says that "Real research should create some action...It's not just research for the sake of getting a degree" (cited in Sherinian, 1998, pp. 448-449 ). His actions and words embody the deeper vision summarised by Borda (2006) that: "Simple activism is not enough: it needs to be guided by good judgement in seeking progress for all" (p. 358). Parattai's utilisation of Dalit assets was entirely focussed on progress for all in terms of positive self-image and egalitarianism. Pieterse (2000) claims that:

The step from a statistical universe to a moral universe is worth taking, but a moral universe also involves action, and which action follows? (pp. 177-178). Pieterse adds that doing nothing essentially equates to the endorsement of the status quo. 'Moral' is an undoubtedly loaded and somewhat risky choice of word. However, I understand Pieterse's 'statistical' to mean 'quantitative,' and 'moral' to mean 'qualitative.' Once research steps outside of a comfortable black and white quantitative framework in order to advocate for change in real human situations, the massive grey area can be overwhelming and there are many pitfalls. My research constituted only interviews rather than action research, which is its largest limitation. Making action research truly participatory requires extended, transformative experiences by the researcher in order to first understand the strengths of the people. This did occur for me, and future research should build upon these experiences and constitute continued learning in order to co-initiate action with local people in the local language. Participatory Action 
Research (PAR) would further assess the use of folk music and religion, and involve joining with willing members of TTS and villages to make music together. Ironically, considering Parattai's focus on local languages, I carried out most of my interviews in English, and my thesis is also published in English. However, one person at TTS has offered to translate the thesis into Tamil. For a strict translation, formal written Tamil will be necessary, so this will still not adhere to Parattai's inclusive style.

\section{Conclusion}

The first objective of my research was to ascertain how Parattai's music was useful and effective for Dalits. Through primary research I found that Parattai used a multi-factor approach grounded in the skills and culture of Dalits to change the discourse around caste and Dalits. In particular, Parattai's folk music compositions were influential. The change in discourse encouraged more positive self identities within Dalits, thereby transforming their realities. Religion is not the only tool for Dalit transformation, but Parattai appreciated the importance of spirituality for identity. He worked from a liberal Christian framework whilst holding an interfaith stance. I came to understand the role of religion and folk music as assets of Dalits in South India through my time spent in Tamil Nadu. The effects of Parattai's compositions support the secondary literature which suggests that song is a strong form of communication, that the implicit theology in songs about God or religion is very influential, and that theology is not static. The other objective of my research was to investigate the sustainability of Parattai's music. While participants reported some negative reactions to Parattai's musical activism, overall the response to Parattai and his messages indicated a high level of respect. Parattai's spirit was clearly alive amongst many interviewees. I am confident that with active maintenance of folk music composition, Parattai's style and spirit will live on. 


\section{References}

Almond, G. A., Appleby, R. S., \& Sivan, E. (2003). Strong religion: The rise of fundamentalisms around the world. Chicago: University of Chicago Press.

Alridge, D. P. (2005). From civil rights to hip hop: Towards a nexus of ideas. The Journal of African American History, 90(3), 226-253.

Ananthamurthy, U. R. (2005). I, a Brahmin. New Internationalist, 380, 20-21.

Anbuselvam. (2006). A biographical note. Arasaradi Journal of Theological Reflection, XIX(1), 1-16.

Appavoo, J. T. (1986). Folklore for change. Madurai: T.T.S. Publications.

Appavoo, J. T. (1993). Communication for Dalit liberation: A search for an appropriate communication model. University of Edinburgh, Edinburgh.

Arora, P. (2006, May). E-karaoke learning for gender empowerment in rural India. Paper presented at the International Conference on Information and Communication Technologies and Development 2006, Berkeley, California.

Azariah, M. (2000). A pastor's search for Dalit theology. Delhi: DLET/ISPCK.

Bayly, S. (1989). Saints, goddesses, and kings: Muslims and Christians in South Indian society, 1700-1900. Cambridge: Cambridge University Press.

Blah, T. (2005, February). Mainstreaming indigenous perspectives in development and the Millennium Development Goals. Paper presented at the 28th session of the IFAD's governing council meeting, Rome. Retrieved September 25, 2006, from http://www.un.org/esa/socdev/unpfii/documents/workshop_IPPMDG_blah_en.do c.

Bob, C. (2007). "Dalit rights are human rights": Caste discrimination, international activism, and the construction of a new human rights issue. Human Rights Quarterly, Feb, 29(1), 167-195.

Boff, L., \& Boff, C. (1987). Introducing liberation theology. New York: Orbis Books.

Borda, F. (2006). The North-South convergence: A 30-year first-person assessment of PAR. Action Research, 4(3), 351-358. 
Brash, D. (2004, January). Nationhood. Paper presented at the Orewa Rotary Club, Auckland. Retrieved October 7, 2007, from http://www.onenzfoundation.co.nz/DonBrashSpeech.htm.

Business and caste in India: With reservations. (2007). The Economist, 385(8549). Retrieved October 24, 2007 from http://www.economist.com/opinion/displaystory.cfm?story id=9909319.

Cameron, J., \& Gibson, K. (2005). Participatory action research in a poststructuralist vein. Geoforum, 36, 315-331.

Caste: One billion eyes documentary film festival. (2007). Retrieved August 23, 2007, from http://www.abillioneyes.in/fest07.htm

CERD. (2007, May). Consideration of reports submitted by states parties under Article 9 of the convention: Concluding observations of the Committee on the Elimination of Racial Discrimination - INDIA. Report from the 70th session of the Committee on the Elimination of Racial Discrimination. Retrieved 13 August, 2007, from http://www.unhchr.ch/tbs/doc.nsf/0/0a287107325678c5c12572ed004ac999/\$FIL E/G0741717.pdf

Chakma, S. (2007). India fails UN caste test. Indigenous Rights Quarterly, 2, 10-13.

Chatterji, A., McKean, L., \& Sur, A. (2005). Genocide in Gujarat: The Sangh Parivar, Narendra Modi, and the government of Gujarat. Retrieved June 12, 2006, from http://www.coalitionagainstgenocide.org/reports/2005/cag.02mar2005.modi.pdf

Clark-Decès, I. (2006). How Dalits have changed the mood at Hindu funerals: A view from South India. International Journal of Hindu Studies, 10(3), 257-269.

Clarke, S. (2003). Conversion to Christianity in Tamil Nadu: Conscious and constitutive community mobilization towards a different symbolic world vision. In R.

Robinson \& S. Clarke (Eds.), Religious conversion in India: Modes, motivations, and meanings. (pp. 319-350). New Delhi: Oxford University Press.

Dale, S. F. (2003). Trade, Conversion, and the Growth of the Islamic Community in Kerala. In R. Robinson \& S. Clarke (Eds.), Religious Conversion in India: Modes, Motivations, and Meanings (pp. 54-74). New Delhi: Oxford University Press. Dangle, A. (Ed.). (1992). Poisoned bread: Translations from modern Marathi Dalit literature Bombay: Orient Longman. 
Dayanandan, P. (2005). A voice crying in the wilderness. Thamukku, 10(9), 10.

Dayanandan, P. (2006). Response from a lay person. In P. M. Larbeer (Ed.), Exploring new vistas for ministry (pp. 99-105). Madurai: Tamilnadu Theological Seminary.

Desai, V., \& Potter, R. B. (Eds.). (2002). The companion to development studies. London: Arnold.

Dietrich, G. (2005). Dalit movement and women's movements. In A. Rao (Ed.), Gender and caste (pp. 57-79). New York: Zed Books.

Dietrich, G. (2006a). Editorial. Arasaradi Journal of Theological Reflection, XIX(1).

Dietrich, G. (2006b). Parattai as cultural activist. Arasaradi Journal of Theological Reflection, XIX(1), 56-75.

Doniger, W. (2002). Foreword: The view from the other side: Postpostcolonialism, religious syncretism, and class conflict. In S. J. Raj \& C. G. Dempsey (Eds.), Popular Christianity in India: Riting between the lines (pp. i-xix). Albany: State University of New York Press.

Dundas, P. (2003). Conversion to Jainism: Historical Perspectives. . In R. Robinson \& S. Clarke (Eds.), Religious Conversion in India: Modes, Motivations, and Meanings (pp. 125-148). New Delhi: Oxford University Press.

Eaton, R. M. (1997). Comparative history as world history: Religious conversion in modern India. Journal of World History, 8(2), 243-271.

Fenech, L. E. (2003). Conversion and Sikh Tradition. . In R. Robinson \& S. Clarke (Eds.), Religious Conversion in India: Modes, Motivations, and Meanings (pp. 149-180). New Delhi: Oxford University Press.

Frame, M. W., \& Williams, C. B. (1996). Counseling African Americans: Integrating spirituality in therapy. Counseling and Values, 41(1), 16-29.

Ganguly, D. (2004). Buddha, Bhakti and superstition: A post-secular reading of Dalit conversion. Postcolonial Studies, 7(1), 49-62.

Geering, L. (2007, August). Wrestling with God. Paper presented at the 'God in the 21st Century' lecture series, Knox Church, Christchurch.

Ghose, S. (2003). The Dalit in India. Social Research, 70(1), 83-109.

Gilbert, S. (2007). Singing against apartheid: ANC cultural groups and the international anti-apartheid struggle. Journal of Southern African Studies, 33(2), 421-441. 
Gorringe, H. (2005). Untouchable citizens: Dalit movements and democratisation in Tamil Nadu. New Delhi: Sage Publications.

Government of Tamil Nadu. (2007). List of Backward Classes. Retrieved October 24, 2007, from http://www.tn.gov.in/department/bclist.htm

Guru, G. (2001). The interface between Ambedkar and the Dalit cultural movement in Maharashtra. In G. Shah (Ed.), Dalit identity and politics: Cultural subordination and the Dalit challenge (Vol. 2, pp. 160-194). New Delhi: Sage Publications.

Hindemithon. (2007). Retrieved October 15, 2007, from http://www.hindemithon.com/ Hipwell, W. T. (2007). The Industria hypothesis. Peace Review: A Journal of Social Justice, 19(4), 305-313.

History: Condition of the Untouchables or the Dalits. (2006). Retrieved May 3, 2006, from http://www.dalitchristians.com/Html/condition.htm

IDSN (Writer) (2007). I'm Dalit, how are you? [Film]. India: IDSN. Retrieved October 10, 2007, from http://www.idsn.org/movie/dalit.htm.

Islam, N. (2005). World Bank data of poverty and poverty of World Bank data. Bangladesh e-Journal of Sociology, 2. Retrieved July 21, 2007 from http://www.bangladeshsociology.org/BEJS\%20-\%202.1.5\%20-\%20Nazrul.htm.

Jaffrelot, C. (2005). Dr. Ambedkar and untouchability: Fighting the Indian caste system. New York: Columbia University Press.

Jayaharan, J. (2007, January). Untouchability. Paper presented at a Masters of Theology (MTh) class at Tamilnadu Theological Seminary, Madurai.

Jesus: a Dalit among Dalits. (2006). Retrieved May 3, 2006, from http://dalitchristians.com/Html/Jesus\%20and\%20Dalit.doc

Kakwani, N. (2004, September). New global poverty counts. In Focus, 9-11. Retrieved February 28, 2006 from http://www.undp.org/povertycentre/newsletters/infocus4sep04eng.pdf.

Kaviraj, S. (1997). Politics in India. Delhi: Oxford University Press.

Kent, E. (2002). Redemptive hegemony and the ritualization of reading. In S. J. Raj \& C. G. Dempsey (Eds.), Popular Christianity in India: Riting between the lines (pp. 191-209). Albany: State University of New York Press. 
Kim, C. N. (2006). Interpreting the Bible: A Minjung perspective. In S. Prabhakar \& J. Kwon (Eds.), Dalit and Minjung theologies: A dialogue (pp. 93-119). Bangalore: BTESSC/SATHRI.

Kretzmann, J., \& McKnight, J. (1993). Building Communities from the Inside Out.

Chicago: ACTA Publications.

Ladkin, D. (2004). Action Research. In C. Seale, G. Gobo, J. F. Gubrium \& D. Silverman (Eds.), Qualitative research practice (pp. 536-548). London: Sage Publications.

Lahiri-Roy, R. (2007, October). Roots and identities: Caste in modern India. Public lecture given at the WEA centre, Christchurch.

Larbeer, P. M. (2003). Ambedkar on Religion: A liberative perspective. New Delhi: ISPCK.

Larbeer, P. M., \& Alexandar, V. (Eds.). (2000). The colours of liberation. Madurai: Dalit Resource Centre, Tamilnadu Theological Seminary.

Lobo, L. (2001). Visions, illusions and dilemmas of Dalit Christians in India. In G. Shah (Ed.), Dalit identity and politics: Cultural subordination and the Dalit challenge (Vol. 2, pp. 242-257). New Delhi: Sage Publications.

Lobo, L. (2002). Persecution of Indian Christians. Dialog: A Journal of Theology, 41(2), 114-122.

Madheswaran, S., \& Attewell, P. (2007). Caste discrimination in the Indian urban labour market: Evidence from the National Sample Survey. Economic and Political Weekly, 42(41), 4146-4153. Retrieved November 8, 2007 from http://www.epw.org.in/uploads/articles/11136.pdf.

Marsh, A. A. (2004). Visualizing verification. Retrieved September 23, 2007, from http://www.isr.umd.edu/ austin/RecentGraduates/Marsh2004.pdf

Massey, J. (1995). Dalits in India: Religion as a source of bondage or liberation with special reference to Christians. New Delhi: Manohar.

Massey, J. (2006). A review of Dalit theology. In S. Prabhakar \& J. Kwon (Eds.), Dalit and Minjung theologies: A dialogue (pp. 1-15). Bangalore: BTESSC/SATHRI.

Mathie, A., \& Cunningham, G. (2003). From Clients to Citizens: Asset-Based Community Development as a Strategy for Community-Driven Development. Development in Practice, 13(5), 474-486. 
Meibohm, M. (2002). Past selves and present others: The ritual construction of identity at a Catholic festival in India. In S. J. Raj \& C. G. Dempsey (Eds.), Popular Christianity in India: Riting between the lines (pp. 61-83). Albany: State University of New York Press.

Melanchthon, M. (2002). Persecution of Indian Christians. Dialog: A Journal of Theology, 41(2), 103-113.

Mitchell, S. (2007, August). Liberating Jesus. Paper presented at the 'God in the 21st Century' lecture series, Knox Church, Christchurch.

Monbiot, G. (2003). Rich in imagination: The figures which purport to show that the world's poor are emerging from poverty don't add up. Retrieved 20 February, 2007, from http://www.zmag.org/content/showarticle.cfm?SectionID=10\&ItemID=3575

Moro, P. (2004). Constructions of nation and the classicisation of music: Comparative perspectives from Southeast and South Asia. Journal of Southeast Asian Studies, $35(2), 187-212$.

Morris, P. (2007, August). The Geering legacy. Paper presented at the 'God in the 21st Century' lecture series, Knox Church, Christchurch.

Murray, W. E., \& Overton, J. (2003). Designing development research. In R. Scheyvens \& D. Story (Eds.), Development fieldwork (pp. 17-35). London: Sage Publications. Narayanan, V. (2002). Afterword: Diverse Hindu responses to diverse Christianities in India In S. J. Raj \& C. G. Dempsey (Eds.), Popular Christianity in India : Riting between the lines (pp. 254-284). Albany: State University of New York Press.

Nespor, Z. R. (2003). Czech folk music in the 1960s-80s from the point of view of the sociology of religion. Sociology Casopis- Czech Sociological Review, 39(1), 7997.

Nomani, A. (2007, November 10). India's new untouchables. The Press, p. B5.

Office of the Registrar General and Census Commissioner. (2007a). Religious composition. Census data 2001: India at a glance. Retrieved October 20, 2007, from http://www.censusindia.gov.in/Census_Data_2001/India_at_glance/religion.aspx 
Office of the Registrar General and Census Commissioner. (2007b). Scheduled Castes and Scheduled Tribes population. Census of India 2001: India at a glance. Retrieved October 20, 2007, from http://www.censusindia.gov.in/Census Data 2001/India at glance/scst.aspx

Olukotun, A. (2002). Traditional protest media and anti-military struggle in Nigeria 1988-1999. African Affairs, 101, 193-211.

Panandiker, V. A. P. (Ed.). (1997). The politics of backwardness: Reservation policy in India. Delhi: Konark Publishers.

Pieterse, J. N. (2000). After post-development. Third World Quarterly, 21(2), 175-191.

Prabhakar, S., \& Kwon, J. (2006). Editorial. In S. Prabhakar \& J. Kwon (Eds.), Dalit and Minjung theologies: A dialogue (pp. v-vii). Bangalore: BTESSC/SATHRI.

Puniyani, R. (2005). Religion: Opium of the masses or... In R. Puniyani (Ed.), Religion, power and violence : Expression of politics in contemporary times (pp. 27-43). New Delhi: Sage.

Rahnema, M. (1992). Poverty. In W. Sachs (Ed.), The Development dictionary: A guide to knowledge as power (pp. 158-176). London: Zed Books.

Raj, M. C. (2006a). Dalits in Pakistan. Unbroken People, 2(4), 20-22.

Raj, M. C. (2006b). Editorial. Unbroken People, 2(4), 2-3.

Raj, M. C. (2006c). Unmasking Gandhi. Unbroken People, 2(4), 14.

Raj, S. J. (2002). Transgressing boundaries, transcending Turner: The pilgrimage tradition at the shrine of St. John de Britto. In S. J. Raj \& C. G. Dempsey (Eds.), Popular Christianity in India: Riting between the lines (pp. 85-111). Albany: State University of New York Press.

Raj, S. J., \& Dempsey, C. G. (2002). Introduction. In S. J. Raj \& C. G. Dempsey (Eds.), Popular Christianity in India: Riting between the lines (pp. 1-7). Albany: State University of New York Press.

Rajagopal, B. (2007, August 18). The caste system - India's apartheid? The Hindu. Retrieved October 29, 2007, from http://www.hindu.com/2007/08/18/stories/2007081856301200.htm.

Rajawat, M. (Ed.). (2004a). Encyclopaedia of Dalits in India: Dalit women - Issues and perspectives (Vol. 3). New Delhi: Anmol Publications PVT. Ltd. 
Rajawat, M. (Ed.). (2004b). Encyclopaedia of Dalits in India: History of Dalits (Vol. 1). New Delhi: Anmol Publications PVT. Ltd.

Rajawat, M. (Ed.). (2004c). Encyclopaedia of Dalits in India: Human rights and Dalits (Vol. 7). New Delhi: Anmol Publications PVT. Ltd.

Rajawat, M. (Ed.). (2004d). Encyclopaedia of Dalits in India: Social justice and Dalits (Vol. 2). New Delhi: Anmol Publications PVT. Ltd.

Ramesh, R. (2006, April 5). A tale of two Indias. The Guardian. Retrieved April 7, 2006 from http://www.guardian.co.uk/india/story/0, 1746948,00.html.

Rapley, T. (2004). Interviews. In C. Seale, G. Gobo, J. F. Gubrium \& D. Silverman (Eds.), Qualitative research practice (pp. 15-33). London: Sage Publications.

Ravallion, M. (2004, September). Monitoring progress against global poverty. In Focus, 12-15. Retrieved February 28, 2006 from http://www.undp.org/povertycentre/newsletters/infocus4sep04eng.pdf.

Roy, A. (2002). War is peace. In R. Burbach \& B. Clarke (Eds.), September 11 and the U.S. war: Beyond the curtain of smoke (pp. 101-110). San Francisco: City Lights Books.

Roy, A. (2003). When the saints go marching out. Text for a 15 minute radio essay broadcast by Radio 4, BBC. Retrieved 8 April, 2006, from http://www.zmag.org/content/showarticle.cfm?ItemID=4120

Roy, R. (2004). "Saptapadi" - the seven steps : a study of the urban Hindu arranged marriage in selected Indian-English fiction by women authors. Unpublished doctoral dissertation, University of Canterbury, Christchurch.

Scruggs, T. M. (2005). (Re)Indigenization?: Post-Vatican II Catholic ritual and "folk masses" in Nicaragua. The World of Music, 47(1), 91-123.

Sebastian, J. J. (2003a). Believing and belonging: Secularism and religion in India. International Review of Mission, 92(365), 204-211.

Sebastian, J. J. (2003b). The joy of conversion. Mizoram Theological Journal, III(3), 1832.

Sebastian, J. J. (2005). Toward a Christological missiology today with the guide-whostands-aside. Theology Today, 62(1), 18-28. 
Shahin, S. (2001, February 21). Indian census could produce 'the most complicated lies'. Asia Times Online. Retrieved May 13, 2006, from http://www.atimes.com/indpak/CB21Df01.html

Sherinian, Z. (1998). The indigenization of Tamil Christian music: Folk music as a liberative transmission system. Unpublished doctoral dissertation, Wesleyan University, Connecticut.

Sherinian, Z. (2002). Dalit theology in Tamil Christian folk music: A transformative liturgy by James Theophilus Appavoo. In S. J. Raj \& C. G. Dempsey (Eds.), Popular Christianity in India: Riting between the lines (pp. 233-253). Albany: State University of New York.

Sherinian, Z. (2005). The indigenization of Tamil Christian music: Musical style and liberation theology. World of Music, 47(1), 125-165.

Shiva, V. (2005). India divided: Diversity and democracy under attack. New York: Seven Stories Press.

Shulman, A. K. (1991). Dances with feminists. Women's review of books, IX(3). Retrieved October 22, 2007 from http://sunsite.berkeley.edu/Goldman/Features/dances_shulman.html.

Sikand, Y. (2000). Another Ayodhya in the making? The Baba Budhangiri Dargah controversy in South India. Journal of Muslim Minority Affairs, 20(2), 211-227.

Simpson, J. (Ed.). (1989). Oxford English Dictionary Online (2 ed.). Retrieved June 12, 2007, from http://dictionary.oed.com.

Sivakami. (2000). Dalit paintings. In P. M. Larbeer \& V. Alexandar (Eds.), The colours of liberation (pp. 15-17). Madurai: Dalit Resource Centre, Tamilnadu Theological Seminary.

Sivanarayanan, A. (2004). Translating Tamil Dalit poetry. World Literature Today, 78(2), 56-58.

Smith, P. J. (2005, June). The changing horizons of politics in a network society - the Dalit case. Paper presented at the Annual Meeting of the Canadian Political Science Association, London, Ontario. Retrieved October 1, 2007, from http://www.cpsa-acsp.ca/papers-2005/Smith.pdf 
Statistics New Zealand. (2007). QuickStats about culture and identity. Retrieved 19 August, 2007, from http://www.stats.govt.nz/census/2006-census-data/quickstatsabout-culture-identity/quickstats-about-culture-andidentity.htm?page=para012Master

Swami Sridharanandaji. (2007, July). Spirituality and its relevance. Address given at Victoria University of Wellington, Wellington.

Tartakov, G. M. (2000). Dalit painting seen from the outside. In P. M. Larbeer \& V. Alexandar (Eds.), The Colours of Liberation (pp. 19-34). Madurai: Dalit Resource Centre, Tamilnadu Theological Seminary.

Tartakov, G. M. (2003). B. R. Ambedkar and the Navayana Diksha. In R. Robinson \& S. Clarke (Eds.), Religious conversion in India: Modes, motivations, and meanings. (pp. 192-216). New Delhi: Oxford University Press.

Thekaekara, M. M. (2005). View from the top. New Internationalist, 380, 16-17.

Third World Institute. (2005). The World Guide 2005/2006: An Alternative Reference to the Countries of Our Planet (10th ed.). Oxford: New Internationalist Publications. TN juggles quota for 7 percent 'minority' reservation. (2007, September 14). The Indian Express. Retrieved October 5, 2007, from http://www.indianexpress.com/story/216578.html.

UNDP. (2005). Human Development Report 2005: International cooperation at a crossroads: Aid, trade and security in an unequal world. Retrieved August 23, 2007 from http://www.sd.undp.org/HDR/HDR05e.pdf.

United Nations. (2005). The UN Millennium Development Goals. Retrieved February 14, 2007, from http://www.un.org/millenniumgoals/

United Nations. (2007). Millennium Development Goals: 2007 Progress Chart. Retrieved 24 August, 2007, from http://www.un.org/millenniumgoals/pdf/mdg2007-progress.pdf

Wade, R. H. (2003). Poverty and income distribution: What is the evidence? In A. Pettifor (Ed.), The real world economic outlook 2003: The legacy of globalization-Debt and deflation (pp. 138-151). London: Palgrave Macmillan.

Walsh, A. C. (1996). Ethnicity, gender and survey biases in Fiji. The Journal of the South Pacific, 19, 145-158. 
Webster, J. C. B. (2003). Christian Conversion in the Punjab: What has Changed? In R. Robinson \& S. Clarke (Eds.), Religious conversion in India: Modes, motivations, and meanings (pp. 351-380). New Delhi: Oxford University Press.

Wikipedia. (2007). Topographic map of India. Retrieved November 30, 2007, from http://en.wikipedia.org/wiki/India

Wingate, A. (1999). The church and conversion: A study of recent conversions to and from Christianity in the Tamil area of South India. Delhi: ISPCK.

Worgs, D. C. (2006). "Beware of the frustrated...": The fantasy and reality of African American violent revolt. Journal of Black Studies, 37(1), 20-45.

Zelliot, E. (2001). The meaning of Ambedkar. In G. Shah (Ed.), Dalit identity and politics: Cultural subordination and the Dalit challenge (Vol. 2, pp. 129-142). New Delhi: Sage Publications.

Zelliot, E., \& Mokashi-Punekar, R. (Eds.). (2005). Untouchable saints: An Indian phenomenon. New Delhi: Manohar Publishers \& Distributors. 


\section{Appendix I: Parattai's Norms for Dalit Liberation Media}

Source: Appavoo, 1993, pp. 41-52

Economic

i) The Dalit liberation media should have only the hardwares (sic) that are inexpensive and easily available to them.

Political

ii) Dalit liberation media should be such that they cannot be controlled by the non-Dalit oppressors.

Social

iii) The Dalit liberation media should not have this communication division. They should be so constructed that all participants are Senders as well as Receivers.

Ideological

iv) The Dalit liberation media should not be based on the abnormal skills that require time for skill training.

v) The Dalit liberation media should not have any physical quality control.

Psychological

vi) The Dalit liberation media should be so safe that the communicator is always hidden so that she/he is not embarrassed or afraid.

Ecological

vii) The Dalit liberation media should not demand unnatural environment for media production as well as dissemination.

viii) The Dalit liberation media should be able to encode messages into all the five sense data and thus appeal to all the human senses.

Gender 
ix) The Dalit liberation media should not abuse women and (should) portray men and women as equals.

Spiritual

x) Trans-physical communication should be one of the dynamics of the Dalit liberation media.

General

xi) The Dalit liberation media demands the demonstration of new, liberating structures, a communication-in-action in terms of EPSI PEGS, and in Biblical terms, a foretaste of the kingdom of God.

xii) The Dalit liberation media should use narratives to counter the narratives of oppression.

xiii) The Dalit liberation media should create awareness about the techniques of the oppressors.

xiv) The Dalit liberation media should also have provision to understand the purpose of the narratives that are communicated to Dalits. 


\section{Appendix II: Question Sheet for Participants \\ General areas of discussion for interviews}

What short and long term effects did Parattai's music (liturgies, street theatre, Oru Olai, etc) have on the people in his community?

What skills and/or sense of empowerment are achieved through his music?

What kinds of action does his music promote?

Did females dance during Oru Olai when Parattai was conducting it?

How has his music continued to be used as a tool for social empowerment and action by Dalits (and/or others), after the loss of its creator?

How has his music been transformed (if at all) since Parattai passed away?

Have actions relating to (or promoted by) his music continued to occur since his passing?

What are the costs and benefits for Dalits in converting to or being of religions other than Hinduism (in particular, Christianity)? 


\title{
Appendix III: Information Sheet for Participants
}

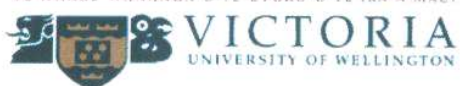

PARTICIPANT INFORMATION SHEET

Researcher: Fiona Dalton: Department of Development Studies, Victoria University of Wellington, New Zealand

I am a Masters student in Development Studies at Victoria University of Wellington, New Zealand. As part of my degree I am undertaking a research project leading to a thesis. The project I am undertaking is exploring the effects of the late Reverend Theophilus Appavoo's musical liturgy Oru Olai on dalits in Madurai. The University requires that ethics approval be obtained for research involving human participants.

I am inviting dalits and other people who have joined in Oru Olai to participate in this study. Participants will be asked how singing Oru Olai has affected their social interactions, social and political actions and attitudes, and self perspective. It is envisaged that the interview will take 30-45 minutes and will be recorded on to a tape recorder.

Should any participants feel the need to withdraw from the project, they may do so without question at any time before the data is analysed. Just let me know at the time.

During any stage of the interview please do not hesitate to tell me or the translator directly. If you would like to withdraw after the interview, please contact me at the address/phone number given below.

If you check the box on the Consent form requesting a summary of the results of my research, this summary will be sent to you either directly (if you provide an address) or otherwise through the translator who was present during your interview.

Reponses collected will form the basis of my research project and will be put into a written report on an anonymous basis. All material collected will be kept confidential. No other person besides me, the interpreter/translator and my two supervisors Dr Rick Weiss and Dr Bill Hipwell, will see the transcripts or hear the tapes of the interviews. The thesis will be submitted for marking to the School of Geography, Environment and Earth Sciences and deposited in the Victoria University of Wellington library. One or more articles based on the information in the thesis may be submitted to scholarly journals at a later stage. Transcripts and tapes of the interviews will be destroyed two years after the end of the project.

If you have any questions or would like to receive further information about the project, please contact me at dalton fiona@yahoo.com or my supervisors, Dr Rick Weiss, in the Religious Studies Programme, rick.weiss@vuw.ac.nz, or Dr Bill Hipwell in the School of Geography, Environment and Earth Sciences, william.hipwell@vuw.ac.nz, both supervisors at Victoria University of Wellington, PO Box 600, Wellington, New Zealand.

Alternatively you can contact me by post at 38 Rata St, Christchurch 8041 , NEW ZEALAND or by telephone on 006433481416 .

Signed:

FerPDalton

Fiona Dalton

$26 / 03 / 07$ 


\title{
Appendix IV: Consent Form for Participants
}

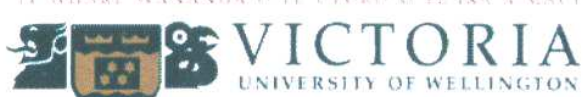

\section{VICTORIA UNIVERSITY OF WELLINGTON CONSENT TO PARTICIPATION IN RESEARCH}

Singing for Justice: Musical Liturgy for the Empowerment of Dalits

I have been given and have understood an explanation of this research project. I have had an opportunity to ask questions and have had them answered to my satisfaction. I understand that I may withdraw myself (or any information I have provided) from this project (before data collection and analysis is complete) without having to give reasons and without penalty of any sort.

I understand that any information I provide will be kept confidential to the researcher, the supervisors and the person who transcribes the tape recordings of our interview, that the published results will not use my name, and that no opinions will be attributed to me in any way that will identify me. I understand that the tape recording of the interviews will be electronically wiped within two years of the date of the interview unless I indicate that I would like them returned to me.

I understand that the data I provide will not be used for any other purpose or released to others without my consent.

(Please check-mark as appropriate):

I would like to receive a summary of the results of this research when it is completed. If you have checked this box, please provide details of your postal/email address:

I agree to take part in this research.

Signed:

Name of participant (please print clearly):

Date: 


\section{Appendix V: CERD Recommendations for India}

Source: CERD, 2007

- Anti-discrimination and affirmative action legislation has not been implemented.

- De facto acts of 'Untouchability,' especially those occurring at places of worship, hospitals, water sources and other public services or areas, have not been punished.

- Personal safety upon reporting crimes has not been assured, and reported crimes have not been registered or investigated by police and other law enforcement officers.

- Perpetrators of acts of sexual violence and exploitation against women have not been prosecuted or punished, and people including police and other law enforcement officers have prevented or discouraged victims from reporting such incidents.

- The rights to freely and safely vote and stand for election and to exercise fully the mandate if elected to reserved seats have been flouted.

- Discrimination or violence against inter-caste couples has not been punished and victims have not been rehabilitated.

- Dalit girls continue to be dedicated to temple deities and forced into ritualised prostitution (devadasi), despite the prohibition of this practice.

- Dalits, particularly Dalit women, do not have access to adequate and affordable land, and perpetrators or acts of violence against Dalits due to land disputes have not been punished.

- Members of scheduled castes and scheduled tribes who have converted to another religion have been denied entitlement to affirmative action programmes.

- Situations in which Dalits were denied assistance or benefits equal to that received by caste fishermen or cases in which they were otherwise discriminated against during the post-tsunami relief and rehabilitation process have not been investigated.

- Very large numbers of Dalits are still forced to work as child labourers, manual 'scavengers,' bonded labourers and in other extremely unhealthy working conditions.

- Dalits have very little or no access to the private sector through the reservation policy.

- Equal access to ration shops, adequate health care facilities, reproductive health services and safe drinking water is not a reality.

- Many Dalit children have dropped out of school after experiencing classroom segregation and discrimination in access to mid-day meals, in addition to poor equipment, staffing, quality of teaching and physical access to schools in dominant caste neighbourhoods.

- Many atrocity cases are still pending in the courts and very few suspects have been convicted or sentenced. 
- Attempts have not been made to reduce social acceptance of caste-based discrimination by intensifying public education, awareness raising campaigns, instruction in the National Curriculum Framework or ensuring adequate media representation of issues. 


\section{Appendix VI: Onward Christian Soldiers}

Onward Christian soldiers!

Marching as to war,

With the Cross of Jesus

Going on before.

Christ the royal Master

Leads against the foe;

Forward into battle,

See, his banners go!

Onward Christian soldiers!

Marching as to war,

With the Cross of Jesus

Going on before

At the sign of triumph

Satan's host doth flee;

On then, Christian soldiers,

On to victory!

Hell's foundations quiver

At the shout of praise;

Brothers, lift your voices,

Loud your anthems raise.

Onward etc

Like a mighty army

Moves the Church of God;

Brothers, we are treading

Where the saints have trod:

We are not divided,

All one body we,

One in hope and doctrine,

One in charity.

Onward etc

Crowns and thrones may perish

Kingdoms rise and wane,

But the Church of Jesus

Constant will remain:

Gates of hell can never

'Gainst that Church prevail;

We have Christ's own promise,

And that cannot fail.

Onward etc

(Verses 1-4. Baring-Gould, 1865. Source: Hymns Ancient and Modern Revised, London: William Clowes and Sons Limited). 


\section{Appendix VII: Who is my Mother?}

Who is my mother? Who is my brother? All those who gather round Jesus Christ:

Spirit-blown people born from the Gospel Sit at the table, round Jesus Christ.

Differently abled, differently labelled Widen the circle round Jesus Christ, Crutches and stigmas, cultures' enigmas All come together round Jesus Christ.

Love will relate us - colour or status Can't segregate us round Jesus Christ: Family failings, human derailings, All are accepted, round Jesus Christ.

(Verses 1-3, Words by Shirley Murray; Music by Ian Render. Reproduced from the St Ninian's Hymnal, with the kind permission of St Ninian's Presbyterian Church, Christchurch, Aotearoa/New Zealand.) 


\section{Appendix VIII: Hymn for 1990}

Land of shining primal forests,

Sculptured ribbon framed by sea;

Land of mystic snow-clad markers

Charged with raw vitality;

Valleys wreathed in mists of mourning,

Earth caressed by sparkling light,

Gift of God, our awesome homeland,

Signed with nature's cross at night.

To the Nation's patterned weaving

We have brought our vibrant threads -

Gifts of language, gifts of custom,

Precious gifts of heart and head.

Let us name our river, mountain,

Make this soil our spirit's earth,

Find the Christ in land and people,

Bring God's tender dream to birth.

(Verses 1 \& 3. Words by William L. (Bill) Wallace. (OWilliam L. (Bill) Wallace). 


\section{Appendix IX: Through All the World}

Through all the world, a hungry Christ

Must scavenge for his daily bread

Must beg the rich for crumb and crust -

We are the rich, the daily fed.

Beyond the Church, a leper Christ,

Takes the untouchable by hand,

Gives hope to those who have no trust,

Whose stigma is our social brand.

In torture cell, a prisoner Christ

For justice and for truth must cry

To free the innocent oppressed

While we at liberty pass by.

We do not know you, beggar Christ,

We do not recognise your sores;

We do not see, for we are blind:

Forgive us, touch us, make us yours.

(Words by Shirley Murray. Reproduced from the St Ninian's Hymnal, with the kind permission of St Ninian's Presbyterian Church, Christchurch, Aotearoa/New Zealand). 


\section{Appendix X: Oru Olai at TTS, February 2007}

(All photographs by Fiona Dalton. Printed with the kind permission of those appearing in the pictures).

1) Stoking up the fires under the clay pots

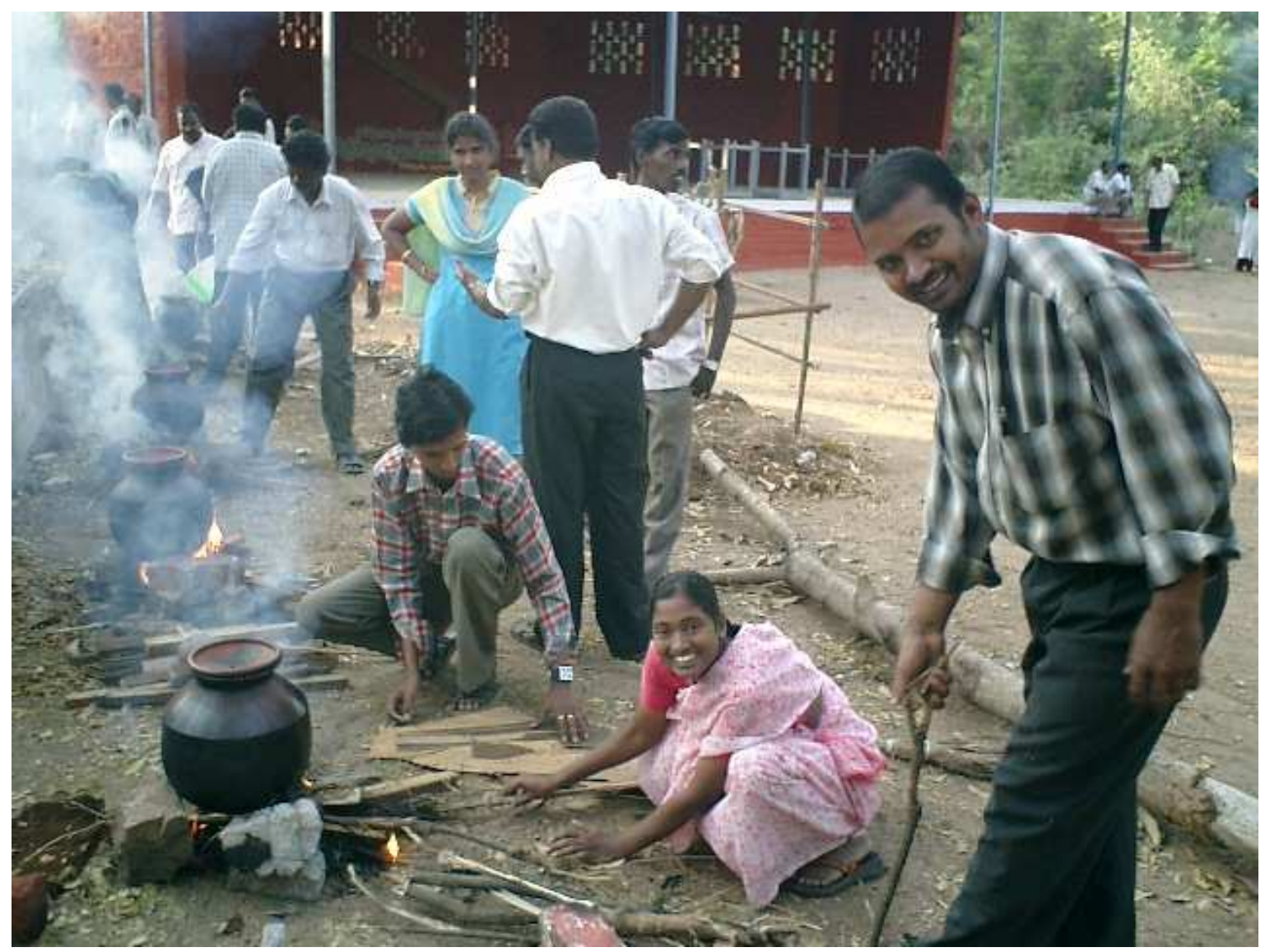


2) Adding the rice

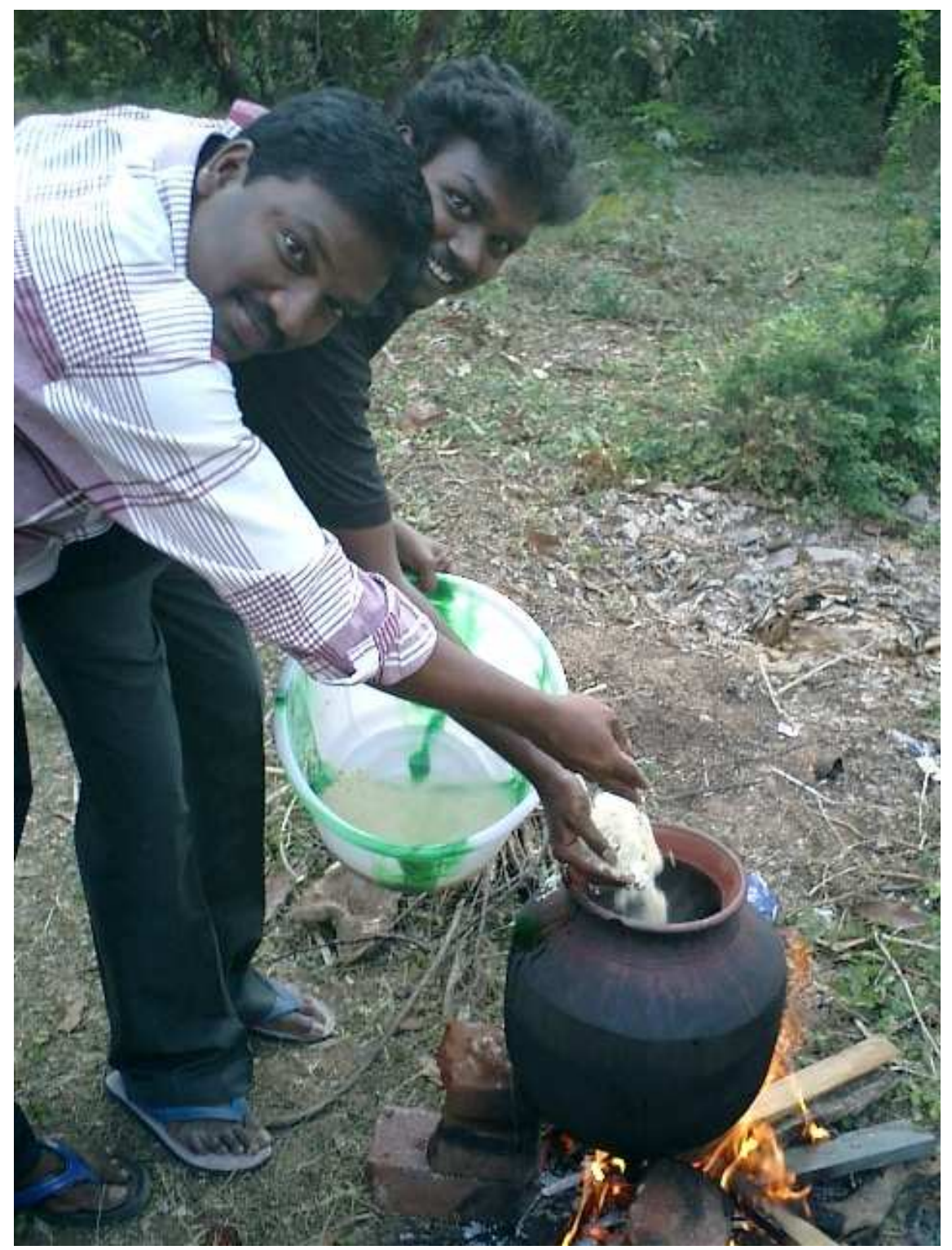


3) Dancing to parai drum music just before the start of the procession around campus

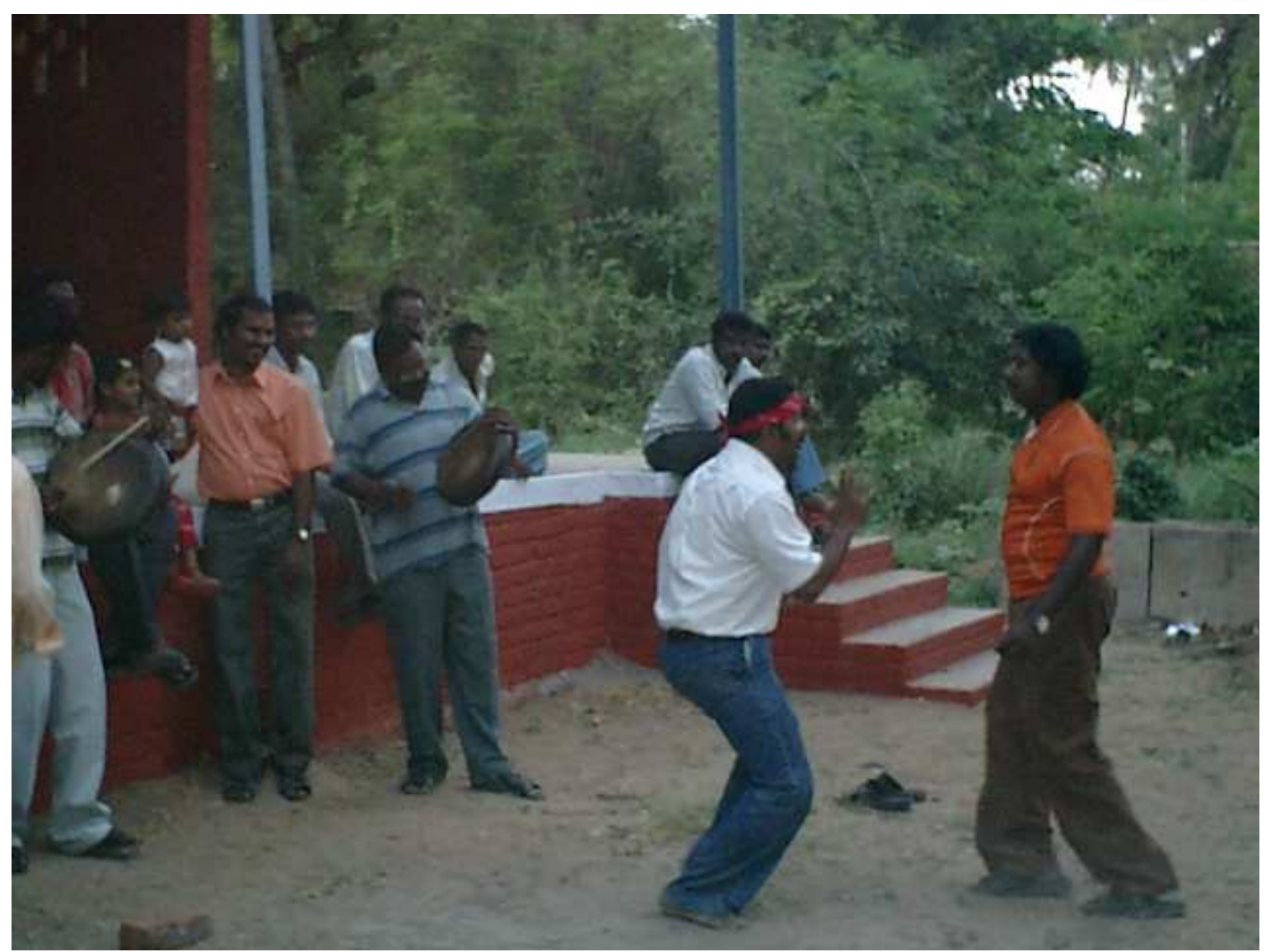


4) Singing, dancing and drumming during the procession to invite people to the meal.

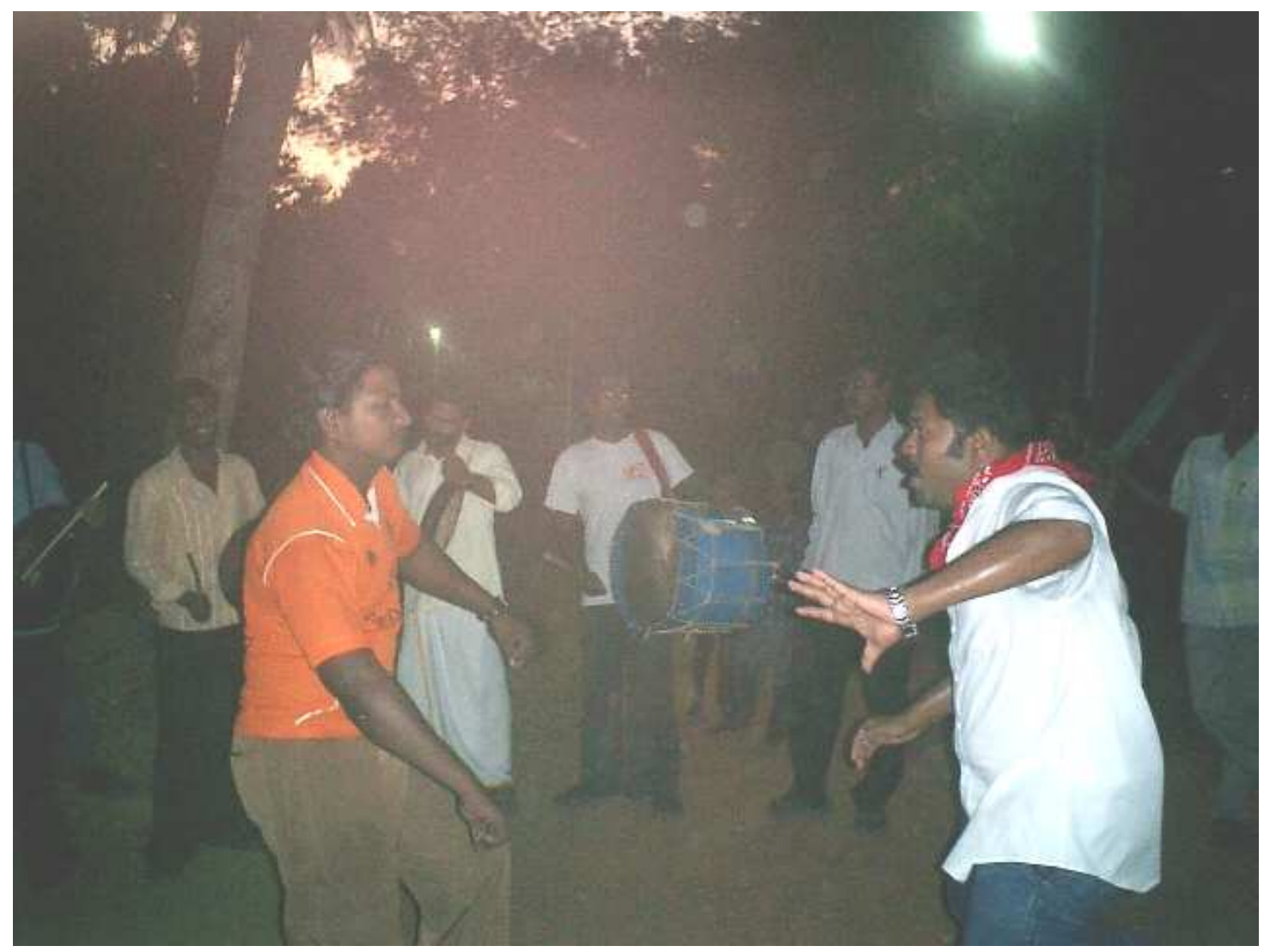


5) Combining the kanjees in one common pot

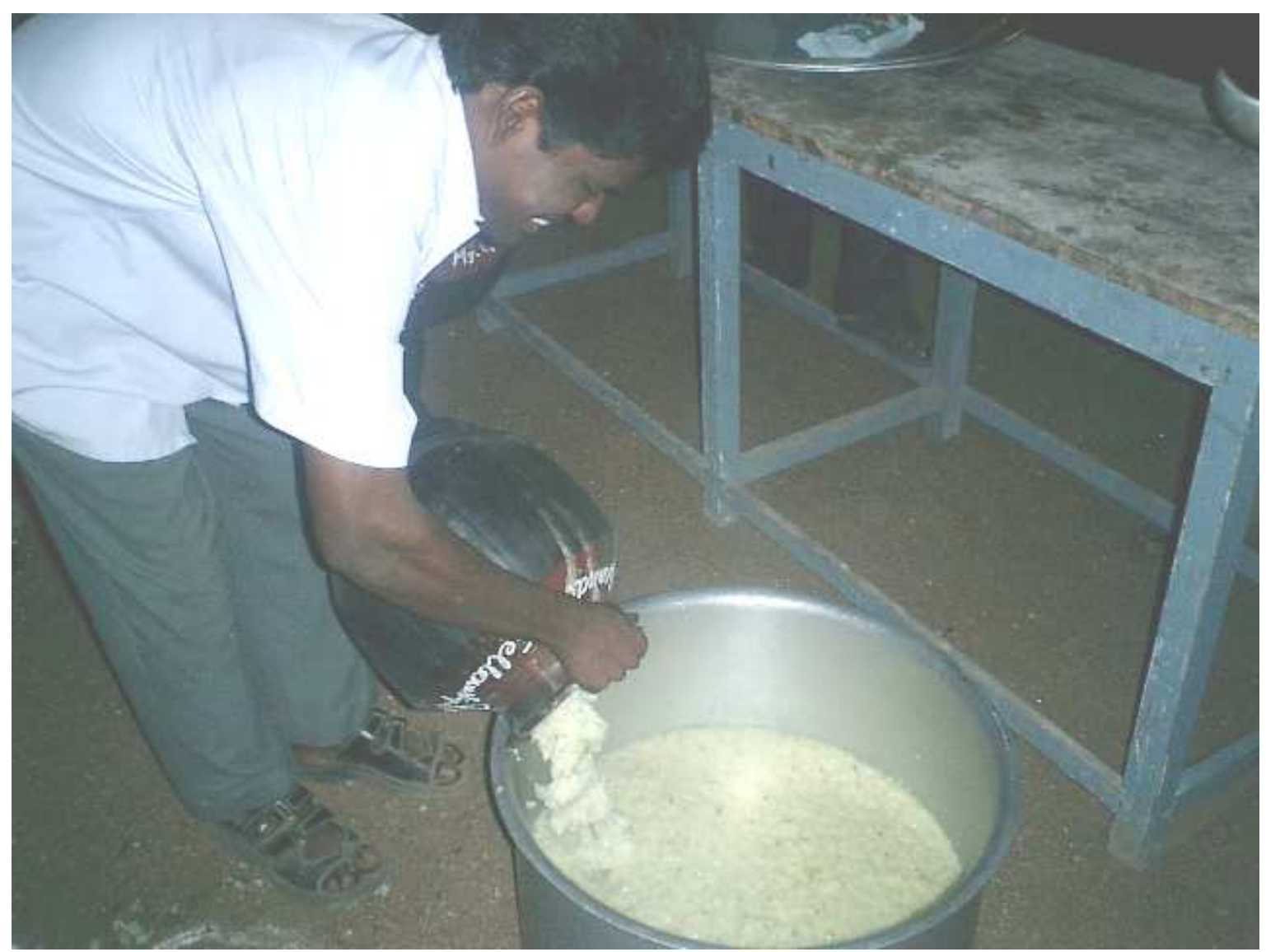


6) Enjoying the final product

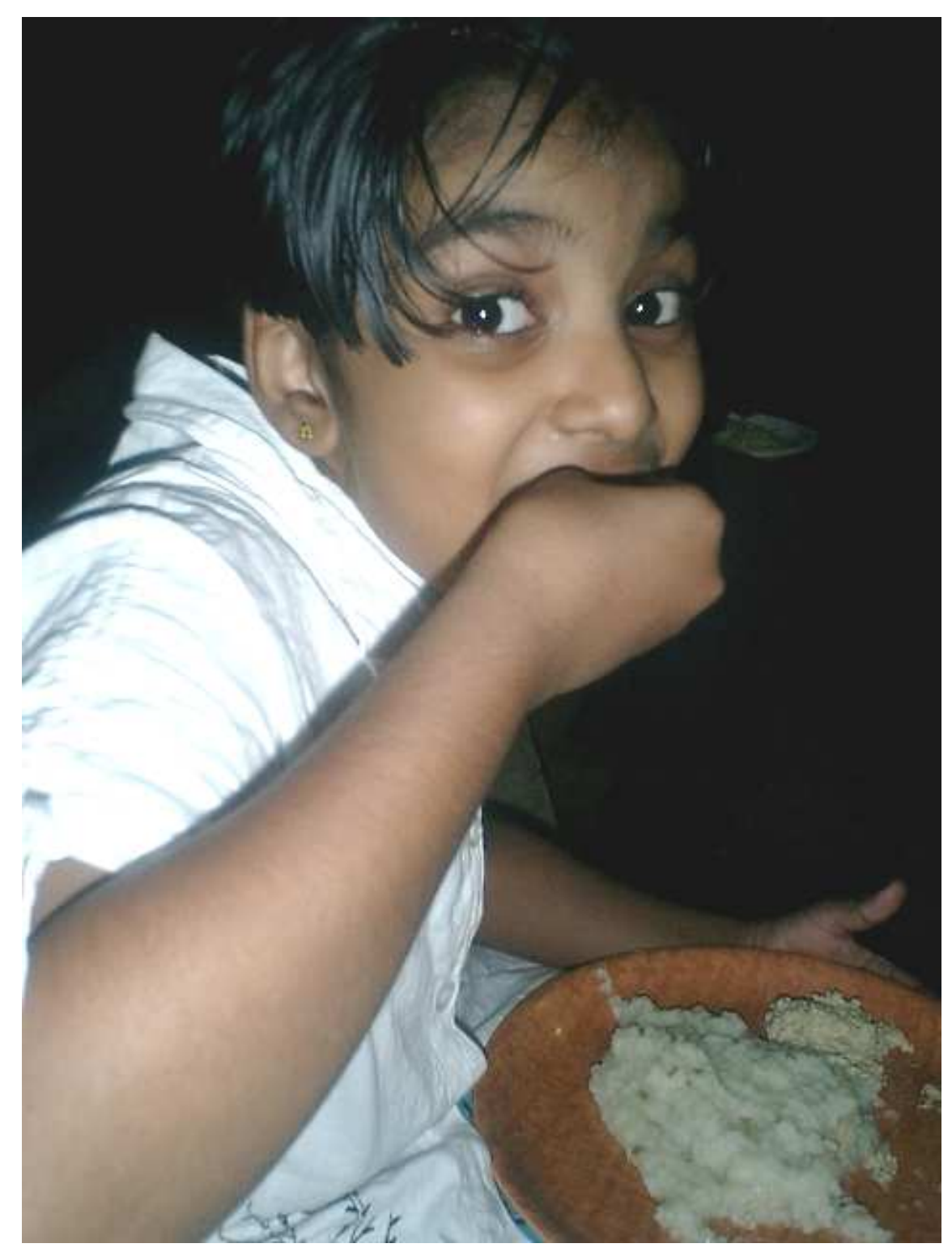


Appendix XI: Elements for Holy Communion at TTS (Photograph by Fiona Dalton)

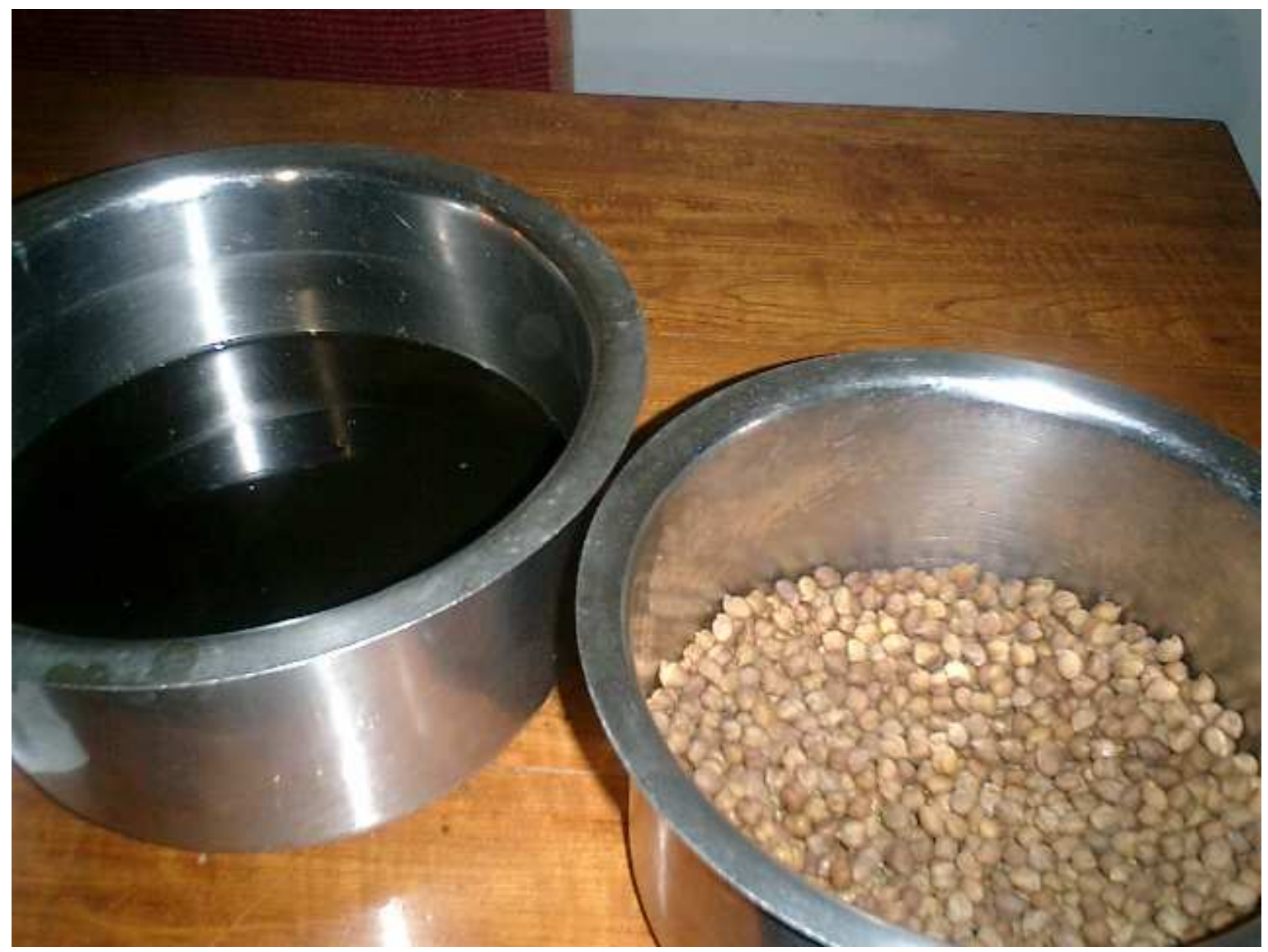


